\title{
Cu-CHA - A Model system for Applied Selective Redox Catalysis
}

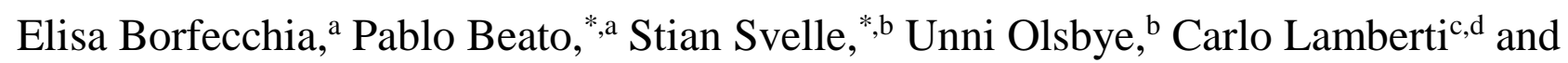 \\ Silvia Bordiga, ${ }^{*}, \mathrm{be}$
}

\footnotetext{
${ }^{a}$ Haldor Topsøe A/S, Haldor Topsøes Allé 1, 2800 Kongens Lyngby, Denmark. E-mail: PABB @ topsoe.com

${ }^{\mathrm{b}}$ Center for Materials Science and Nanotechnology (SMN), Department of Chemistry, University of Oslo, P.O. Box 1033 Blindern, N-0315 Oslo, Norway. E-mail: stian.svelle@kjemi.uio.no

${ }^{c}$ The Smart Materials Research Center, Southern Federal University, Sladkova 174/28, 344090 Rostov-on-Don, Russia

${ }^{\mathrm{d}}$ Department of Physics, INSTM Reference Center and CrisDi Interdepartmental Centre for Crystallography, University of Turin, Via P. Giuria 1, 10125 Turin Italy

e Department of Chemistry, INSTM Reference Center and NIS Interdepartmental Centre, University of Turin, Via Quarello 15, I-10135, Turin, Italy. E-mail: PABB@topsoe.com
}

We review the structural chemistry and reactivity of copper-exchanged molecular sieves with chabazite (CHA) topology, as industrially applied catalyst in ammonia mediated reduction of harmful nitrogen oxides $\left(\mathrm{NH}_{3}-\mathrm{SCR}\right)$ and as a general model system for red-ox active materials (also the recent results in the direct conversion of methane to methanol are considered). Notwithstanding the apparent structural simplicity of the material, a crystalline zeolite with only one crystallographically independent $\mathrm{T}$ site, the Cu-SSZ-13 catalyst reveals a high degree of complexity that has been decrypted by state of the art characterization tools. From the reviewed data, the following important aspects in the understanding of the Cu-SSZ-13 catalyst clearly emerged: (i) the structural dynamics of the $\mathrm{Cu}$-species require precise control of the environmental conditions during activation and characterization; (ii) the availability of a large library of well-defined catalysts with different Si/Al and $\mathrm{Cu} / \mathrm{Al}$ compositional ratios is key in unravelling the red-ox property of the active $\mathrm{Cu}$ sites; (iii) a multi-technique approach is required, combining complementary techniques able to provide independent structural, electronic and vibrational information; (iv) synchrotron radiation based techniques (EXAFS, XANES, XES and time-resolved powder XRD) played a relevant role; (v) operando methodology (possibly supported by advanced chemometric approaches) is essential in obtaining structure-reactivity relations; (vi) the support of theoretical studies has been indispensable for the interpretation of the experimental output from characterization and for a critical assessment of mechanistic models.

The old literature, that classified $\mathrm{Cu}$-exchanged zeolites in the category of single-site catalysts, has been partially disproved by the recent advanced studies where it has been shown that the active site in low temperature $\mathrm{NH}_{3}$-SCR catalyst is a mobile $\mathrm{Cu}$-molecular entity that "lives in symbiosis" with an inorganic solid framework. Only in the high temperature $\mathrm{NH}_{3}-\mathrm{SCR}$ regime, the mobile $\mathrm{Cu}$-species lose their ligands and find docking sites at the internal walls of the zeolite framework thus reflecting the idea of a single-site catalysts.

After a brief introduction, the review is divided into three main parts devoted to characterization (Section 2), reactivity (Section 3), and industrial applications (Section 4), followed by some concluding remarks and providing a perspective of the field. 


\section{Introduction}

Natural chabazite is a tectosilicate mineral of the zeolite group, with a high aluminum content, that crystalize in the trigonal R-3m space group. ${ }^{1-3}$ Its synthetic counterpart can be obtained, by the use of a sophisticated template, with $\mathrm{Si} / \mathrm{Al}$ ratio higher than 10 and is known as SSZ-13. ${ }^{4}$ Finally, the same topology can be obtained also as silicon aluminum phosphate, known as SAPO-34. ${ }^{5}$ The chabazite topology is identified by layers of double six-membered rings $(d 6 r)$ that are interconnected by units of four-membered rings (4r). The double six-membered-ring layers are stacked in an ABC sequence, leading to a framework with a regular array of barrel-shaped cages interconnected by eightmembered-ring windows ( $8 r$ ) (Fig. 1a). The chabazite framework is characterized by a high symmetry, as the asymmetric unit contains just one $\mathrm{T}$ site ${ }^{1-3,6}$ and four non-equivalent oxygens, which give origin to two families of Brønsted sites. ${ }^{7}$ The first family include Brønsted sites associated with $\mathrm{O}_{1}, \mathrm{O}_{2}$ and $\mathrm{O}_{4}$, that point inside the big cage and are easily accessible to reactants. The Brønsted sites associated with $\mathrm{O}_{3}$ are instead less accessible, pointing inside the six-membered ring (6r) (Fig. 1b).
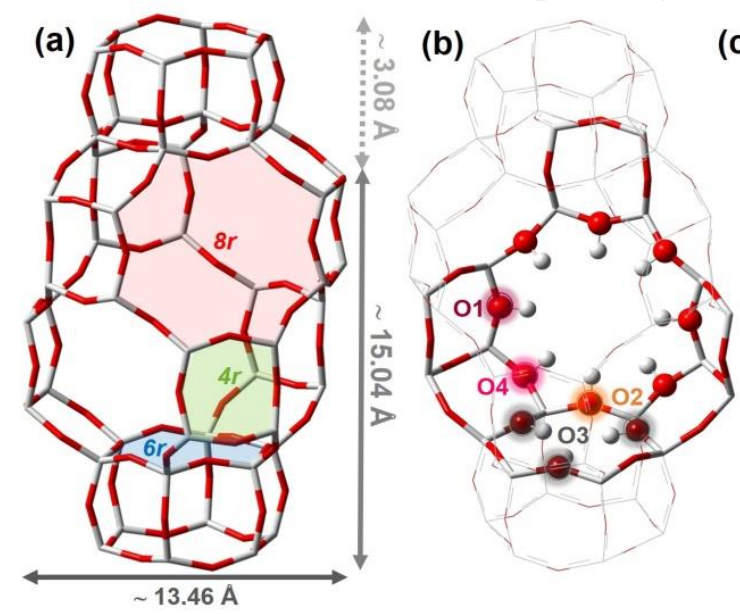

(c)

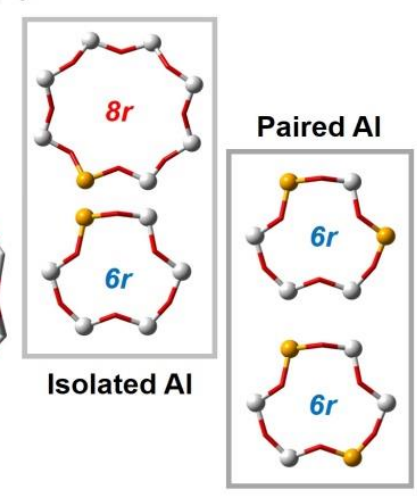

Fig. 1. Part (a): schematic representation of CHA topology, underlying the presence of $4 r, 6 r$ and $8 r$ rings and the major dimension of the cages. Part (b): illustration of the four different oxygens available in the framework. Part (c): possibilities of isolated and paired $\mathrm{Al}$ sites, considered in the literature as most probable locations for $\mathrm{Cu}$ cations. Colour code: $\mathrm{O}$ red; Si grey; Al orange in case of zeolites (CHA or SSZ-13). A similar picture can be used to describe SAPO-34, where Al is replaced by $\mathrm{Si}$ and $\mathrm{Si}$ by alternating $\mathrm{Al}$ and $\mathrm{P}$ atoms. Previously unpublished figure.

A further element of complexity, in case of the CHA or the SSZ-13 zeolites, is represented by the Al loading, that implies a variability in the presence of one or two Al atoms in the zeolite rings. In particular, the different possibilities of isolated and paired $\mathrm{Al}$ sites are illustrated in Fig. 1c. Equivalent structures can be used to describe the SAPO-34 case, ${ }^{8}$ where the $\mathrm{Al}$ is replaced by $\mathrm{Si}$ and $\mathrm{Si}$ by alternating $\mathrm{Al}$ and $\mathrm{P}$ atoms.

Apart from the interest in the acidic form of chabazites (H-CHA, H-SSZ-13 and H-SAPO-34), mostly associated to the catalytic conversion of methanol into light olefins (MTO reaction), ${ }^{9}$ the structural simplicity of the material attracted a great interest in $\mathrm{Cu}-\mathrm{CHA}$ as a model system to resolve fundamental questions of structure-performance relationships in the general context of metalexchanged zeolite catalysis.

In particular two relevant redox processes, where copper interconverts between $\mathrm{Cu}$ (I) and $\mathrm{Cu}$ (II) have been the subject of important research efforts in the last years: (i) the reduction of environmentally harmful $\mathrm{NO}_{x}$ by $\mathrm{NH}_{3}$, i.e. selective catalytic reduction $(\mathrm{SCR})^{10-21}$ and (ii) the direct conversion of methane to methanol (MTM).22-29

In order to shed light on the structural dynamics of the $\mathrm{Cu}-\mathrm{CHA}$ system, it has been mandatory to apply advanced in situ/operando characterization approaches on a well-defined set of samples, by varying, in a controlled way, the measuring conditions. ${ }^{16,30-34}$ Additional insights were provided by the use of probe molecules, by performing ab-initio calculations on clusters and on periodic models, and by combining appropriate analytic tools, specifically developed to manage complex 
spectroscopic datasets. Fig. 2 illustrates the large variety of approaches employed in the literature to tackle the complexity of the problem, as will be exemplified by the studies discussed in this review.

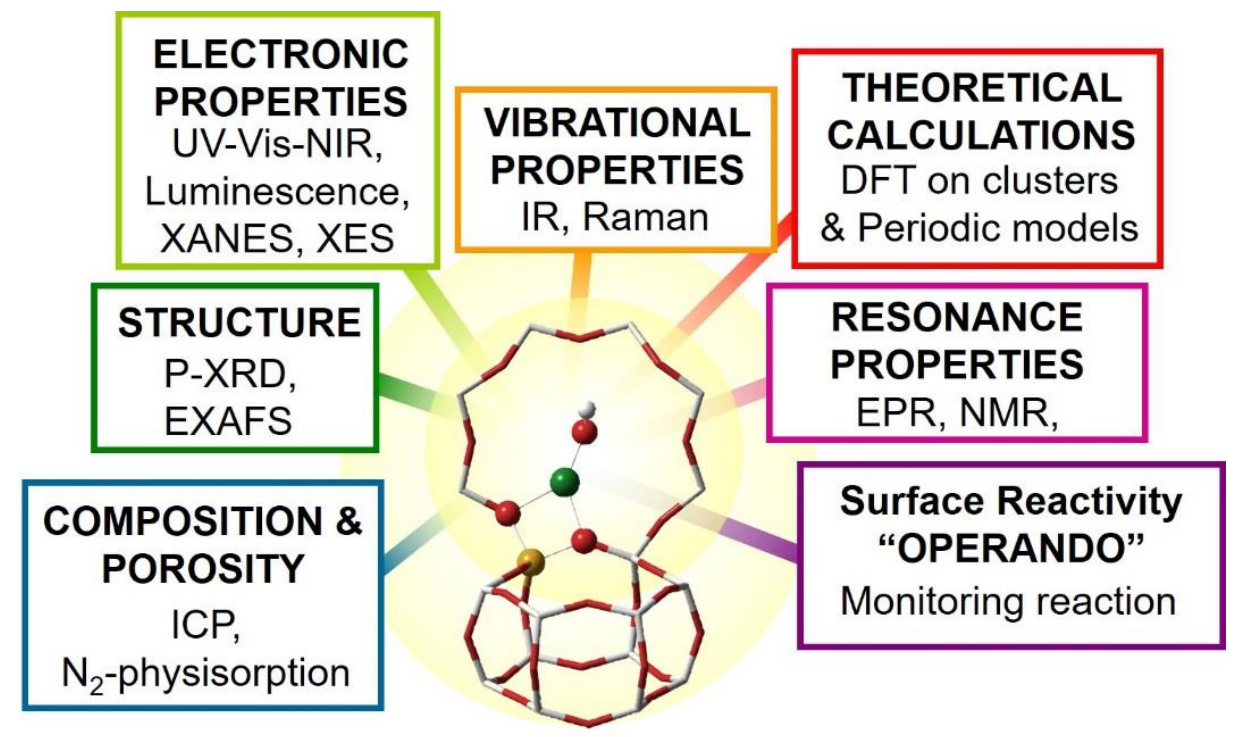

Fig. 2. Scheme reporting the main experimental and theoretical tools used to shed light on the structure of the active $\mathrm{Cu}$ sites in CHA frameworks and their reactivity in the context of $\mathrm{NH}_{3} \mathrm{SCR}$ and MTM reactions. Previously unpublished figure.

Starting from the bottom left, we can mention the use of: analytical tools such as ICP and $\mathrm{N}_{2-}$ physisorption to define the sample composition and surface area. Powder X-ray diffraction (PXRD) results in the phases identification needed to verify the purity of the crystalline phase. Moreover, if highly $2 \theta$-resolved pattern (with a high signal-to-noise in the high-q-region) are available, PXRD can also be used to track the positions of the cations, thanks to a structure refinement procedure. ${ }^{6,12,35}$ Conversely, the short range order is mostly described by extended X-ray absorption fine structure (EXAFS), ${ }^{31,36-46}$ while spectroscopies involving electron transitions (UV-Vis-NIR, luminescence, XANES and XES) $)^{21,29,38,46-53}$ are able to discriminate between $\mathrm{Cu}(\mathrm{I})$ and $\mathrm{Cu}(\mathrm{II})$ and to give insight on the local symmetry and coordinative state and the nature of coordinating ligands. Infrared spectroscopy ${ }^{54-56}$ provides a clear picture about the number and the different families of Brønsted sites and, when used in combination with probe molecules, ${ }^{57-60}$ can provide insight about the oxidation state and accessible coordinative environment of the $\mathrm{Cu}$ species. Raman spectroscopy, mostly exploiting the resonance conditions ${ }^{25,}{ }^{61-67}$ allows the identification of even very diluted surface species in controlled atmosphere. Theoretical calculations performed on both clusters and periodic models using DFT, ${ }^{18,30,46,68-72}$ provide a relevant contribution in the understanding of the local geometries and reactions paths. $\mathrm{As} \mathrm{Cu}$ (II) is paramagnetic, EPR spectroscopy is widely used to characterize $\mathrm{Cu}(\mathrm{II})$ sites in exchanged zeolites. ${ }^{20,73-80}$ or $\mathrm{Cu}(\mathrm{I})$ sites accessible to paramagnetic molecules such as NO. ${ }^{81}$ Solid state NMR has been mostly used to give insight on ${ }^{27} \mathrm{Al}$ local structure and in particular to identify extra lattice aluminium sites. ${ }^{82,83} \mathrm{In}$ addition, ${ }^{29} \mathrm{Si}$ was used to determine the distribution of $\mathrm{Si}(2 \mathrm{Al}), \mathrm{Si}(1 \mathrm{Al})$ and $\mathrm{Si}(0 \mathrm{Al})$ in $\mathrm{SSZ}-13{ }^{19}$ and ${ }^{15} \mathrm{~N}-\mathrm{MAS}$ NMR provided insight on the adducts formed upon $\mathrm{NH}_{3}$ dosage ${ }^{84}$ Last but not least, operando facilities, starting from reaction tests, are more and more frequently combined with spectroscopies, providing insight on the surface species formed and evolving under reaction conditions. ${ }^{16,30-34}$

The present review is focused on Cu-SSZ-13 zeolites, as these are the materials on which the most abundant literature is available. The manuscript is divided into three main parts devoted to characterization (Section 2), reactivity (Section 3), and industrial applications (Section 4), that are finally followed by a section where conclusions and perspectives are drawn. 


\section{Structural complexity in the activated material}

The coincidence of the structural simplicity of the CHA topology, ${ }^{1-3}$ together with the outstanding performance of $\mathrm{Cu}-\mathrm{SSZ}-13$ in $\mathrm{NH}_{3}-\mathrm{SCR}$, provoked a real boom of academic and industrial research groups using $\mathrm{Cu}-\mathrm{SSZ}-13$ materials as model systems to address long-standing questions in metalexchanged zeolite catalysis. Nonetheless, the vast literature accumulated in almost a decade of extensive research, reshaped the initial premise of a simple model material, progressively unveiling the complexity associated with metal speciation in the CHA framework.

Early reports ${ }^{12,45,85}$ described Cu-SSZ-13 as a 'single-site' catalyst, indicating an extra-framework site in the plane of the $6 r$ as the sole position for $\mathrm{Cu}$ ions in the dehydrated material. However, in the following years, it has become clear that the CHA topology offers multiple docking sites for $\mathrm{Cu}$ (II) and $\mathrm{Cu}(\mathrm{I})$ ions. $6,35,46,52,68$ Today it is well established that the chemical identity (oxidation state, coordination geometry, nuclearity) and the framework location of $\mathrm{Cu}$-species are determined by (i) physico-chemical environment (i.e. temperature, gas composition and gas flow rate) and (ii) sample composition (i.e. $\mathrm{Si} / \mathrm{Al}$ ratio in the parent framework and $\mathrm{Cu} / \mathrm{Al}$ ratio in the exchanged zeolite). ${ }^{46,52 \text {, }}$ $68,69,86$

This section addresses the current understanding of $\mathrm{Cu}$-species formation and transformation in $\mathrm{Cu}-\mathrm{CHA}$ materials as a function of two key factors: activation procedure (Section 2.1) and starting chemical composition (Section 2.2). Additional complexity is connected to the possibility of modifying the $\mathrm{Al}$ distribution in the $\mathrm{CHA}$ framework (e.g. abundance of $6 r$ hosting a pair of neighbouring $\mathrm{Al}$ atoms in $-\mathrm{Al}-\mathrm{Si}-\mathrm{Al}-$ or $-\mathrm{Al}-\mathrm{Si}-\mathrm{Si}-\mathrm{Al}-$ coordination motifs $)^{87}$ by tuning the synthesis methods and parameters. However, for the sake of brevity, here we will not consider in detail the synthesis influence on $\mathrm{Cu}$-speciation; the interested reader is referred to the excellent chapter by Paolucci et al., ${ }^{69}$ which exhaustively discusses this matter for $\mathrm{Cu}-\mathrm{SSZ}-13$ and $\mathrm{Cu}-\mathrm{SAPO}-$ 34 catalysts.

Our focus here will be on the dehydrated (or 'activated') state of the material, which represents generally the starting point before catalysis. Herein we will demonstrate how in situ/operando multitechnique characterization guided by computational modelling has now enabled a renewed understanding of metal speciation and redox chemistry in these fascinating materials. The impact of the $\mathrm{Cu}$-speciation in the activated material on the performance, as well as its reaction-induced modifications, will be then examined in Section 3 for two selected processes, namely $\mathrm{NH}_{3}-\mathrm{SCR}$ and MTM conversion.

\subsection{Activation-dependent $\mathrm{Cu}$-speciation}

Activation of zeolites, that are microporous materials, is a key step for both catalysis and sorption purposes, because the evacuation of water and other molecules adsorbed in the channels and cavities is necessary to make the active sites accessible to reactants. Incomplete activation can result in residual $\mathrm{H}_{2} \mathrm{O}$ or hydrocarbon molecules, which may block and/or modify the activity of a fraction of the sites. ${ }^{56,88}$ The same holds when activation precedes a volumetric, calorimetric or spectroscopic investigation with a specific probe molecule; the simultaneous presence of water may prevent 
adsorption of the probe and/or may result in misleading results because of competition for the adsorption at the same site.

Since the discovery in the nineties that Cu-ZSM-5 zeolites are active in the direct decomposition of $\mathrm{NO}_{\mathrm{x}}$ into $\mathrm{N}_{2}$ and $\mathrm{O}_{2},{ }^{89-95}$ the activation of $\mathrm{Cu}$-exchanged zeolites has been followed by several spectroscopic studies. Besides isolated cases where copper was inserted in the zeolite as $\mathrm{Cu}(\mathrm{I})$ species via gas-phase $\mathrm{s}^{39,41-43,96-100}$ or solid phase ${ }^{101-103}$ exchanges with $\mathrm{CuCl}$, in the vast majority of the literature the cation exchange was performed via aqueous phase ion-exchange using different cupric salts.

The nature of copper in as-prepared ion-exchanged zeolites from aqueous preparation conditions, is generally agreed to be hydrated $\mathrm{Cu}$ (II) species. It was also immediately recognized that hydrated $\mathrm{Cu}$ (II) species in copper-exchanged zeolites undergo a progressive reduction to $\mathrm{Cu}$ (I) upon activation under vacuum or inert atmosphere $\left(\mathrm{He}\right.$ or $\left.\mathrm{N}_{2}\right)$ at increasing temperatures. ${ }^{74-76,104-109}$ The phenomenon has been described as "self-reduction" or "auto-reduction", owing to the fact that even though several different reduction processes were proposed, no direct proof or identification of the species that has to become oxidized in the process was found.

On the other hand, already in the middle of the nineties it became evident that an activation performed in presence of $\mathrm{O}_{2}$ resulted in samples characterized by very different copper species, ${ }^{110,111}$ as compared to an inert or vacuum activation. This evidence was confirmed in successive works. ${ }^{46}$, $52,58,65,66,112$ This was actually an important finding, since in a catalytic redox process both states, the reduced and oxidized metal state, should be addressed. In this regard, the collaboration between Haldor Topsøe and different academic partners provided a systematic investigation of three batches of Cu-SSZ-13 samples prepared in the same way with comparable chemical composition $(13.1 \leq$ $\mathrm{Si} / \mathrm{Al} \leq 15.5$ and $0.44 \leq \mathrm{Cu} / \mathrm{Al} \leq 0.48)$ subjected to both inert- and $\mathrm{O}_{2}$-activation using an impressive number of complementary characterization techniques: IR, ${ }^{46,58} \mathrm{IR}$ of adsorbed probe molecules, ${ }^{51,58}$ UV-Vis, ${ }^{58}$ EPR, ${ }^{58,78}$ XANES, ${ }^{46,}$ 51, 52 EXAFS, ${ }^{46,}{ }^{52}$ XES, ${ }^{46,}{ }^{51}$ synchrotron radiation PXRD $^{6}$ and simultaneous synchrotron radiation PXRD/XANES. ${ }^{35}$ The picture was then also supported by quantum mechanical modelling using DFT. ${ }^{6,46,52}$ Hereafter we will mainly summarize the results of those combined studies as they represent a set of self-consistent data sets coming from independent spectroscopic and scattering techniques, providing a complete structural, electronic and vibrational picture on the evolution of the population of $\mathrm{Cu}$ sites along the two different activation procedures. ${ }^{6}$, $35,46,51,52,58,78$

2.1.1. IR spectroscopy: revealing the presence of $\mathrm{Cu}(\mathrm{I})$ and $\mathrm{Cu}(\mathrm{II})$ sites. Starting form IR spectroscopy, Fig. 3a reports the FTIR spectra of dehydrated Cu-SSZ-13 zeolite collected after $\mathrm{O}_{2-}$ activation and vacuum-activation, red and black curves, respectively. The main features in the $v\left(\mathrm{O}_{-}\right.$ $\mathrm{H})$ stretching region, left part, are the bands due to external silanols $\left(3737 \mathrm{~cm}^{-1}\right)$ and to internal Brønsted sites $\left(3611 \mathrm{~cm}^{-1}, 3584 \mathrm{~cm}^{-1}\right),{ }^{7,58}$ that are similarly present after both activations. In the low wavenumber region (right part of Fig. 3a), the main feature in the $840-770 \mathrm{~cm}^{-1}$ region, which is due to the total symmetric stretching of the $\left[\mathrm{SiO}_{4}\right]$ units, ${ }^{61}$ dominates both spectra. However, the spectrum of the $\mathrm{O}_{2}$-activated sample exhibits two minor, but distinct, features at 3656 and $905 \mathrm{~cm}^{-1}$ which are not observed for the vacuum activated sample. Giordanino et al. ${ }^{58}$ were the first to assign those bands to the stretching and bending fingerprints of $[\mathrm{CuOH}]^{+}$species stabilized in the SSZ-13 matrix, ${ }^{46,58}$ assignment successively confirmed by authoritative groups active in the field, ${ }^{29,68,113}$ vide infra Fig. 
5a for a pictorial representation of this $\mathrm{Cu}$ (II) species hosted in the large cage of the CHA framework. The absence of both bands in the vacuum-activated sample allowed Borfecchia et al. to conclude that the stabilization of the $\mathrm{OH}$ extra-ligand on $\mathrm{Cu}(\mathrm{I})$ does not occur. ${ }^{46}$

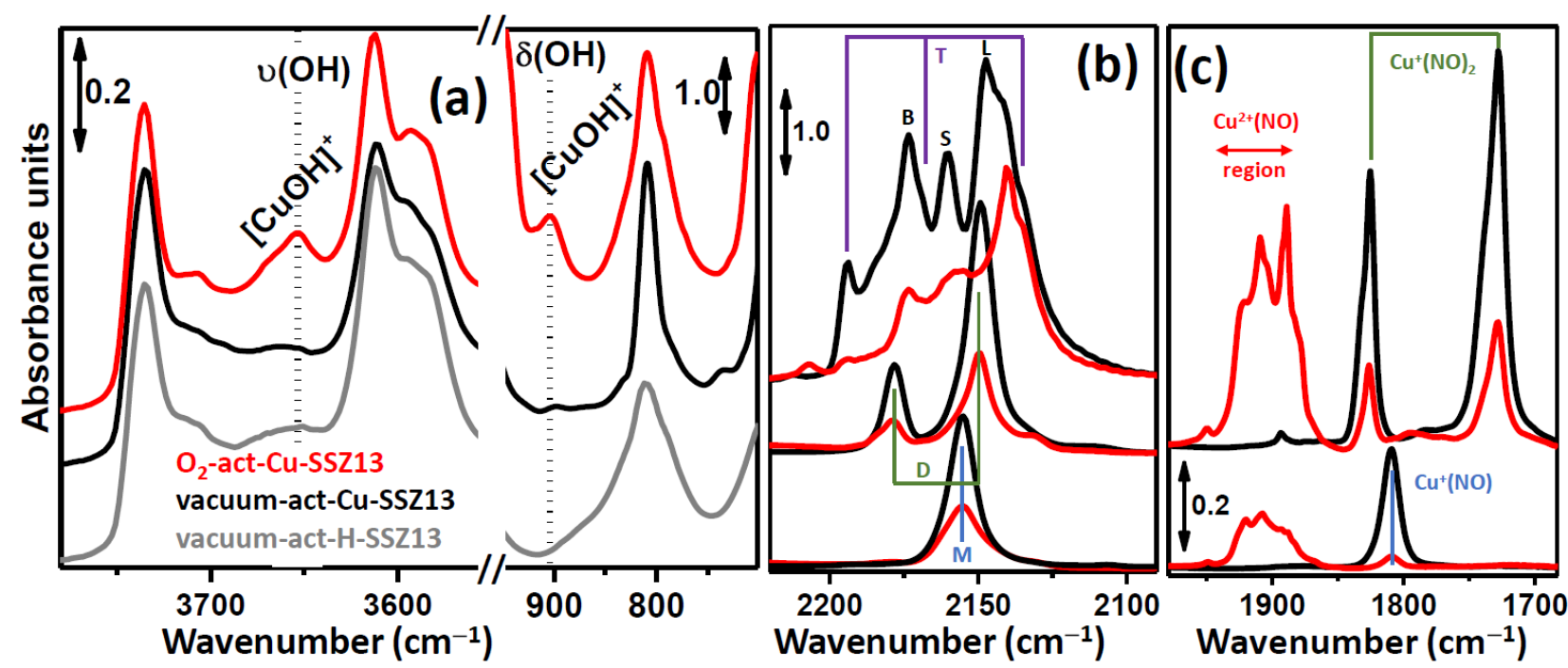

Fig. 3. Low temperature ( $100 \mathrm{~K})$ IR spectra of $\mathrm{O}_{2}$-activated (red) and vacuum-activated (black) Cu-SSZ-13 zeolite (Si/Al $=13.1$ and $\mathrm{Cu} / \mathrm{Al}=0.444)$. Part $(\mathrm{a})$ : effect of activation at $400{ }^{\circ} \mathrm{C}$ in the $v(\mathrm{OH})$ and $\delta(\mathrm{OH})$ stretching regions, left and right parts, respectively. For comparison, also the spectrum of the vacuum-activated H-SSZ-13 material (gray) is reported. The $\mathrm{O}_{2}$-activated zeolites presents the fingerprint bands of $[\mathrm{CuOH}]^{+}$species at 3655 and $905 \mathrm{~cm}^{-1}$. Part (b): IR spectra of $\mathrm{CO}$ adsorption at low, intermediate and high $\mathrm{P}_{\mathrm{CO}}$, bottom, middle and top curves respectively, approximately corresponding to the saturation of mono- (M band), di- (D doublet) and tri-carbonyl ( $\mathrm{T}$ triplet) complexes. At the highest $\mathrm{P}_{\mathrm{CO}}$, also the bands of $\mathrm{CO}$ adsorbed on Brønsted (B), silanols (S) and the band of liquid-like CO are present after both activation. Part c: IR spectra of NO adsorption at low and high $\mathrm{P}_{\mathrm{CO}}$, bottom and top curves respectively, approximately corresponding to the saturation of mono- and di-nitrosyl complexes on $\mathrm{Cu}(\mathrm{I})$ sites. In all parts some spectra have been vertically shifted for clarity. Unpublished figure reporting spectra previously published in Ref. ${ }^{46}$ for part (a) and in Ref. ${ }^{58}$ for parts (b) and (c).

The comparison with the spectrum collected on the non-exchanged parent H-SSZ-13 material (gray curves in Fig. 3a) highlighted that the intensities of the 3611 and $3584 \mathrm{~cm}^{-1}$ bands related to Brønsted sites are only slightly lower in the $\mathrm{Cu}$ exchanged sample (red or black spectra). This spectroscopic observation was particularly relevant because it could explain why a sample which has been theoretically almost fully ion-exchanged $(\mathrm{Cu} / \mathrm{Al}$ ratio of 0.444$)$ can still preserve plenty of free Brønsted acid sites. The formation of $[\mathrm{CuOH}]^{+}$species was explained according to two possible mechanisms. ${ }^{46}$

In case two framework $\mathrm{Al}$ atoms are in a close proximity $\left(2 \mathrm{Al} \mathrm{Z}_{2}\right.$ sites $)$, the stabilization of divalent $\left[\mathrm{Cu}(\mathrm{II})\left(\mathrm{H}_{2} \mathrm{O}\right)_{\mathrm{n}}\right]^{2+}$ complexes is favored and their progressive dehydration leads to $\mathrm{H}_{2} \mathrm{O}$ dissociation into $[\mathrm{Cu}(\mathrm{II}) \mathrm{OH}]^{+}$and $\mathrm{H}^{+}$species, Eq. (1a); the two cationic species will balance the charge of the two adjacent framework $\mathrm{Al}$ atoms. The FTIR study of Borfeccia et al. ${ }^{46}$ proved that, at $250{ }^{\circ} \mathrm{C}$, copper sites are fully dehydrated and for higher temperatures $[\mathrm{Cu}(\mathrm{II}) \mathrm{OH}]^{+}$species can only be stabilized in an oxidative atmosphere only, otherwise they undergo "self-reduction" as a consequence of $\mathrm{OH}^{-}$ extra-ligand loss. Alternatively, dehydration of $\left[\mathrm{Cu}(\mathrm{II})\left(\mathrm{H}_{2} \mathrm{O}\right)_{\mathrm{n}}\right]^{2+}$ complexes could lead to bare $\mathrm{Cu}$ (II) cations, Eq. (1b). Conversely, in those sites characterized by only one $\mathrm{Al}$ in the proximity (1Al Z sites), the hydrated state upon aqueous ion exchange is a monovalent $\left[\mathrm{Cu}(\mathrm{II})\left(\mathrm{H}_{2} \mathrm{O}\right)_{\mathrm{n}}(\mathrm{OH})\right]^{+}$complex, that does not require any water dissociation to be transformed into $[\mathrm{Cu}(\mathrm{II}) \mathrm{OH}]^{+}$upon dehydration, 
see Eq. (2), and the concentration of Brønsted sites in the dehydrated material is the one predicted from a total exchange level of $[\mathrm{Cu}(\mathrm{II}) \mathrm{OH}]^{+} / \mathrm{Al}^{3+}=1$. In all these cases, the loss of the $\mathrm{OH}^{-}$extraligand results in the reduction of the $\mathrm{Cu}(\mathrm{II})$ center to $\mathrm{Cu}(\mathrm{I}){ }^{46}$

$$
\begin{gathered}
2 A l \mathrm{Z}_{2}:\left[\mathrm{Cu}(\mathrm{II})\left(\mathrm{H}_{2} \mathrm{O}\right)_{n}\right]^{2+} \rightarrow\left[\mathrm{Cu}(\mathrm{II})\left(\mathrm{H}_{2} \mathrm{O}\right)\right]^{2+}+(n-1)\left(\mathrm{H}_{2} \mathrm{O}\right)^{\uparrow} \rightarrow[\mathrm{Cu}(\mathrm{II}) \mathrm{OH}]^{+}+\mathrm{H}^{+} \rightarrow \\
\rightarrow \mathrm{Cu}(\mathrm{I})+(\mathrm{OH})^{\uparrow}+\mathrm{H}^{+} \\
2 A l \mathrm{Z}_{2}:\left[\mathrm{Cu}(\mathrm{II})\left(\mathrm{H}_{2} \mathrm{O}\right)_{n}\right]^{2+} \rightarrow \mathrm{Cu}(\mathrm{II})+n\left(\mathrm{H}_{2} \mathrm{O}\right)^{\uparrow} \\
1 A l \mathrm{Z}:\left[\mathrm{Cu}(\mathrm{II})\left(\mathrm{H}_{2} \mathrm{O}\right)_{n}(\mathrm{OH})\right]^{+} \rightarrow[\mathrm{Cu}(\mathrm{II}) \mathrm{OH}]^{+}+n\left(\mathrm{H}_{2} \mathrm{O}\right)^{\uparrow} \rightarrow \mathrm{Cu}(\mathrm{I})+(\mathrm{OH})^{\uparrow}
\end{gathered}
$$

The reversibility of the $\mathrm{OH}^{-}$extra-ligand loss has been confirmed by XAS and FTIR, demonstrating that $\mathrm{Cu}(\mathrm{I})$ sites rapidly undergo re-oxidation with consequent restoration of $[\mathrm{Cu}(\mathrm{II}) \mathrm{OH}]^{+}$species if they are exposed to a gas mixture of $\mathrm{O}_{2} / \mathrm{H}_{2} \mathrm{O} .{ }^{46}$

IR spectroscopy of adsorbed probe molecules is a powerful technique in the characterization of surface sites of porous, high surface area, materials. ${ }^{54-57,114}$ The choice of probe molecule is a crucial point in this approach; different probe molecules may be able to reveal different aspects of the investigated surface, and often the combined use of markedly different probes is the key to reach a comprehensive understanding of the surface. ${ }^{57}$ In this regard, Giordanino et al. reported an extensive characterization of Cu-SSZ-13 activated under oxidative and reductive (vacuum) conditions and tested by $\mathrm{N}_{2}, \mathrm{CO}$ and $\mathrm{NO}$ probes. ${ }^{58}$

$\mathrm{CO}$ is the ideal molecule to probe $\mathrm{Cu}(\mathrm{I})$ sites because of both the high extinction coefficient and the strong adsorption energy. ${ }^{98,115}$ The high coordinative unsaturation of $\mathrm{Cu}(\mathrm{I})$ cations hosted in vacuumactivated zeolites was already demonstrated in the 1990's by the observation that multiple carbonyl complexes form, i.e. $\mathrm{Cu}(\mathrm{I})(\mathrm{CO})_{n}(n=1,2,3)$, depending on $\mathrm{CO}$ equilibrium pressure $\left(\mathrm{P}_{\mathrm{CO}}\right)$ and temperature. ${ }^{38,39,42,43,76,97,116,117}$ At low $\mathrm{P}_{\mathrm{CO}}$ (bottom spectra in Fig. 3b) the typical band (M) at 2155 $\mathrm{cm}^{-1}$ due to $\mathrm{Cu}(\mathrm{I})(\mathrm{CO})$ monocarbonyl complexes is observed. By increasing $\mathrm{P}_{\mathrm{CO}}$ the doublet at 2178 and $2148 \mathrm{~cm}^{-1}$, due to the symmetric and asymmetric stretching modes of the $\mathrm{Cu}(\mathrm{I})(\mathrm{CO})_{2}$ complexes, ${ }^{38,39,42,43,76,96,97,116,117}$ (D-bands, in the middle spectra of Fig. 3b) start to appear at the expense of the monocarbonyls (M-band). M- and D-bands appear independently on the activation treatment but are significantly more intense (by a factor 4 ) in case of inert-activated sample (black curves), confirming the higher concentration of $\mathrm{Cu}(\mathrm{I})$ ions relative to the $\mathrm{O}_{2}$ activated one (red curves). In addition, a more heterogeneous distribution of the $\mathrm{Cu}(\mathrm{I})$ sites after oxidative pretreatment compared to inert-activation is recognized by comparing the FWHM of the M bands, which are 14 and $9 \mathrm{~cm}^{-1}$, respectively.

Higher $\mathrm{P}_{\mathrm{CO}}$ leads to the formation $\mathrm{Cu}(\mathrm{I})(\mathrm{CO})_{3}$ tri-carbonyl complexes (triplet $\mathrm{T}$ at 2134,2169 and $2194 \mathrm{~cm}^{-1}$, in the top spectra in Fig. 3b), that are however less clearly visible because of an increased complexity in the IR spectra. Indeed, at such $\mathrm{P}_{\mathrm{CO}}$ values, $\mathrm{CO}$ starts to be coordinated also on sites characterized by lower adsorption enthalpies such as Brønsted and silanols, bands at $2173 \mathrm{~cm}^{-1}$ (B) and $2160 \mathrm{~cm}^{-1}(\mathrm{~S})$, respectively ${ }^{118,119}$. The band at $2138 \mathrm{~cm}^{-1}$ is due to liquid-like CO physisorbed in the zeolite channels. ${ }^{119-121}$ Giordanino et al. ${ }^{58}$ noticed that the intensity of the Brønsted acid sites related bands is not enhanced in the vacuum activated sample compared to the $\mathrm{O}_{2}$ activation. This indicates that for a $\mathrm{Cu}-\mathrm{CHA}$ sample with $\mathrm{Si} / \mathrm{Al} \sim 15$ and $\mathrm{Cu} / \mathrm{Al} \sim 0.5$ the self-reduction of $\mathrm{Cu}$ (II) into 
$\mathrm{Cu}(\mathrm{I})$ during the vacuum activation process does not generate new $\mathrm{H}^{+}$sites to compensate the loss of one positive charge for all copper atoms. This observation rules out the presence of a significant fraction of $\mathrm{Cu}$ (II) able to balance the negative framework charge induced by two adjacent $\mathrm{Al}$ atoms and implies that most of the cupric sites are inserted in form of monovalent complexes such as $[\mathrm{Cu}(\mathrm{II}) \mathrm{OH}]^{+} .58$

Due to the weaker interaction between $\mathrm{Cu}(\mathrm{II})$ and $\mathrm{CO}$ the corresponding $\mathrm{Cu}(\mathrm{II})(\mathrm{CO})$ complexes are very unstable and difficult to detect even at low temperature, ${ }^{114,}{ }^{122}$ particularly when they coexist with even just a minority of $\mathrm{Cu}(\mathrm{I})$ sites. This is the reason why the IR band of $\mathrm{Cu}(\mathrm{II})(\mathrm{CO})$ complexes, expected around $2194 \mathrm{~cm}^{-1}$, is not appreciable, even in the $\mathrm{O}_{2}$-activated sample, where $\mathrm{Cu}$ (II) surface species are the most abundant ones. Cupric species can be monitored by NO as a probe,

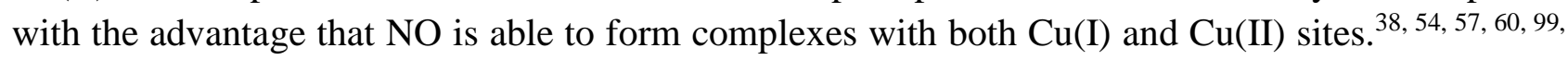
${ }^{123,124}$ At low $\mathrm{P}_{\mathrm{NO}}$, vacuum activated Cu-SSZ-13 (black curve in the bottom of Fig. 3c) shows a band centered at $1810 \mathrm{~cm}^{-1}$ due to $\mathrm{Cu}(\mathrm{I})(\mathrm{NO})$ mononitrosyl complexes; ${ }^{38,54,57,96,99,123}$ At high $\mathrm{P}_{\mathrm{NO}}$ (top black curve), the $1810 \mathrm{~cm}^{-1}$ band evolves in two main components at 1826 and $1728 \mathrm{~cm}^{-1}$ due to the

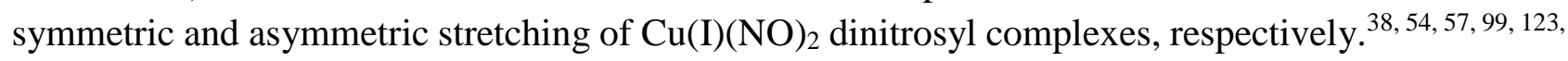
${ }^{124}$ The absence of any significant band in the $1950-1870 \mathrm{~cm}^{-1}$ range, where $\mathrm{Cu}(\mathrm{II})(\mathrm{NO})$ complexes are expected, implies that almost all cupric ions in accessible positions have been reduced to cuprous ions during the thermal activation in vacuo. The situation is different for the $\mathrm{O}_{2}$-activated sample (red curves in Fig. 3c), where bands due to $\mathrm{Cu}(\mathrm{I})(\mathrm{NO})$ and $\mathrm{Cu}(\mathrm{I})(\mathrm{NO})_{2}$ complexes are present as a minority, and the spectra are dominated, at both low and high $\mathrm{P}_{\mathrm{NO}}$, by a complex and structured absorption in the $1970-1850 \mathrm{~cm}^{-1}$ range due to $\mathrm{Cu}(\mathrm{II})(\mathrm{NO})$ adducts. The complexity of the absorption features of $\mathrm{Cu}(\mathrm{II})(\mathrm{NO})$ adducts indicates the presence of different $\mathrm{Cu}(\mathrm{II})$ cationic sites, that are not present in the reduced cuprous sites. ${ }^{58}$ The heterogeneity of $\mathrm{Cu}$ (II) sites was also confirmed by the combined $\mathrm{H}_{2}$-TPR/IR study of Kwak et al. ${ }^{125}$ and by the EPR study of Godiksen et al. ${ }^{78}$ who found two EPR active sites in the $6 r$. In the same work the authors also addressed the long-standing question of the EPR silent monomeric $\mathrm{Cu}$ (II) species in $\mathrm{Cu}$-zeolites ${ }^{74-76}$ in terms of $[\mathrm{Cu}(\mathrm{II}) \mathrm{OH}]^{+}$species coordinated to two framework oxygen atoms bonded to an isolated $\mathrm{Al}$ atom, namely $1 \mathrm{Al} \mathrm{Z}[\mathrm{Cu}(\mathrm{II}) \mathrm{OH}]$ according to the nomenclature introduced above. ${ }^{78} \mathrm{CO}$ and $\mathrm{NO}$ molecules are coordinated too strongly to $\mathrm{Cu}(\mathrm{I})$ to be suitable probes to discriminate among small cuprous site inhomogeneities; weakly interacting molecules such as $\mathrm{N}_{2}$ are required for this porpoise. Giordanino et al. ${ }^{58}$ followed the evolution of IR spectra of when dosing $\mathrm{N}_{2}$ at around $100 \mathrm{~K}$ on vacuum activated Cu-SSZ-13, observing two components at 2293 and $2300 \mathrm{~cm}^{-1}$. The two bands were assigned to $\mathrm{N}_{2}$ molecules adsorbed on $\mathrm{Cu}(\mathrm{I})$ sites in the $8 r$ and $6 r$ respectively, ${ }^{52,58}$ the former being a stronger adsorption site, because the $2300 \mathrm{~cm}^{-1}$ band is the only one observed at low $\mathrm{P}_{\mathrm{N} 2}$, and because it is characterized by a larger red-shift of the $v(\mathrm{~N} \equiv \mathrm{O})$ stretching mode. The observation that the relative intensity of the IR components of the two $\mathrm{Cu}(\mathrm{I}) \cdots \mathrm{N}_{2}$ complexes changes in $\mathrm{Cu}-\mathrm{SSZ}-13$ samples characterized by different $\mathrm{Cu} / \mathrm{Al}$ and $\mathrm{Si} / \mathrm{Al}$ ratios clearly indicated a dependence of $\mathrm{Cu}(\mathrm{I})$ site distribution on the catalyst composition and will be commented in Section 2.2, vide infra Fig. 13b.

2.1.2. UV-V is and Raman spectroscopies: insights on $\mathrm{Cu}(\mathrm{II})$ active-oxygen species. Very peculiar are the d-d transitions of $\mathrm{Cu}$ (II) species in $\mathrm{O}_{2}$-activated $\mathrm{Cu}-\mathrm{SSZ}-13$, see the UV-Vis-NIR spectrum in Fig. 4a (blue curve). Giordanino et al. ${ }^{58}$ highlighted the presence of a very intense and very well defined quadruplet with maxima at 19700, 16500, 13600 and $11000 \mathrm{~cm}^{-1}$, that is responsible for the deep blue color of the $\mathrm{O}_{2}$-activated sample, see inset in Fig. 4a. Still under debate is the precise 
assignment of this quadruplet either to different $\mathrm{Cu}(\mathrm{II})$ species/sites, reflecting the $\mathrm{Cu}(\mathrm{II})$ heterogeneity discussed above, or to a single site subjected to a very specific ligand field. ${ }^{78}$ Support from advanced DFT calculations is needed here. The sample is also characterized by a complex charge-transfer band extending down to $25000 \mathrm{~cm}^{-1}$. Oord et al. ${ }^{29}$ reported operando UV-Vis-NIR spectra following the sample activation, both in $\mathrm{O}_{2^{-}}$and He-flow conditions, see Fig. $4 \mathrm{~b}$ and $\mathrm{c}$, respectively. Upon activation the typical $d-d$ component of hydrated $\mathrm{Cu}$ (II) species around 12000 $\mathrm{cm}^{-1}$ (green spectra in Fig. 4a,b,c) progressively evolves into the structured quadruplet discussed above, which intensity however does not show a monotonic increase with activation temperature as it reaches a maximum at $320{ }^{\circ} \mathrm{C}$ and then partially loses intensity (see arrows in Fig. 4b,c). This observation is in line with the in situ FTIR study by Pappas et al. ${ }^{27}$ who observed that the finger print band of cupric $[\mathrm{Cu}(\mathrm{II}) \mathrm{OH}]^{+}$species was depleted by increasing the $\mathrm{O}_{2}$-activation temperature form $250{ }^{\circ} \mathrm{C}$ (Fig. 4d). The activation experiments by Oord et al. were successively followed by methane addition during temperature ramp from 60 to $200{ }^{\circ} \mathrm{C}$ (vide infra section 3.2.4, in particular Fig. 21e); the authors concluded their operando UV-Vis-NIR study observing that an oxidizing agent is needed to create the active site for methane to methanol activation in Cu-SSZ-13 as no methanol production was measured after He-activation. ${ }^{29}$
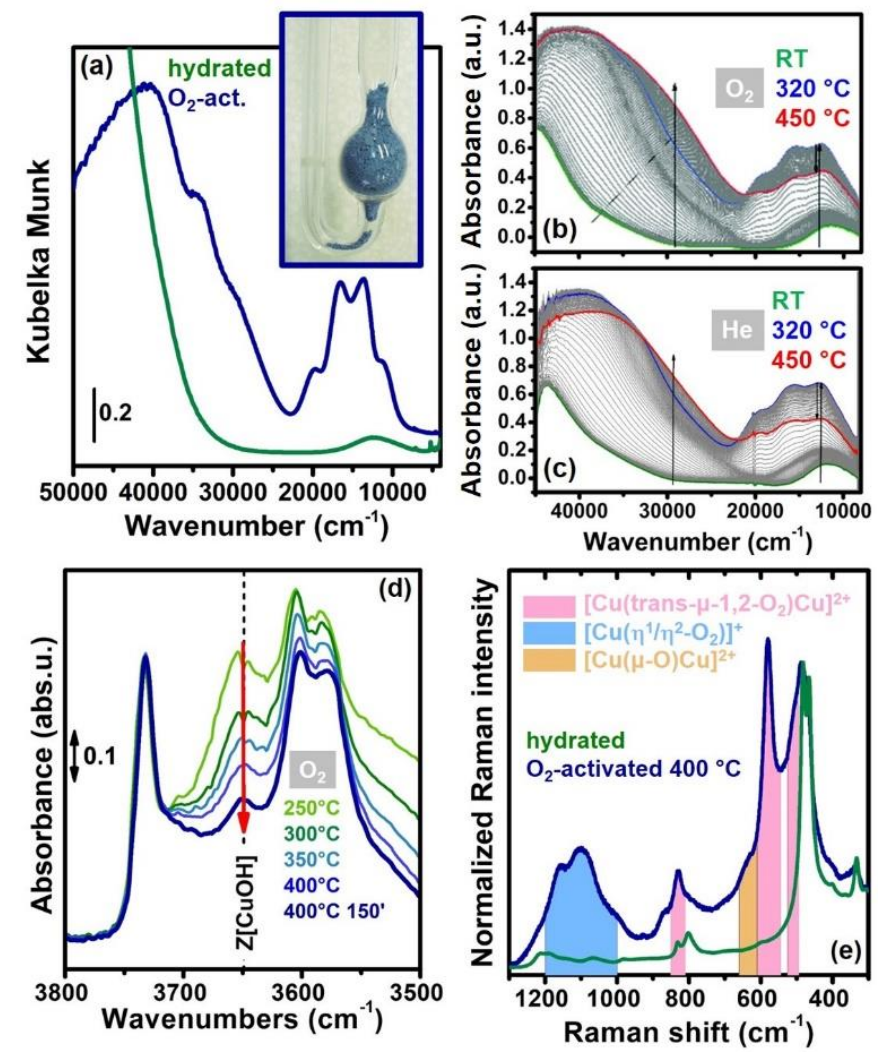

Fig. 4. Part (a): Comparison between in situ UV-Vis-NIR spectra of hydrated (green curve) and $\mathrm{O}_{2}$-activated (blue curve) $\mathrm{Cu}-\mathrm{SSZ}-13$ zeolite $(\mathrm{Si} / \mathrm{Al}=13.1$ and $\mathrm{Cu} / \mathrm{Al}=0.444)$. Adapted by permission of the Royal Chemical Society (copyright 2013) from ref. ${ }^{58}$ Part (b): operando UV-vis spectra of the $\mathrm{Cu}-1.21-\mathrm{Na}-\mathrm{Cu}-\mathrm{SSZ}-13$ zeolite $(\mathrm{Si} / \mathrm{Al}=20 \mathrm{and} 1.21 \mathrm{Cu} \mathrm{wt}$ $\%$ ) during $\mathrm{O}_{2}$-activation from $\mathrm{RT}$ (green spectrum) to $450{ }^{\circ} \mathrm{C}$ (red spectrum). The arrows indicate the time evolution, the green spectrum is the starting point of the experiment, the $\mathrm{d}-\mathrm{d}$ quadruplet reaches maximum intensity at $320{ }^{\circ} \mathrm{C}$, blue spectrum. Part (c): as part (b) during He-activation. Parts (b,c) adapted with permission of the Royal Chemical Society (copyright 2018) from ref. ${ }^{29}$. Part (d): FTIR spectroscopy in the $v(\mathrm{OH})$ stretching region as monitored in situ along $\mathrm{O}_{2-}$ activation of $\mathrm{Cu}-\mathrm{SSZ}-13(\mathrm{Si} / \mathrm{Al}=14.8$ and $\mathrm{Cu} / \mathrm{Al}=0.53)$ catalyst in the $250-300{ }^{\circ} \mathrm{C}$ range. The red arrow highlights the progressive decrease in the intensity of the band at ca. $3650 \mathrm{~cm}^{-1}$ fingerprint band of cupric $[\mathrm{CuOH}]^{+}$species upon 
increasing the activation temperature from $250{ }^{\circ} \mathrm{C}$. Part $(\mathrm{e})$ : Raman spectra $\left(\lambda_{\mathrm{ex}}=488 \mathrm{~nm}\right)$ of Cu-SSZ-13 $(\mathrm{Si} / \mathrm{Al}=14.8$ and $\mathrm{Cu} / \mathrm{Al}=0.53$ ) catalyst in its hydrated (green line) and $\mathrm{O}_{2}$-activated (blue line) forms. The spectral contributions from the observed $\mathrm{Cu}(\mathrm{II})_{\mathrm{x}} \mathrm{O}_{\mathrm{y}}$ moieties are highlighted: $\left[\mathrm{Cu}\left(\text { trans }-\mu-1,2-\mathrm{O}_{2}\right) \mathrm{Cu}\right]^{2+}$ (pink shading); $[\mathrm{Cu}-(\mu-\mathrm{O})-\mathrm{Cu}]^{2+}(\mathrm{orange}$ shading); and $\left[\mathrm{Cu}(\mathrm{II}) \mathrm{O}_{2}{ }^{\circ}\right]^{+}$(light-blue shading). Parts (d,e): adapted by permission of the American Chemical Society (copyright 2017) from ref. ${ }^{27}$

Raman spectroscopy is particularly suited to detect multinuclear $\mathrm{Cu}(\mathrm{II})_{\mathrm{x}} \mathrm{O}_{\mathrm{y}}$, it has been widely used to characterize active copper sites in biological systems ${ }^{50,126}$ and in $\mathrm{O}_{2}$-activated zeolites. ${ }^{25,27,65-67 \text {, }}$ ${ }^{127}$ Fig. 4 e reports the evolution of the Raman spectrum of Cu-SSZ-13 catalyst before (green line) and after (blue line) $\mathrm{O}_{2}$-activation. ${ }^{27}$

Several new vibrational features, related to oxygen-activated $\mathrm{Cu}(\mathrm{II})$ species appear after $\mathrm{O}_{2-}$ activation: $\left[\mathrm{Cu}(\mathrm{II}) \mathrm{O}_{2}{ }^{\circ}\right]^{+}$end-on superoxo species (strong and complex light-blue shaded components in the $1000-1200 \mathrm{~cm}^{-1}$ interval, with two maxima at 1100 and $\left.1155 \mathrm{~cm}^{-1}\right)^{27,65}$ in equilibrium with the corresponding side-on species, pictorially represented in Fig. $5 b ;{ }^{27}\left[\mathrm{Cu}\left(\text { trans }-\mu-1,2-\mathrm{O}_{2}\right) \mathrm{Cu}\right]^{2+}$ complex (orange shaded components at 510, 580, and $830 \mathrm{~cm}^{-1}$ ), see Fig. $5 \mathrm{c}$ for a pictorial representation; ${ }^{25,27}$ and $[\mathrm{Cu}-(\mu-\mathrm{O})-\mathrm{Cu}]^{2+}$ complexes (pink shaded shoulder around $620 \mathrm{~cm}^{-1}$ ).

\section{Cu-CHA (SSZ-13 and SAPO-34)}
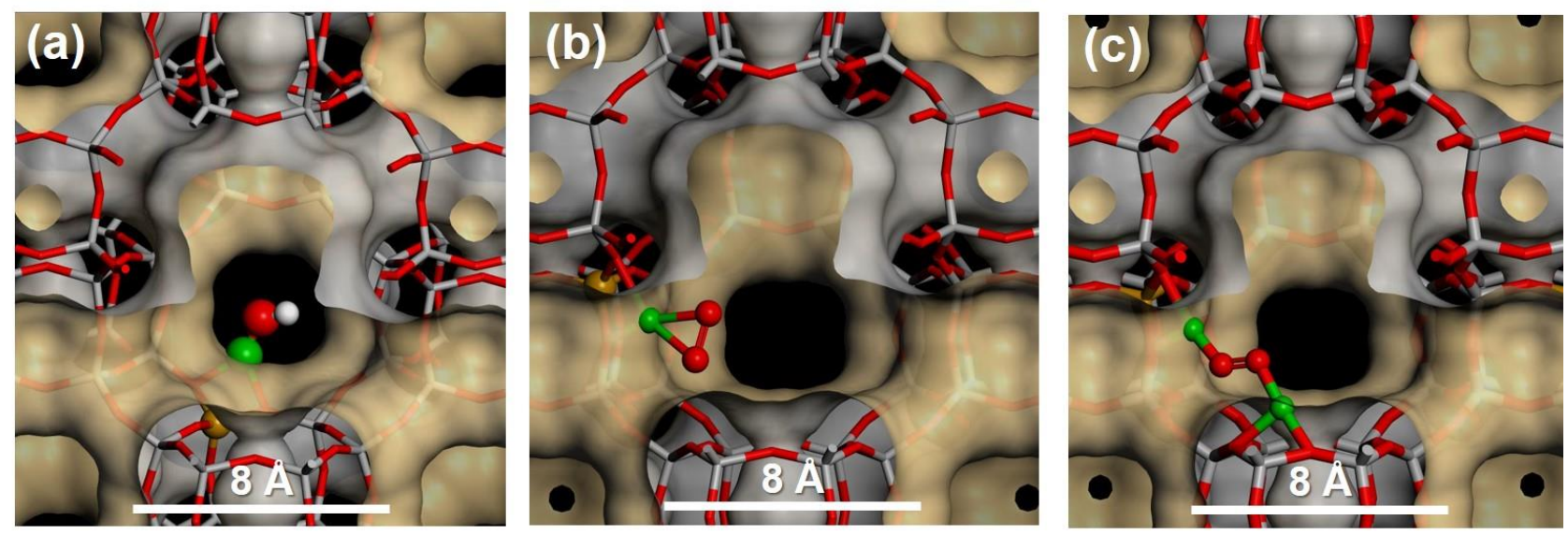

Fig. 5. Pictorial representation of some proposed local structures of the copper species formed in the large cage of the CHA frameworks under oxygen treatment at high temperature. (a): $[\mathrm{CuOH}]^{+}$species. (b): $\left[\mathrm{Cu}(\mathrm{II}) \mathrm{O}_{2}{ }^{\circ}\right]^{+}$side on superoxo species. (c): $\left[\mathrm{Cu}\left(\text { trans }-\mu-1,2-\mathrm{O}_{2}\right) \mathrm{Cu}\right]^{2+}$. Colour code: Si grey, O, red, Al gold, $\mathrm{Cu}$ green, H, white. By courtesy of K. P. Lillerud (Department of Chemistry, University of Oslo), previously unpublished Figure.

\subsubsection{DFT supported XAS and XES investigation: understanding the structure of the $\mathrm{Cu}(\mathrm{II})$} and $\mathrm{Cu}(\mathrm{I})$ species inn activated samples. Borfecchia et al. ${ }^{46}$ followed the activation in temperature up to $400{ }^{\circ} \mathrm{C}$ in both $\mathrm{O}_{2} / \mathrm{He}$ and pure He flows with XANES, EXAFS and valence-to-core XES spectroscopies. The EXAFS-optimized experimental setup and rather high copper content in the sample allowed a very good data quality paving the way to a detailed quantitative analysis. XANES, EXAFS and valence-to-core XES spectra, together with the optimized DFT models and corresponding XANES and XES simulations are reported in Fig. 6 and Fig. 7 for $\mathrm{O}_{2}$ - and Heactivated samples, respectively. Borfecchia et al., ${ }^{46}$ tested several DFT models for $\mathrm{Cu}(\mathrm{II})$ and $\mathrm{Cu}(\mathrm{I})$ sites in the $8 r$ or in the $6 r$, obtained inserting either one or two $\mathrm{Al}$ atoms in the $\mathrm{T}$ positions of the rings. Structures reported in Fig. $6 c$ and Fig. 7c,d are only those that are compatible with the experimental results. 

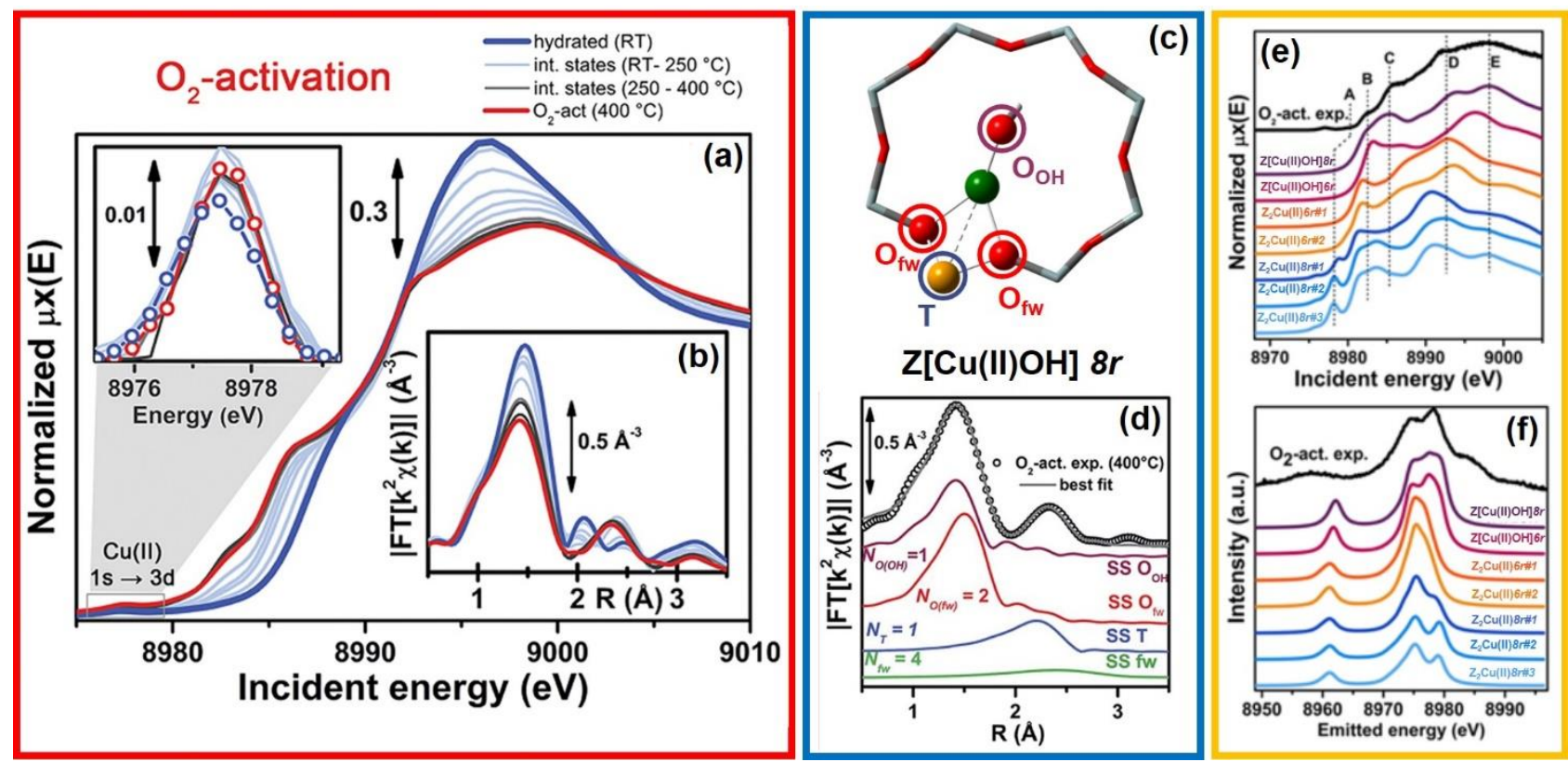

Fig. 6. Part (a): XANES spectra following the activation from room temperature (blue curve, hydrated material) to 400 ${ }^{\circ} \mathrm{C}$ (red curve, activated material) of $\mathrm{Cu}-\mathrm{SSZ}-13(\mathrm{Cu} / \mathrm{Al}=0.444, \mathrm{Si} / \mathrm{Al}=13.1)$ in $50 \% \mathrm{O}_{2} / \mathrm{He}$ flow. The inset shows a magnification of the $1 \mathrm{~s} \rightarrow 3 \mathrm{~d}$ transition, typical of $\mathrm{Cu}(\mathrm{II})$ species. Part (b) as part (a) for the $\mathrm{k}^{2}$-weighted FT of the EXAFS spectra. Part (c): DFT model of the dominant $\mathrm{Cu}$-site in the $\mathrm{O}_{2}$-activated material. Part (d): best EXAFS fit and related main individual components obtained using the model reported in part (c). Part (e): experimental HERFD XANES spectrum (black curve) and computed XANES spectra (colored curves) for the different optimized possible sites. Part (f): as part (e) for the valence to core XES spectra. Both HERFD XANES and XES simulations support the EXAFS results. Adapted by permission of the Royal Society of Chemistry (copyright 2015) from ref. ${ }^{46}$

Upon activation in $\mathrm{O}_{2} / \mathrm{He}$ flux, $\mathrm{Cu}(\mathrm{II})$ centers undergo progressive dehydration, while interacting more closely with the framework, maintaining the +2 oxidation state. Features typical for $\mathrm{Cu}$ (II) in low-symmetry environment were observed in XANES (Fig. 6a), while EXAFS witnesses the marked decrease of the first shell intensity due to the loss of the coordinated water molecules (Fig. 6b). Comparable evolution of the XANES spectra upon similar activation in oxidative environment was observed also by Kwak et al. ${ }^{32}$ Conversely, as already observed by IR spectroscopy studies (see Section 2.1.1), upon activation in vacuum or in inert atmosphere the $\mathrm{Cu}$ oxidation state changes to +1 , as evidenced for the $\mathrm{Cu}(\mathrm{II})-\mathrm{SSZ}-13$ system by the disappearance of $1 \mathrm{~s} \rightarrow 3 \mathrm{~d}$ transition and by the additional redshift of the edge, see Fig. 7a. Most interestingly, the EXAFS data reveal that the coordination of $\mathrm{Cu}$ upon $\mathrm{He}$-activation was further decreased compared to the activation in $\mathrm{O}_{2}$. Coupled with the observation that the reduction in He flow appears only at high temperature $(\mathrm{T}>250$ ${ }^{\circ} \mathrm{C}$ ), while at lower $\mathrm{T}$ the evolution of the spectra is identical to the $\mathrm{O}_{2}$-activation case, it indicates that a charged extra-ligand is still coordinated to $\mathrm{Cu}$ even at high temperature in case of $\mathrm{O}_{2}$-activation. This evidence supports the hypothesis of the presence of an $\mathrm{OH}^{-}$ligand in the first coordination shell of $\mathrm{Cu}(\mathrm{II})$ as advanced in the IR study of Giordanino et al. ${ }^{58}$ to assign the $v(\mathrm{OH})$ stretching mode at $3657 \mathrm{~cm}^{-1}$ and discussed in the previous section. 

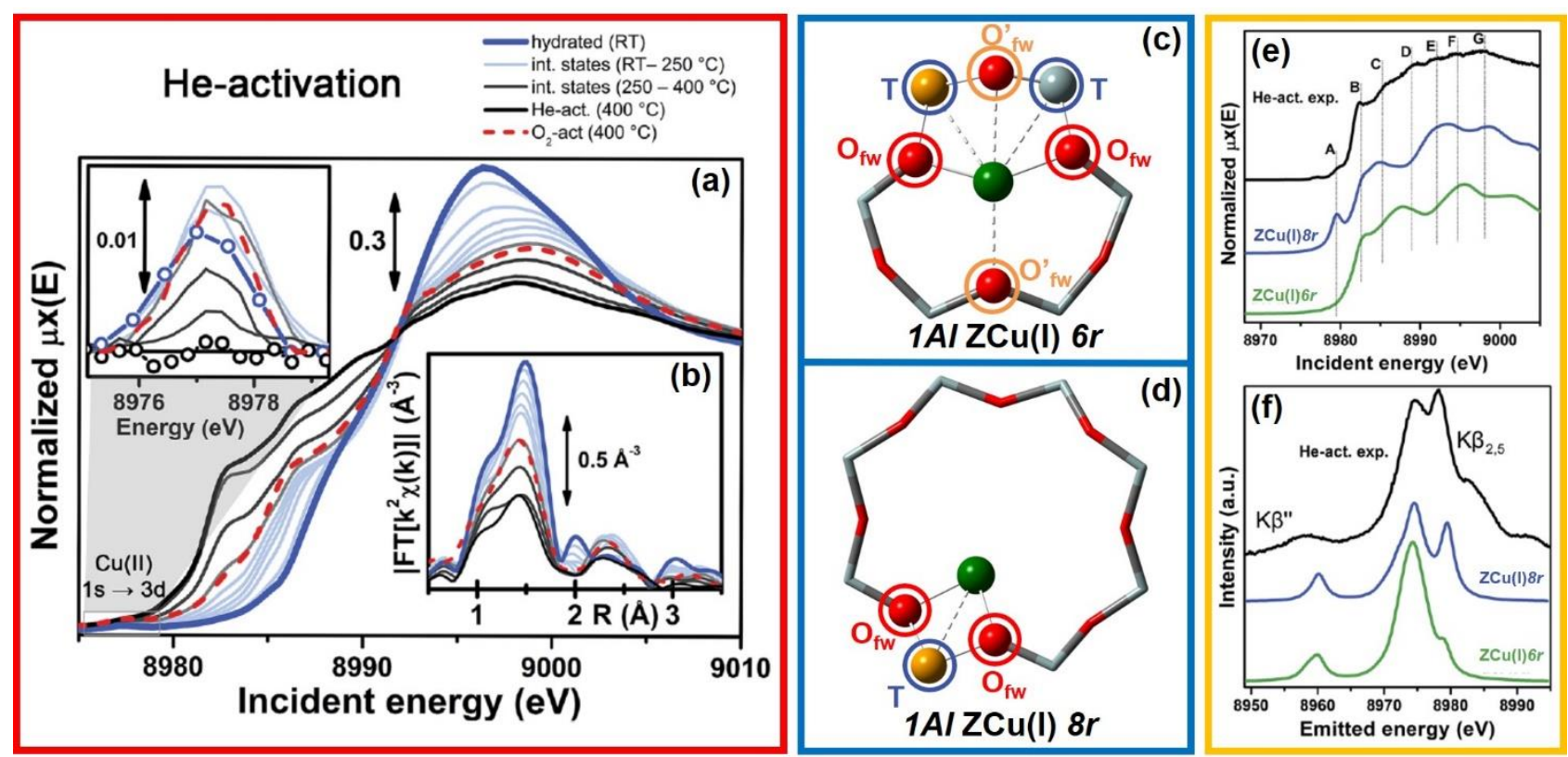

Fig. 7. Part (a): XANES spectra following the activation from room temperature (blue curve, hydrated material) to 400 ${ }^{\circ} \mathrm{C}$ (red curve, activated material) of $\mathrm{Cu}-\mathrm{SSZ}-13(\mathrm{Cu} / \mathrm{Al}=0.444, \mathrm{Si} / \mathrm{Al}=13.1)$ in inert $\mathrm{He}$ flow. The inset shows a magnification of the $1 \mathrm{~s} \rightarrow 3 \mathrm{~d}$ transition, typical of $\mathrm{Cu}(\mathrm{II})$ species and disappearing at high temperature. Part (b) as part (a) for the $\mathrm{k}^{2}$-weighted FT of the EXAFS spectra. Parts $(\mathrm{c}, \mathrm{d})$ : DFT model of the dominant $\mathrm{Cu}$-sites in the He-activated material. Best EXAFS fit and related main individual components obtained using the model reported in part (c). Part (d): experimental HERFD XANES spectrum (black curve) and computed XANES spectra (colored curves) for the different optimized possible sites. Part (f): as part (e) for the valence to core XES spectra. Both HERFD XANES and XES simulations support the EXAFS results. Adapted by permission of the Royal Society of Chemistry (copyright 2015) from ref. $^{46}$

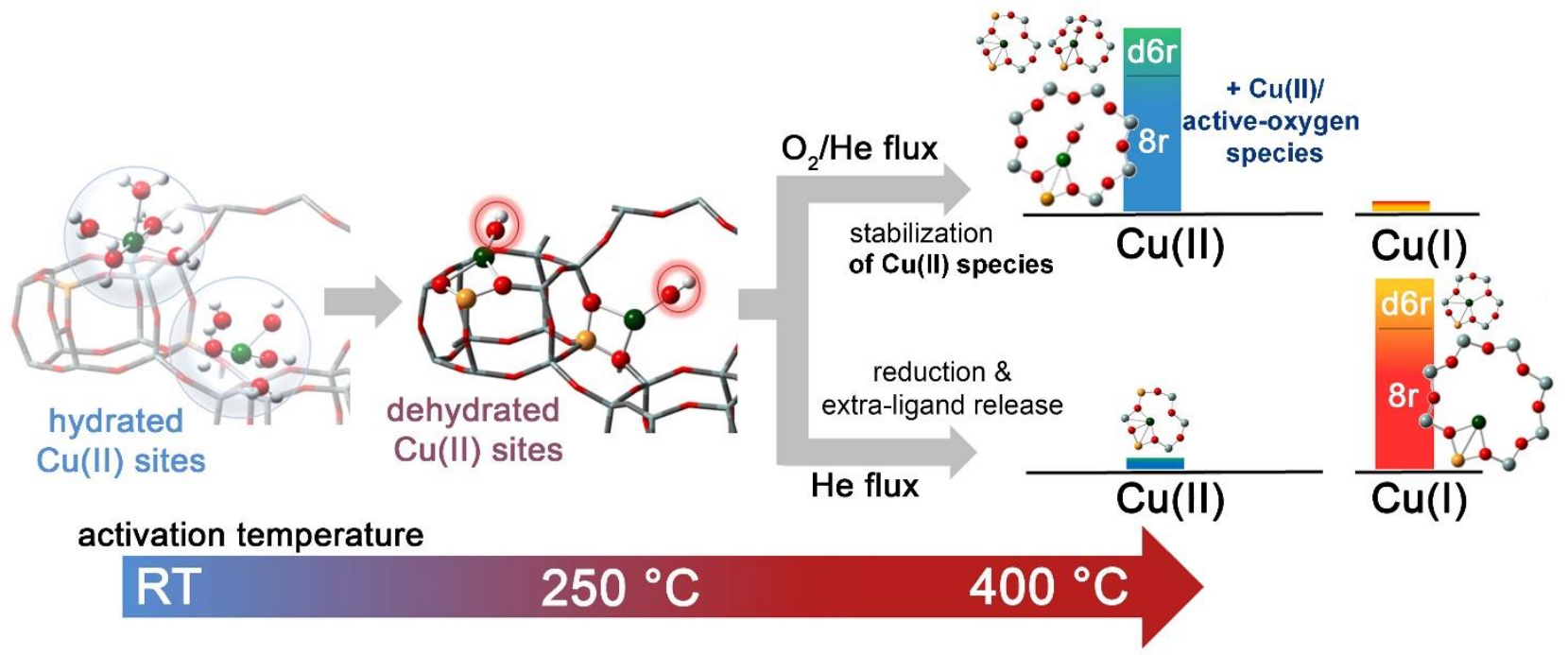

Fig. 8. Schematic representation of temperature/condition dependent $\mathrm{Cu}$-speciation in $\mathrm{Cu}-\mathrm{SSZ}-13(\mathrm{Cu} / \mathrm{Al}=0.444$ and $\mathrm{Si} / \mathrm{Al}=13.1$ ). $\mathrm{O}_{2}$-activation resulted in a virtually $100 \% \mathrm{Cu}(\mathrm{II})$ sample, while the presence of a minor fraction (around $10 \%$ ) of $\mathrm{Cu}(\mathrm{II})$ was detectable in the He-activated sample using HERFD XANES spectroscopy. The larger geometries depicted in the right side of the scheme are the dominant structural components identified by XAS, XES and FTIR in the $\mathrm{Cu}-\mathrm{SSZ}-13$ sample with this composition. As indicated in the scheme, based on the UV-Vis and Raman results discussed in Section 2.1.2 (Fig. 4), high-temperature thermal treatment in the presence of $\mathrm{O}_{2}$ could also result in the formation of $\mathrm{Cu}$ (II)/active-oxygen species, see Fig. 5. Adapted by permission of the Royal Society of Chemistry (copyright 2015) from ref. $^{46}$

Borfecchia et $a l .{ }^{46}$ have further tested this hypothesis by performing a set of DFT simulations of $\mathrm{Cu}$ ions in different locations of the framework and using the resulting structures as input for EXAFS 
fits and for the simulations of the high energy resolution fluorescence detected (HRFD) XANES and XES spectra, see parts (e) and (f) of Fig. 6 and Fig. 7. For the $\mathrm{O}_{2}$-activated material, the best overall agreement with the experimental data was obtained for the models of $\mathrm{Cu}$ (II) in the $8 r$, in form of a $\mathrm{Z}[\mathrm{Cu}(\mathrm{II}) \mathrm{OH}]$ complex, see Fig. $6 \mathrm{c}$ confirming the first assignment of the $v(\mathrm{OH})$ stretching mode at $3657 \mathrm{~cm}^{-1},{ }^{58}$ while in case of He-activation it was a bare $\mathrm{Cu}(\mathrm{I})$ cation hosted mainly in the $8 \mathrm{r}$, with a minority occupancy of the $6 r$ site, as summarized in the scheme reported in Fig. 8. This study was then extended in a successive work of the same group ${ }^{52}$ to a set of six Cu-SSZ-13 samples characterized by different $\mathrm{Si} / \mathrm{Al} \mathrm{And} \mathrm{Cu} / \mathrm{Al}$ ratios, that will be discussed hereafter in Section 2.2.3, see Fig. 12.

\subsubsection{Combined XANES/PXRD: highlighting the correlation between $\mathrm{Cu}$ (II) self-reduction and} cation migration in the CHA framework. As discussed in the previous section, the in situ XAS/XES study by Borfecchia et al. ${ }^{46}$ shed light on the evolution of the oxidation state and local environment of copper species along the two different activation procedures. Moreover, the support of DFT, allowed the use of the EXAFS spectra as an indirect tool to determine whether $\mathrm{Cu}$ species are located in the $8 r$ or $6 r$, see Fig. 12. A direct determination of the copper location in the unit cell requires however diffraction techniques. In this regard, Andersen et al. ${ }^{6}$ provided a detailed structural description of an $\mathrm{O}_{2}$-activated $\mathrm{Cu}-\mathrm{SSZ}-13(\mathrm{Si} / \mathrm{Al}=15.5, \mathrm{Cu} / \mathrm{Al}=0.45)$ analyzing with iterative Rietveld analysis and maximum entropy method high-resolution synchrotron PXRD, finding that $\mathrm{Cu}$ cations occupied two crystallographic independent sites located in the $8 r$ and in the $6 r$. The limitation of the first study by Andersen et al. ${ }^{6}$ is however that information on the oxidation state of copper ions cannot be extracted from diffraction data.

To overcome this limitation, Andersen et al. ${ }^{35}$ performed a new experiment on the SwissNorwegian beamline of the ESRF synchrotron that is equipped with two independent monochromators, allowing a rapid (about $30 \mathrm{~s}$ ) plug and play switch between X-ray absorption and X-ray diffraction setups. ${ }^{128-130}$ Thus both XAFS spectra and PXRD patterns (with a 2D detector) can be measured on exactly the same sample in almost the same conditions.

Using the two $\mathrm{Cu}$ sites determined in the previous experiment, ${ }^{6}$ and constraining the sum of the refined $\mathrm{Cu}$ species to be equal to 1.08 atoms per unit cell (as determined by ICP elemental analysis) Andersen et al. ${ }^{35}$ found that along the $\mathrm{O}_{2}$-activation, there is a migration of $\mathrm{Cu}$ species from the $8 r$ into the $6 r$ site (black and red data, respectively in Fig. 9a) and that this phenomenon is accompanied by a partial reduction of $\mathrm{Cu}(\mathrm{II})$ into $\mathrm{Cu}(\mathrm{I})$ (violet and orange data in Fig. 9b). This reduction phenomenon occurs once virtually all water molecules have left the zeolite framework, as confirmed by the in dependent PXRD and XANES analyses, blue data in parts (a) and (b) of Fig. 9, respectively. The reduction of a fraction of $\mathrm{Cu}$ (II) into $\mathrm{Cu}(\mathrm{I})$, determined by linear combination analysis of the XANES data, is essential to explain how, at the end of the treatment, copper species can occupy the $6 r$ site with an occupancy almost twice as large as the maximum allowed for $\mathrm{Cu}$ (II) species on the basis of the $\mathrm{Si} / \mathrm{Al}$ ratio of the investigated zeolite (15.5). The same experiment, repeated in Heatmosphere (Fig. 9c,d), resulted in a more pronounced migration of copper species from the $8 r$ into the $6 r$ site and in a total reduction of $\mathrm{Cu}(\mathrm{II})$ into $\mathrm{Cu}(\mathrm{I})$, regardless of which site is occupied. 


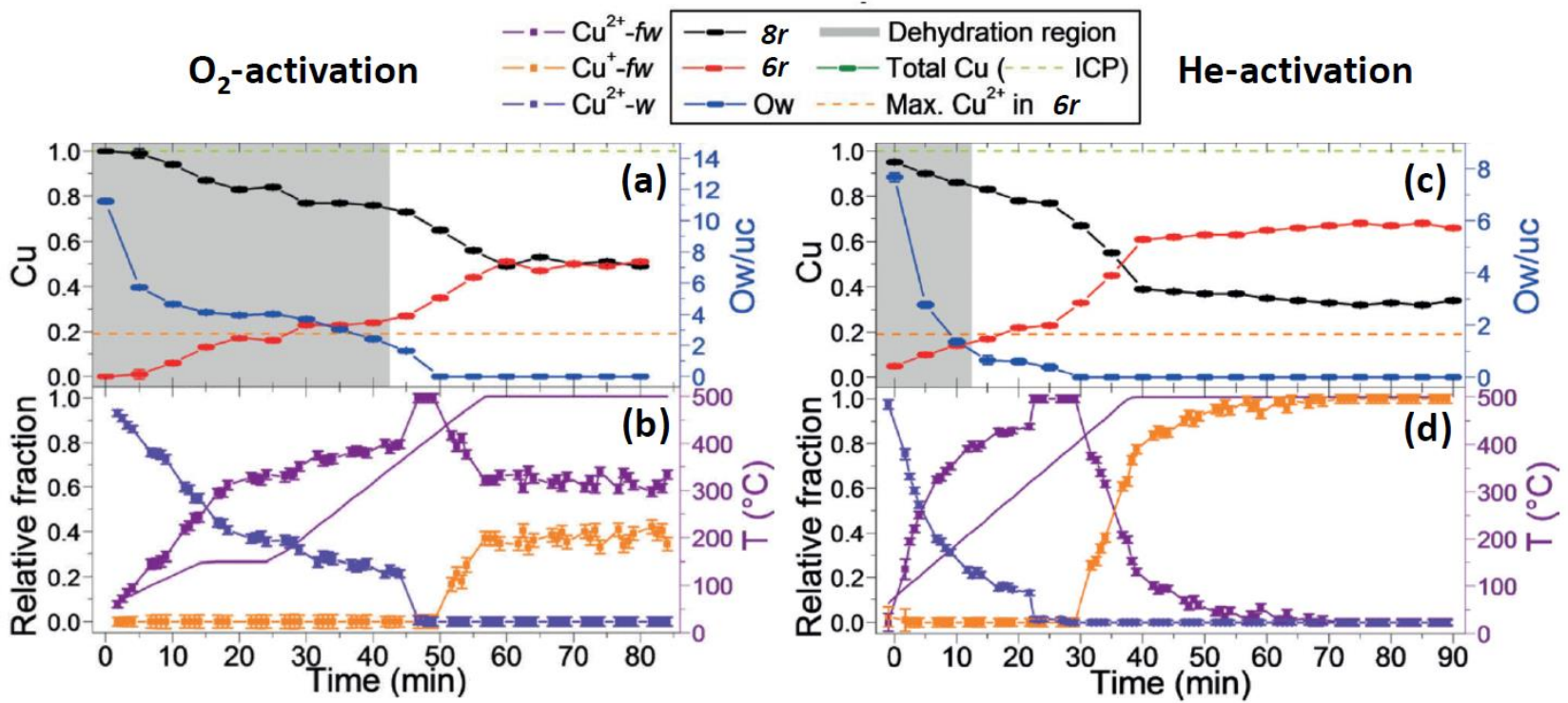

Fig. 9. Part (a): Evolution of the $\mathrm{Cu}$ occupancies in the $8 r$ (black data) and $6 r$ (red data) sites during $\mathrm{O}_{2}$-activation (10\% $\mathrm{O}_{2}$ in $\mathrm{He}$ ) of $\mathrm{Cu}-\mathrm{CHA}(\mathrm{Si} / \mathrm{Al}=15.1 ; \mathrm{Cu} / \mathrm{Al}=0.48)$ from the Rietveld refinement of the time-resolved synchrotron PXRD data. In all refinements, the sum of the occupancies of the two sites has been constrained to the value determined by chemical analysis (dashed vertical gray line). Also reported is the number of water molecules per unit cell optimized in the refinements (blue data). The horizontal dashed orange line represents the theoretical maximum amount of $\mathrm{Cu}$ (II) species that can be hosted in $6 r$ in a CHA framework with $\mathrm{Si} / \mathrm{Al}=15.5$. Part (b): fraction of hydrated $\mathrm{Cu}$ (II) species (blue data) of $\mathrm{Cu}$ (II) species interacting with the zeolite framework (violet data) and of $\mathrm{Cu}(\mathrm{I})$ species interacting with the zeolite framework (orange data) as determined by the linear combination analysis of the XANES data collected almost simultaneously with the PXRD data. Parts (c) and (d): as parts (a) and (b) for the He-activation of the same sample.

Comparing the overall results of the IR experiments of $\mathrm{CO}$ and NO adsorption, (Section 2.1.1, Fig. 3) with the combined XANES/EXAFS/XES experiments (Section 2.1.3, Fig. 6, Fig. 7 and Fig. 8) and with the parallel PXRD/XANES study reviewed here above (Fig. 9), it emerges that all experiments are in semi-qualitative agreement and that some (minor) disagreement exists on the quantification of the fraction of $\mathrm{Cu}(\mathrm{I})$ and $\mathrm{Cu}(\mathrm{II})$ species obtained at the end of both $\mathrm{O}_{2}$ - and inertactivations. To better understand such discrepancies the next section extends the analysis of the complexity of the problem to two important variables that are the $\mathrm{Si} / \mathrm{Al}$ and the $\mathrm{Cu} / \mathrm{Al}$ ratios.

\subsection{Composition-dependent Cu-speciation}

2.2.1. Multiple cationic positions in $\mathrm{Cu}-\mathrm{CHA}$ : insight and compositional trends from TPR. As anticipated in the beginning of Section 2, the initial structural investigations on $\mathrm{Cu}-\mathrm{CHA}$ zeolites $^{3,85}$ claimed that $\mathrm{Cu}$ is located in a single cationic site, coordinated to three framework oxygen atoms $\left(\mathrm{O}_{\mathrm{fw}}\right)$ just outside the $6 r$ plane. In particular, the study by Fickel et al. ${ }^{85}$ was conducted on a Cu-SSZ13 catalyst with $\mathrm{Si} / \mathrm{Al}=12$ and $\mathrm{Cu} / \mathrm{Al}=0.35$ by Rietveld refinement of temperature-dependent synchrotron XRD data. A subsequent report by Korhonen et $a l .{ }^{45}$ supported the previously proposed 'single-site' scenario for a Cu-SSZ-13 catalyst with $\mathrm{Si} / \mathrm{Al}=9$ and $\mathrm{Cu} / \mathrm{Al}=0.18$, based on in situ $\mathrm{UV}$ Vis and XAS data. As a consequence, the isolated $\mathrm{Cu}$ (II) species in $6 r$ identified by XRD were initially proposed as the active sites for $\mathrm{NH}_{3}-\mathrm{SCR}$.

This simple and elegant structural picture was however challenged by the TPR results reported by Peden and co-workers. ${ }^{125}$ The authors performed $\mathrm{H}_{2}$-TPR measurements on a series of $\mathrm{Cu}$ - 
exchanged SSZ-13 zeolites, with Si/ $/ \mathrm{Al}_{2}=12$ and exchange levels from $20 \%$ to $100 \%$. In particular, $\mathrm{H}_{2}$-TPR experiments performed in $2 \% \mathrm{H}_{2} / \mathrm{Ar}$ in the $\mathrm{RT}-600^{\circ} \mathrm{C}$ temperature range on $\mathrm{O}_{2}$-calcinated catalysts evidenced only a single $\mathrm{H}_{2}$ consumption peak at $340{ }^{\circ} \mathrm{C}$ for the $20 \%$ exchanged zeolite. Increasing the $\mathrm{Cu}$-exchange level, an additional peak developed at $230{ }^{\circ} \mathrm{C}$, the intensity of which increased proportionally to the $\mathrm{Cu}$-loading, and was maximized at $100 \% \mathrm{Cu}$-exchange. As for the high-temperature peak at $340{ }^{\circ} \mathrm{C}$, its intensity was observed to be stabilized at $40 \%$ exchange, remaining unchanged at higher $\mathrm{Cu}$-loadings. These findings provided a direct proof of two different $\mathrm{Cu}$ (II) species/sites in SSZ-13, with Cu-loading-dependent distribution and markedly different redox barriers. In the same work, the authors also explored the effect of $\mathrm{H}_{2} \mathrm{O}$ presence during TPR, working in $2 \% \mathrm{H}_{2} / \mathrm{Ar}+1 \% \mathrm{H}_{2} \mathrm{O}$. Under these conditions, the two reduction peaks observed during 'dry' TPR would progressively shift towards each other as $\mathrm{Cu}$-loading increased, coalescing finally to a single peak at $210{ }^{\circ} \mathrm{C}$ for the $100 \%$-exchanged sample.

These findings, together with complementary evidence from FTIR spectroscopy of adsorbed CO and NO (see above the discussion of Fig. 3b,c), were interpreted with two types of $\mathrm{Cu}$ ions in $\mathrm{Cu}-$ SSZ-13: (i) $\mathrm{Cu}$ in highly coordinated and stable sites in the $6 r$, proposed to be primarily occupied at low exchange level and associated with the high-temperature TPR peak; (ii) $\mathrm{Cu}$ in the large cages of the $\mathrm{CHA}$ framework responsible for the low-temperature $\mathrm{H}_{2}$ consumption peak and favored at higher exchange levels. Interaction with $\mathrm{H}_{2} \mathrm{O}$, even in very small amounts, was suggested to cause migration of the $\mathrm{Cu}$ ions, driving $\mathrm{Cu}$ out from the $6 r$ site towards the large $\mathrm{CHA}$ cages, where it could be more easily reduced.

A subsequent study by the same research group ${ }^{131}$ comprehensively addressed the impact of both $\mathrm{Cu} / \mathrm{Al}$ and $\mathrm{Si} / \mathrm{Al}$ ratios on the redox behaviour of $\mathrm{Cu}-\mathrm{SSZ}-13$ catalysts as probed by $\mathrm{H}_{2}$-TPR. In this work, Gao et al. collected $\mathrm{H}_{2}$-TPR data for a large set of samples, with Si/Al ratios of 6, 12 and 35 and several different $\mathrm{Cu} / \mathrm{Al}$ ratios in the $0.06-0.44$ range. Fig. 10 reports an overview of the results. The materials were analysed starting from their hydrated state ('hydrated' labels in Fig. 10) and after being pre-dehydrated in dry $5 \% \mathrm{O}_{2} / \mathrm{He}$ at $550{ }^{\circ} \mathrm{C}$ ('dehydrated' labels in Fig. 10).

The high-temperature $\mathrm{H}_{2}$ consumption peak is favoured at low values of both $\mathrm{Si} / \mathrm{Al}$ and $\mathrm{Cu} / \mathrm{Al}$ ratios. It becomes almost undetectable for $\mathrm{Si} / \mathrm{Al}=35$ catalysts, where the low-temperature peak dominates the TPR profile, irrespectively of the $\mathrm{Cu}$-loading. For the hydrated catalysts a general enhancement of the low-temperature peak is observed. Notably, at high $\mathrm{Cu} / \mathrm{Al}$ ratio, dehydrated samples exhibited a significant shift of the first reduction peak to lower temperature relative to the hydrated ones. 
(a) $\mathrm{Si} / \mathrm{Al}=6$

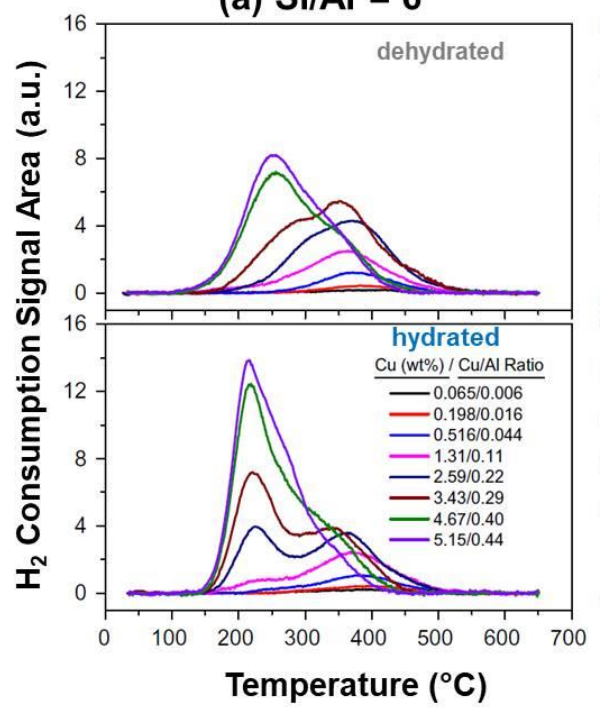

(b) $\mathrm{Si} / \mathrm{Al}=12$

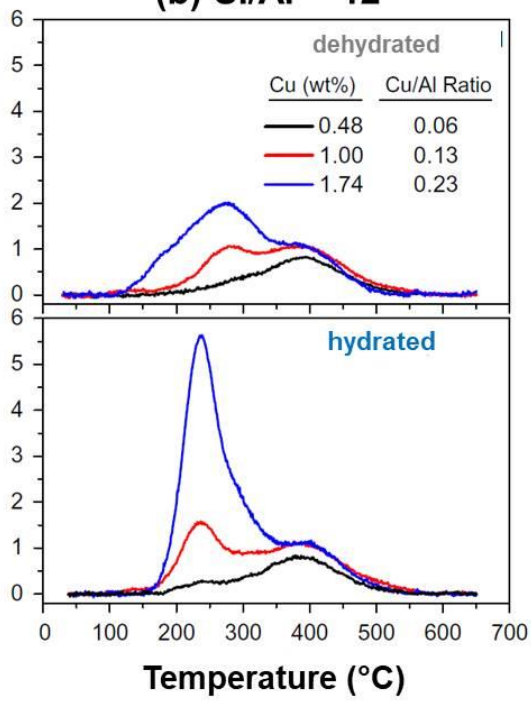

(c) $\mathrm{Si} / \mathrm{Al}=35$

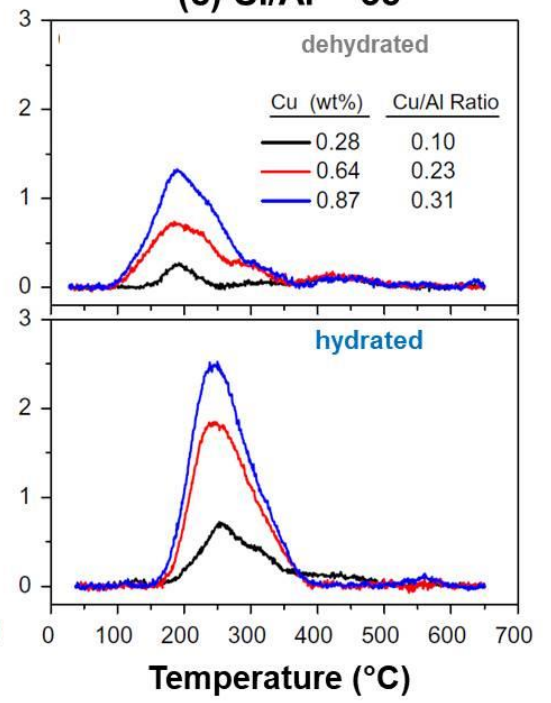

Fig. 10. $\mathrm{H}_{2}$-TPR results for $\mathrm{Cu}-\mathrm{SSZ}-13$ samples with different $\mathrm{Cu}$ loadings for (a) $\mathrm{Si} / \mathrm{Al}=6$, (b) $\mathrm{Si} / \mathrm{Al}=12$ and (c) $\mathrm{Si} / \mathrm{Al}$ $=35$. Top panels report TPR for dehydrated samples while bottom panels show TPR for fully hydrated samples with the same composition. Adapted with permission from ref. ${ }^{131}$. Copyright 2015 Elsevier Inc.

The authors also found that the total $\mathrm{H}_{2}$ consumption for the two highest $\mathrm{Cu}$ loadings diminished for dehydrated samples with respect to the hydrated ones. This observation was interpreted with selfreduction of some $\mathrm{Cu}$ (II) already during dehydration step prior to TPR, even if the treatment was carried out in a $5 \% \mathrm{O}_{2} / \mathrm{He}$ flow. Evidence for self-reduction of about $40 \%$ of the total $\mathrm{Cu}$ content during thermal treatment in diluted $\mathrm{O}_{2}$ flow $\left(10 \% \mathrm{O}_{2} / \mathrm{He}\right)$ at temperature $>450{ }^{\circ} \mathrm{C}$ was also reported by Andersen et al., ${ }^{35}$ see above Section 2.1. The integrated area of the TPR peaks for the dehydrated samples with $\mathrm{Si} / \mathrm{Al}=35$ where connected with the highest self-reduction levels, showing a peculiar decrease of self-reduced $\mathrm{Cu}$ at increasing $\mathrm{Cu}$-loading.

It clearly appears that the redox-properties of the $\mathrm{Cu}$-ions in $\mathrm{Cu}-\mathrm{SSZ}-13$ can be systematically tuned by modifying the compositional parameters of the material. The TPR results reviewed above point to two major $\mathrm{Cu}$ (II) species (or, possibly, classes of $\mathrm{Cu}$ (II) species). These include a redoxresistant component favoured at low $\mathrm{Si} / \mathrm{Al}$ and $\mathrm{Cu} / \mathrm{Al}$ values and a redox-active one, becoming more abundant at high $\mathrm{Si} / \mathrm{Al}$ and $\mathrm{Cu} / \mathrm{Al}$ ratios. Based on the TPR trends with composition, the redoxresistant component is consistent with bare $\mathrm{Cu}$ (II) species charge-balanced by two proximal $\mathrm{Al}$ atoms at $\mathrm{T}$-sites in a $6 r, \mathrm{Z}_{2} \mathrm{Cu}(\mathrm{II})$, statistically more abundant in Al-rich frameworks, see above Eq. (1a) and related discussion. Highly stable and firmly coordinated to the framework, this site well matches the initial proposals formulated from XRD analysis. The assignment of the redox-active component, based on TPR, appears somehow more uncertain. Its composition-dependent $\mathrm{H}_{2}$-TPR response strongly supports a $\mathrm{Cu}(\mathrm{II})$ species hosted at a $1 \mathrm{Al}$ sites, where the charge balance is closed by extraframework ligands. The $\mathrm{Z}[\mathrm{Cu}(\mathrm{II}) \mathrm{OH}]^{+}$complex extensively discussed in Section 2.1 represents a very plausible candidate. Nonetheless, the differences among hydrated and dehydrated conditions evidenced in Fig. 10 indicate a role of high-temperature treatment in $\mathrm{O}_{2}$. According to Gao et al. ${ }^{131}$ a reduction onset as low as $100{ }^{\circ} \mathrm{C}$ for materials pre-activated in $\mathrm{O}_{2}$, suggests the presence of dimeric oxo-bridged $\mathrm{Cu}$-species, or possibly other $\mathrm{O}_{2}$-derived superoxo or peroxo moieties, undergoing facile reduction even at very low temperature. The formation of such types of species, already introduced in Section 2.1.2, will be further discussed in sub-section 2.2.4. 
2.2.2. A compositional phase diagram for $\mathrm{Cu}-\mathrm{SSZ}$-13. The TPR results described above where paralleled by an impressive amount of characterization results on $\mathrm{Cu}-\mathrm{CHA}$ materials at reference composition (typically $\mathrm{Si} / \mathrm{Al} \sim 12-15, \mathrm{Cu} / \mathrm{Al} \sim 0.5$, giving optimal performance in $\mathrm{NH}_{3}-\mathrm{SCR}$ ) under different activation conditions (see Section 2.1). In 2016, a milestone work from Schneider and coworkers $^{68}$ synergized theory and experiment to rationalize in a consistent picture the abundant literature that has appeared on the topic in the last years.
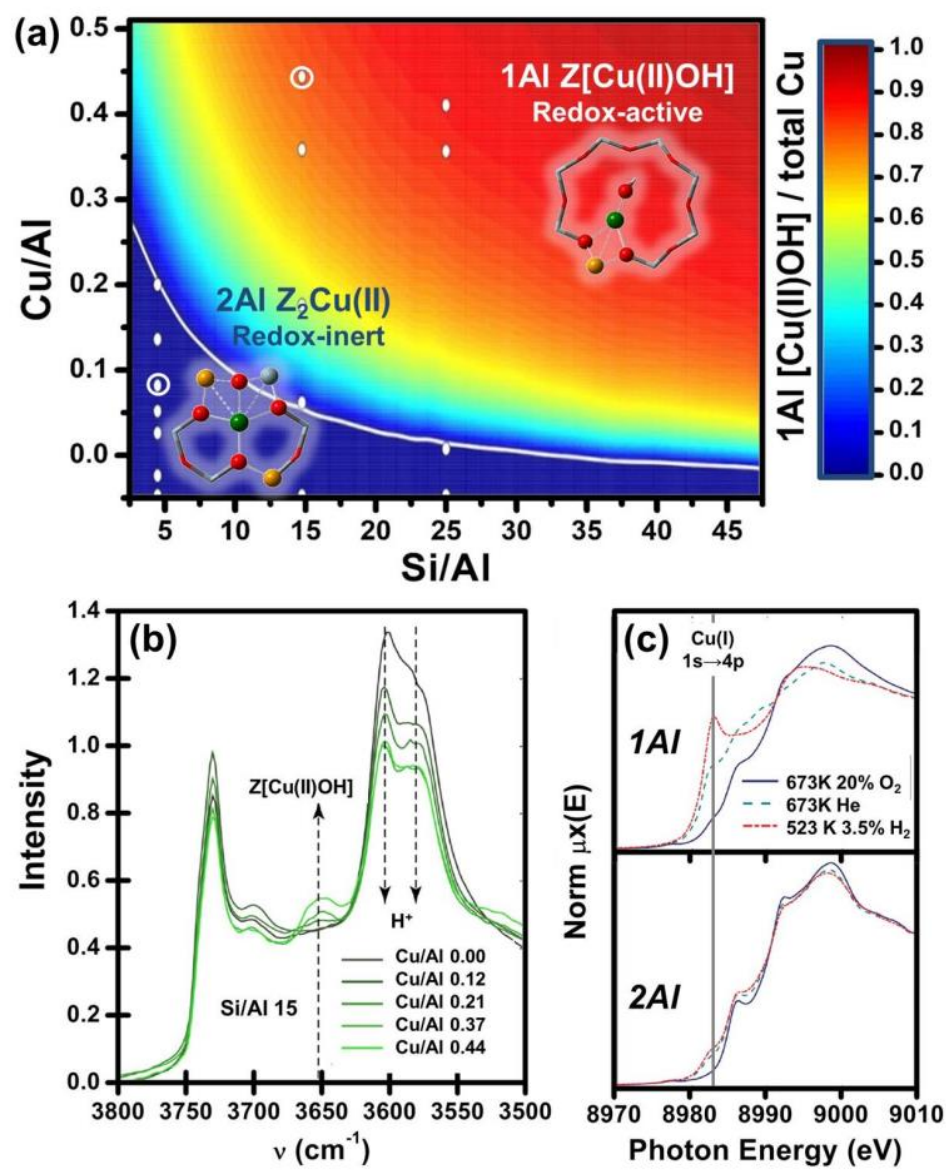

Fig. 11. (a) Theoretical compositional phase diagram for $\mathrm{Cu}$-sites in $\mathrm{O}_{2}$-activated $\mathrm{Cu}$-SSZ-13. Color scale on the right indicates the predicted fraction of redox-active $1 A l \mathrm{Z}[\mathrm{Cu}(\mathrm{II}) \mathrm{OH}]$ species as a function of $\mathrm{Cu} / \mathrm{Al}$ and $\mathrm{Si} / \mathrm{Al}$ ratios. The white line demarcates the transition from $2 A l \mathrm{Z}_{2} \mathrm{Cu}$ (II)-only region to the mixed $2 A l \mathrm{Z}_{2} \mathrm{Cu}$ (II) $/ 1 \mathrm{Al} \mathrm{Z}[\mathrm{Cu}$ (II)OH] region. Structural models of the two $\mathrm{Cu}$-species are also reported (atom colour code: $\mathrm{Cu}$, green; $\mathrm{O}$, red; $\mathrm{Si}$, grey, $\mathrm{Al}$, orange; $\mathrm{H}$, white). Full white dots indicates compositions of Cu-SSZ-13 samples synthetized and characterized by FTIR and acid sites titration by Paolucci et al. in the original work. ${ }^{68}$ The two compositions selected as representative of $\mathrm{Cu}$-species at $l \mathrm{Al}$ and $2 \mathrm{Al}$ sites and further characterized by XAS, part (c), are highlighted by white circles. (b) FTIR spectra of CuSSZ-13 samples with $\mathrm{Si} / \mathrm{Al}=15$ and variable $\mathrm{Cu} / \mathrm{Al}$ ratio in the $0-0.44$ range, collected at $200{ }^{\circ} \mathrm{C}$ after of $\mathrm{O}_{2}$-activation at $400{ }^{\circ} \mathrm{C}$. The dashed arrows indicate the increase of the fingerprint band assigned to $1 \mathrm{Al} \mathrm{Z}[\mathrm{Cu}(\mathrm{II}) \mathrm{OH}]$ complexes and the simultaneous decrease of the Brønsted acid sites bands, as $\mathrm{Cu} / \mathrm{Al}$ ratio increases. (c) $\mathrm{Cu} \mathrm{K}$-edge XANES spectra collected on the two samples representative of $\mathrm{Cu}$-species at $l \mathrm{Al}$ and $2 \mathrm{Al}$ sites (top and bottom panels, respectively) after treatment in $20 \% \mathrm{O}_{2}$ at $400{ }^{\circ} \mathrm{C}$ (solid blue lines), $\mathrm{He}$ at $400{ }^{\circ} \mathrm{C}$ (dashed teal lines), and in $3 \% \mathrm{H}_{2}$ at (dot-dash red lines). Adapted by permission of the American Chemical Society (copyright 2016) from ref. ${ }^{68}$

Schneider and co-workers reported several experimental results to validate the theoretical diagram in Fig. 11a. They synthesized a large series of $\mathrm{Cu}-\mathrm{SSZ}-13$ catalysts with $\mathrm{Si} / \mathrm{Al}=5,15,25$ and various Cu-loadings (full white dots in Fig. 11a). The samples were characterized by Brønsted acid sites titration as well as in situ FTIR (Fig. 11b) and XAS spectroscopy (Fig. 11c) for selected catalysts. $\mathrm{Cu} / \mathrm{H}^{+}$exchange stoichiometries obtained quantifying the residual $\mathrm{H}^{+}$in the exchanged materials by $\mathrm{NH}_{3}-\mathrm{TPD}$, revealed that $\mathrm{Cu}$ ion exchange occurs in a sequential way: first as $\mathrm{Z}_{2} \mathrm{Cu}(\mathrm{II})\left[\mathrm{Z}_{2} \mathrm{H}_{2}+\right.$ 
$\left.\mathrm{Cu}(\mathrm{II}) \rightarrow \mathrm{Z}_{2} \mathrm{Cu}(\mathrm{II})+2 \mathrm{H}^{+}\right]$up to saturation of available $2 A l$ sites and then as $\mathrm{Z}[\mathrm{Cu}(\mathrm{II}) \mathrm{OH}]$ at $1 A l$ sites $\left[\mathrm{ZH}+\mathrm{Cu}(\mathrm{II}) \mathrm{H}_{2} \mathrm{O} \rightarrow \mathrm{Z}[\mathrm{Cu}(\mathrm{II}) \mathrm{OH}]+2 \mathrm{H}^{+}\right]$. Further spectroscopic evidence on this point came from the FTIR data shown in Fig. $11 \mathrm{~b}$. Here, the $\mathrm{Z}[\mathrm{Cu}(\mathrm{II}) \mathrm{OH}]$ fingerprint band at ca. $3650 \mathrm{~cm}^{-1}$ (see also Section 2.1) remains undetected until a threshold in $\mathrm{Cu}$-loading is reached, corresponding to $\mathrm{Cu} / \mathrm{Al}=$ 0.21 for the investigated samples with $\mathrm{Si} / \mathrm{Al}=15$. For $\mathrm{Cu} / \mathrm{Al}>0.21$, a progressive increase in the $3660 \mathrm{~cm}^{-1}$ band intensity is observed. Complementary insights were obtained by monitoring the characteristic vibrations of Brønsted sites at 3605 and $3580 \mathrm{~cm}^{-1} \cdot{ }^{56,132}$ In particular, by comparing the integrated peak areas for these two bands in the $\mathrm{Cu}$-exchanged and protonic zeolites, a $2: 1 \mathrm{H}^{+} / \mathrm{Cu}$ ratio was found until $\mathrm{Cu} / \mathrm{Al}=0.12$, while a $1: 1 \mathrm{H}^{+} / \mathrm{Cu}$ was determined for $\mathrm{Cu} / \mathrm{Al} \geq 0.21$.

In situ XAS finally allowed the authors to directly probe the redox behaviour and local coordination environment of $\mathrm{Cu}$ for two selected compositional points (white circles in Fig. 11a), representative of $1 \mathrm{Al}$ and $2 \mathrm{Al} \mathrm{Cu}$-species. Fig. 11c shows the $\mathrm{Cu} \mathrm{K}$-edge XANES spectra for the two catalysts collected after high-temperature treatment under oxidant $\left(20 \% \mathrm{O}_{2} / \mathrm{He}\right)$ and reducing atmosphere (both $\mathrm{He}$ and diluted $\mathrm{H}_{2}$ ). While treatment in oxygen results in a largely dominant $\mathrm{Cu}$ (II) oxidation state in both the samples, their response to reducing conditions is drastically different. The $2 \mathrm{Al}$ sample only undergoes very minor modifications, preserving the characteristic $\mathrm{Cu}$ (II) XANES features even in $\mathrm{H}_{2}$. Conversely, the $1 A l$ sample undergoes substantial reduction after treatment in both $\mathrm{He}$ (self-reduction process) and $\mathrm{H}_{2}$. Corresponding EXAFS spectra collected for $1 \mathrm{Al}$ and $2 \mathrm{Al}$ samples in $\mathrm{O}_{2}$ and $\mathrm{He}$ were in qualitative agreement with the model structures of $\mathrm{Z}[\mathrm{Cu}(\mathrm{II}) \mathrm{OH}] / \mathrm{ZCu}(\mathrm{I})$ $\left(\mathrm{O}_{2} / \mathrm{He}\right)$ and $\mathrm{Z}_{2} \mathrm{Cu}(\mathrm{II})$ (both $\mathrm{O}_{2}$ and $\mathrm{He}$ ), respectively.

\subsubsection{Further spectroscopic validation, quantification and deviations from the ideal picture.}

Overall, the results reviewed in the previous section represent a qualitative fundamental contribution to our current understanding of composition-dependent $\mathrm{Cu}$-speciation in $\mathrm{Cu}-\mathrm{SSZ}$-13. Redox-active $\mathrm{Z}[\mathrm{Cu}(\mathrm{II}) \mathrm{OH}]$ and redox-inert $\mathrm{Z}_{2} \mathrm{Cu}$ (II) species emerge as the two key players in the field, with the latter preferentially stabilized at low values of both $\mathrm{Si} / \mathrm{Al}$ and $\mathrm{Cu} / \mathrm{Al}$ ratios, due to statistical availability of suitable $2 \mathrm{Al}$ docking sites and more favourable energetics. However, open questions remained on how these framework-interacting $\mathrm{Cu}$-species are formed from the fully hydrated $\mathrm{Cu}$ (II) aquo complexes known to dominate in the as-prepared materials (see Section 2.1). Even more important, the need for a more quantitative evaluation of the experimental results was highly desirable since this was often hampered by the co-existence of several rather similar species.

Firstly, the authors employed DFT to rank the stability of different $\mathrm{Cu}$-species in the $\mathrm{CHA}$ framework. They found the free energy associated with $\mathrm{Cu}$ at $2 \mathrm{Al}$ sites to be significantly lower than that for $\mathrm{Cu}$ near $1 \mathrm{Al}$ at both $25^{\circ} \mathrm{C}$ and $400{ }^{\circ} \mathrm{C}$. In line with TPR findings described in Section 2.2.1 (Fig. 10), $2 A l$ exchange sites in $6 r$ are thus predicted to represent preferential locations for $\mathrm{Cu}(\mathrm{II})$ ions, over a wide interval of conditions. The $\mathrm{Al}$ distribution for a given $\mathrm{Si} / \mathrm{Al}$ ratio in the framework was then determined by numerical simulations ${ }^{133}$ imposing random $\mathrm{Al}$ siting subject to the Löwenstein's rule. ${ }^{134}$ Based on the results of computational analysis, all the $2 A l$ sites available at a fixed $\mathrm{Si} / \mathrm{Al}$ are assumed to be saturated, before $\mathrm{Z}[\mathrm{Cu}(\mathrm{II}) \mathrm{OH}]$ species are formed at $1 A l$ sites. Under these hypotheses, the authors computed the compositional phase diagram for $\mathrm{Cu}$-sites in $\mathrm{O}_{2}$-activated $\mathrm{Cu}-\mathrm{SSZ}-13$, reported in Fig. 11a. It shows the fraction of $\mathrm{Cu}$ occurring as $1 A l \mathrm{Z}[\mathrm{Cu}(\mathrm{II}) \mathrm{OH}]$ as a function of $\mathrm{Si} / \mathrm{Al}$ and $\mathrm{Cu} / \mathrm{Al}$ ratios. Below the white line, $2 \mathrm{Al} \mathrm{Z}_{2} \mathrm{Cu}$ (II) is predicted to be the only $\mathrm{Cu}$ species present, while above the line the fraction of $\mathrm{Z}[\mathrm{Cu}(\mathrm{II}) \mathrm{OH}]$ progressively increases, becoming largely dominant in the right top corner of the compositional plane. Bates et al. ${ }^{135}$ previously computed the $\mathrm{Cu} / \mathrm{Al}$ ratio required to saturate the available $2 \mathrm{Al}$ sites in $6 r$ as a function of the $\mathrm{Si} / \mathrm{Al}$ ratio under similar assumptions. They predicted $2 A l$ saturation at $\mathrm{Cu} / \mathrm{Al} \approx 0.24,0.09$, and 0.05 for $\mathrm{Si} / \mathrm{Al}=5,15$ and 29 , respectively. 
Aiming at a comprehensive experimental exploration of the composition effects on $\mathrm{Cu}$-speciation and (self-) reducibility in $\mathrm{Cu}-\mathrm{CHA}$, Martini et al. ${ }^{52}$ monitored by in situ XANES the He-activation process from room temperature (RT) to $400{ }^{\circ} \mathrm{C}$ on a series of six $\mathrm{Cu}-\mathrm{SSZ}-13$ samples with $\mathrm{Si} / \mathrm{Al}$ ratios in the 5-29 range and $\mathrm{Cu} / \mathrm{Al}$ ratios from $\sim 0.1$ to $\sim 0.6$. Thermal treatment in inert atmosphere was preferred in order to achieve a better spectroscopic contrast between redox-active and redox-resistant $\mathrm{Cu}$-sites, as well as to gain deeper insights in the self-reduction process. High-quality EXAFS spectra on the whole sample series were also collected upon stabilization at $400{ }^{\circ} \mathrm{C}$ in $\mathrm{He}$.

Principal component analysis (PCA) of the in situ XANES dataset in Fig. 12a revealed the presence of five principal components (PCs). Thus, the authors applied a multivariate curve resolution (MCR) procedure, based on alternating least square (ALS) method ${ }^{136-138}$ to extract chemically meaningful spectra (Fig. 12b) and concentration profiles (Fig. 12c) of the five 'pure' Cu-species highlighted by PCA, as a function of temperature and compositional parameters.

The theoretical XANES spectra obtained from MCR-ALS are in excellent agreement with previous XAS studies on Cu-SSZ-13. ${ }^{46,51,68,139 .}$ Based on the spectroscopic fingerprints of each theoretical XANES component and the corresponding temperature-dependent concentration profiles, it was possible to reliably assign each pure spectrum to the $\mathrm{Cu}$-species shown in Fig. 12d. The assignment was further corroborated by XANES simulations computed from the DFT-optimized geometries of the proposed $\mathrm{Cu}$-species. Notably, the MCR spectra attributed to $\mathrm{Z}[\mathrm{Cu}(\mathrm{II}) \mathrm{OH}]$ and $\mathrm{Z}_{2} \mathrm{Cu}$ (II) (black and orange curves in Fig. 12b, respectively) are in perfect agreement with the XANES reported by Paolucci et al ${ }^{68}$ for $\mathrm{O}_{2}$-treated catalysts representative of $\mathrm{Cu}$ at $1 \mathrm{Al}$ and $2 \mathrm{Al}$ sites, shown here in Fig. 11c.
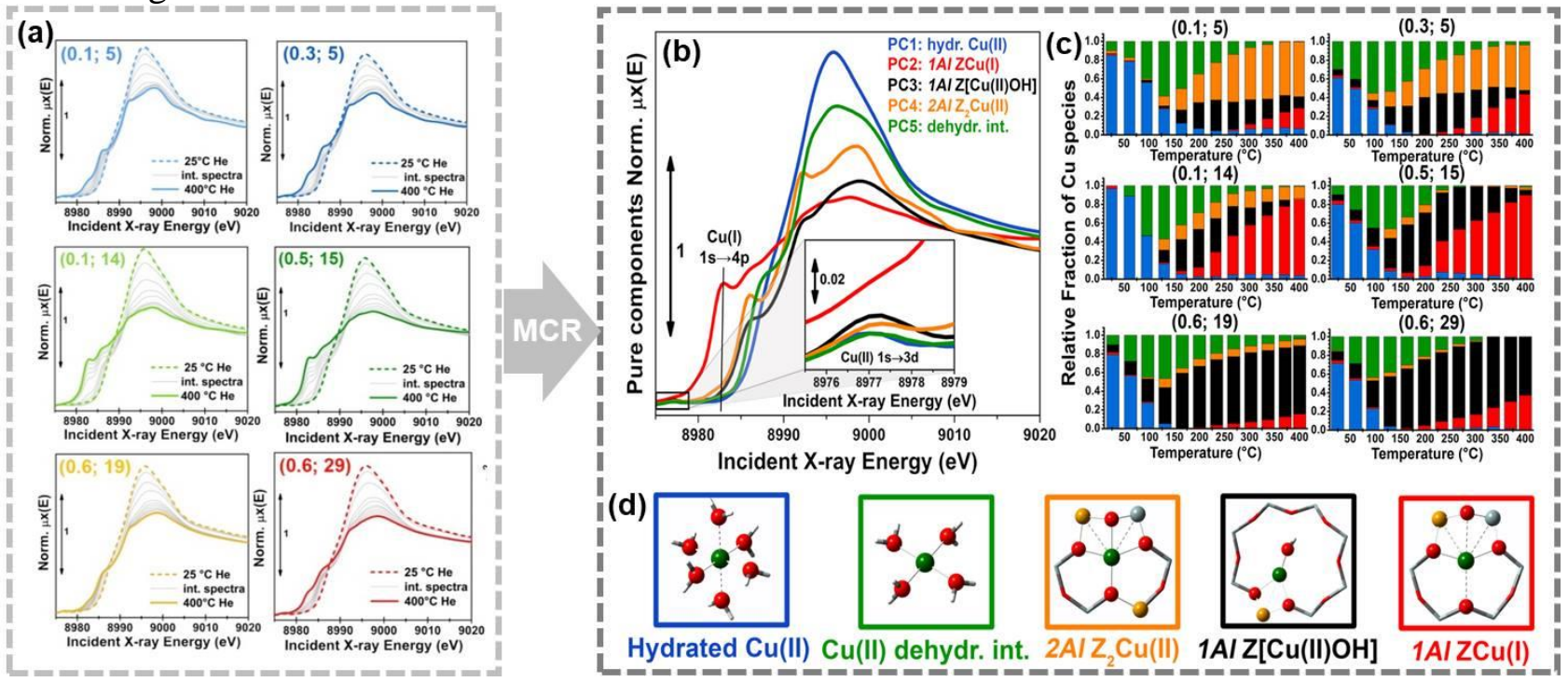

Fig. 12. (a) Experimental temperature-dependent in situ XANES spectra collected on six Cu-SSZ-13 samples with different composition (denoted by $\left(\mathrm{Cu} / \mathrm{Al}\right.$; $\mathrm{Si} / \mathrm{Al}$ ) labels) during thermal treatment from 25 to $400{ }^{\circ} \mathrm{C}$ (heating rate: 5 ${ }^{\circ} \mathrm{C} / \mathrm{min}$ ) in $100 \mathrm{ml} / \mathrm{min}$ of pure He. Thick dashed lines: starting spectrum at RT; grey thin lines: intermediate states during thermal treatment, thick solid lines: final state at $400{ }^{\circ} \mathrm{C}$. The global dataset includes 72 spectra. (b) Theoretical XANES spectra of the five pure components derived from MCR-ALS analysis. The inset reports a magnification of the pre-edge region in the theoretical spectra. (c) Bar plots reporting temperature-dependent concentration profiles of pure species for the six investigated compositional points. (d) Proposed assignment of the five pure components to specific $\mathrm{Cu}$ species/sites formed in the catalyst as a function of composition and activation temperature. Atom colour code in the structures: $\mathrm{Cu}$, green; $\mathrm{H}$, white; $\mathrm{O}$, red, $\mathrm{Si}$, grey; Al, yellow. In parts b-d, the same colour code is used to indicate the identified pure $\mathrm{Cu}$-species. Unpublished Figure, reporting data previously published in ref. ${ }^{52}$.

These results demonstrated the potential of XAS spectroscopy combined with multivariate data modelling in tackling the structural complexity associated with $\mathrm{Cu}$-speciation in $\mathrm{Cu}-\mathrm{CHA}$. Moreover, the study provided novel insights into the temperature/time-dependent dynamics yielding to framework interacting $\mathrm{Cu}$-sites in the cages of the $\mathrm{CHA}$ zeolite during the dehydration process. In 
particular, the formation of framework-interacting $\mathrm{Cu}$-species from the mobile $\mathrm{Cu}$ (II) aquocomplexes present at $\mathrm{RT}$ is observed to occur via a four-coordinated $\mathrm{Cu}$ (II) dehydration intermediate, peaking around $130{ }^{\circ} \mathrm{C}$ (green curve and bars in Fig. 12b,c). Then, $\mathrm{Z}[\mathrm{Cu}(\mathrm{II}) \mathrm{OH}]$ and $\mathrm{Z}_{2} \mathrm{Cu}$ (II) species progressively develop, with relative abundance determined by composition. $\mathrm{Z}[\mathrm{Cu}(\mathrm{II}) \mathrm{OH}]$ peaks appear around $200{ }^{\circ} \mathrm{C}$ and thereafter progressively decrease, in favour of self-reduced $\mathrm{ZCu}(\mathrm{I})$ species. Conversely, $\mathrm{Z}_{2} \mathrm{Cu}$ (II) sites, dominant at $\mathrm{Si} / \mathrm{Al}=5$ and favored by low $\mathrm{Cu} / \mathrm{Al}$ values, reach a steady population in the $200-300{ }^{\circ} \mathrm{C}$ range and remain stable until $400{ }^{\circ} \mathrm{C}$. $\mathrm{Cu}$-speciation at $400{ }^{\circ} \mathrm{C}$ can be described for all samples as a combination of redox-active $\mathrm{Cu}$-species at $1 A l$ sites (in their oxidized, $\mathrm{Z}[\mathrm{Cu}(\mathrm{II}) \mathrm{OH}]$, or reduced, $\mathrm{ZCu}(\mathrm{I})$, form) and redox-inert $\mathrm{Z}_{2} \mathrm{Cu}(\mathrm{II})$ species at $2 A l$ sites in $6 r$, as independently validated by DFT-assisted multi-component EXAFS fits in the original work. ${ }^{52}$

The quantitative knowledge of $\mathrm{Cu}$-speciation enabled from MCR analysis of in situ XANES provided further spectroscopic support to the compositional phase diagram by Paolucci et al. ${ }^{68}$ However, it also highlighted intriguing deviations from the ideal picture, herein examined in critical comparison with other recent results appeared in the literature.

\subsubsection{Composition impact on self-reducibility and nature of $Z C u(I)$ species. A first consideration} concerns the redox behavior observed by Martini et al. ${ }^{52}$ for Cu-SSZ-13 with Si/Al $=19$ and 29. Not surprisingly, at such high $\mathrm{Si} / \mathrm{Al}$ ratios, redox-resistant $\mathrm{Z}_{2} \mathrm{Cu}(\mathrm{II})$ species represent a minor contribution to $\mathrm{Cu}$-speciation, becoming barely detectable at $\mathrm{Si} / \mathrm{Al}=29$ (Fig. 12c). Although in these catalysts $\mathrm{Cu}-$ speciation is dominated by $\mathrm{Z}[\mathrm{Cu}(\mathrm{II}) \mathrm{OH}]$ species, it appears that, at such high $\mathrm{Si} / \mathrm{Al}$ values, selfreduction to $\mathrm{ZCu}(\mathrm{I})$ is hampered. The global picture about the composition impact on self-reducibility in $\mathrm{Cu}-\mathrm{SSZ}-13$ for the key compositional points investigated by Martini et al. ${ }^{52}$ is summarized in Fig. 13a. The bar plot reports the fractions of $\mathrm{Cu}$-species evaluated from MCR-ALS analysis of the XANES spectra collected $400{ }^{\circ} \mathrm{C}$ in $\mathrm{He}$, at the end of the thermal treatment.

At low $\mathrm{Si} / \mathrm{Al}$, redox-resistant $\mathrm{Z}_{2} \mathrm{Cu}$ (II) species dominates the speciation, while at high $\mathrm{Si} / \mathrm{Al}$ selfreduction of $\mathrm{Z}[\mathrm{Cu}(\mathrm{II}) \mathrm{OH}]$ only occurs to a limited extent. Consequently, the catalyst self-reducibility, quantified by the measured fraction of $\mathrm{ZCu}(\mathrm{I})$, reaches an optimum at intermediate $\mathrm{Si} / \mathrm{Al} \sim 15$, and it is overall promoted by high $\mathrm{Cu} / \mathrm{Al}$ ratios. 

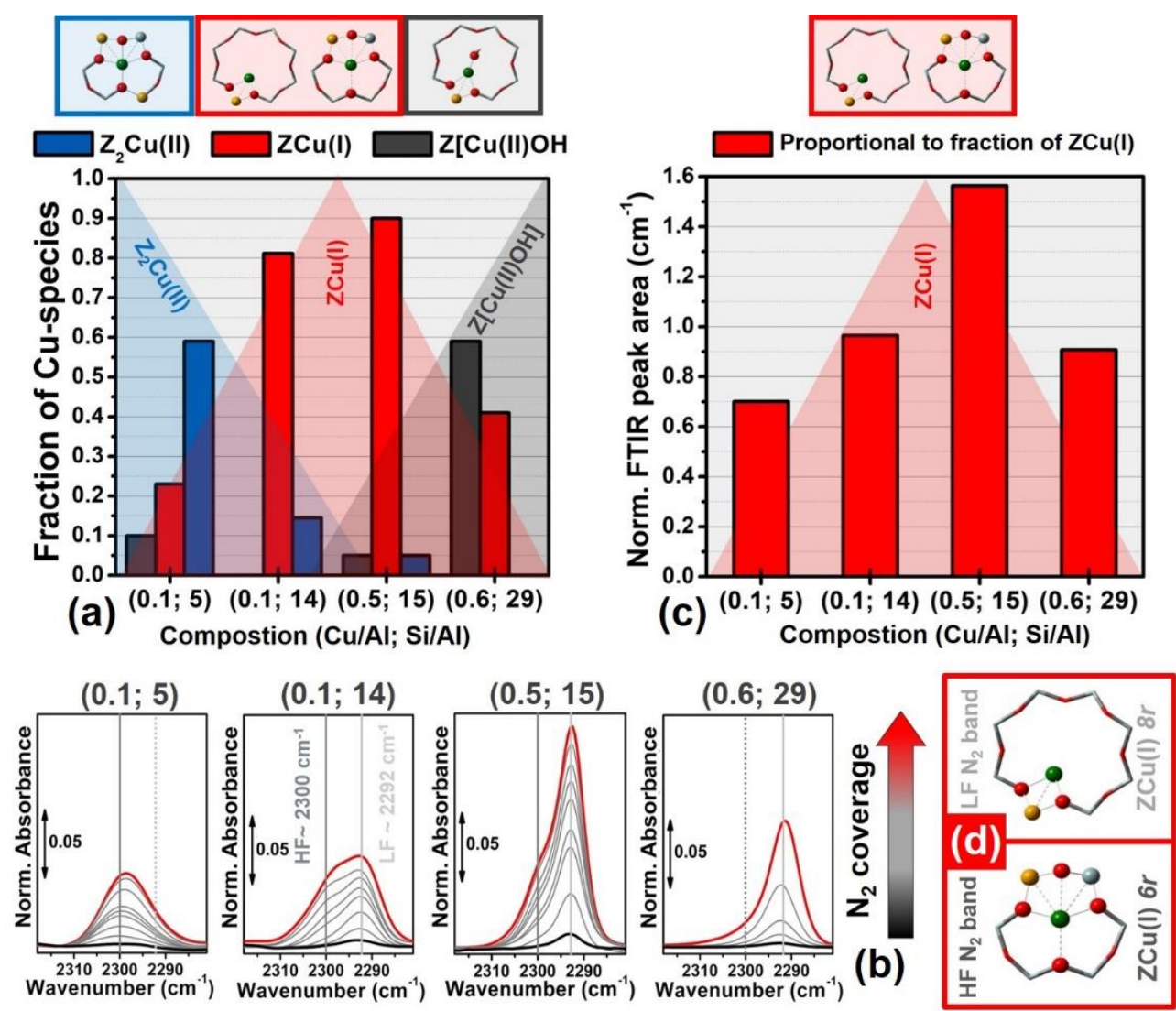

Fig. 13. (a) Bar plot summarizing $\mathrm{Cu}$-speciation evaluated from MCR-ALS analysis of the in situ XANES spectra collected $400{ }^{\circ} \mathrm{C}$ in $\mathrm{He}$ for selected $\mathrm{Cu}$-SSZ-13 samples with different composition, indicated by $(\mathrm{Cu} / \mathrm{Al}$; Si/Al) labels. (b) Low temperature $\left(\sim-160{ }^{\circ} \mathrm{C}\right)$ normalized IR spectra of $\mathrm{N}_{2}$ dosed ad increasing equilibrium pressure (from $10^{-2}$ to 5 Torr; 1 Torr $=133.3 \mathrm{~Pa}$ ) on the same set of samples considered in part $(\mathrm{a})$, after thermal treatment in vacuum at $400{ }^{\circ} \mathrm{C}$. Black, red and light grey curves refer to lowest, highest and intermediate $\mathrm{N}_{2}$ coverage, respectively. Vertical lines indicate the two IR bands assigned to $\mathrm{Cu}(\mathrm{I}) / \mathrm{N}_{2}$ adducts: low-frequency (LF) band at $2292 \mathrm{~cm}^{-1}$ in light grey; high-frequency (HF) band at $2300 \mathrm{~cm}^{-1}$ in grey. (c) Bar plots reporting the normalized areas of the $\mathrm{N}_{2} / \mathrm{Cu}$ (I) IR bands measured at the highest coverage. (d) DFT-optimized models for $l \mathrm{Al} \mathrm{ZCu}(\mathrm{I})$ in $8 r$ (top) and $6 r$ (bottom) connected with the LF and HF components detected in the IR spectra in part (b); atom color code: $\mathrm{Cu}$, green; $\mathrm{H}$, white; $\mathrm{O}$, red; $\mathrm{Si}$, grey; Al, yellow). Unpublished Figure, reporting results previously published in ref. ${ }^{52}$.

Further insights into the abundance and the nature of $\mathrm{ZCu}(\mathrm{I})$ species were obtained by in situ IR spectroscopy of adsorbed $\mathrm{N}_{2}$ on the same series of Cu-SSZ-13 samples. The $\mathrm{N}_{2}$ probe molecule selectively forms $\mathrm{Cu}(\mathrm{I}) / \mathrm{N}_{2}$ adducts, stable at liquid nitrogen temperature, $\sim-160{ }^{\circ} \mathrm{C} .{ }^{38,58}$ Although several precautions should be taken in the comparison with XAS results (different experimental conditions, i.e. thermal treatment in $\mathrm{He}$ gas flow vs vacuum and data collection at different temperature; differences in the extinction coefficients for different IR bands), the integrated areas of the two bands assigned to $\mathrm{Cu}(\mathrm{I}) / \mathrm{N}_{2}$ adducts (see Fig. 13b and discussion below), after appropriate normalization for the total $\mathrm{Cu}$ content in the samples, can be semi-quantitatively correlated with the fraction of $\mathrm{ZCu}(\mathrm{I})$ formed though self-reductive pathways. As shown in Fig. 13c, IR results qualitatively confirm the composition $\leftrightarrow$ self-reducibility trend observed from XANES MCR analysis, with a maximum in $\mathrm{ZCu}(\mathrm{I})$ abundance at intermediate $\mathrm{Si} / \mathrm{Al}$.

The IR results reported in Fig. 13b also provided a further confirmation of two distinct $\mathrm{ZCu}(\mathrm{I})$ sites in $\mathrm{Cu}-\mathrm{SSZ}-13$, in agreement with the early report by Dědeček et al. ${ }^{140}$ Indeed, being a weakly interacting probe, $\mathrm{N}_{2}$ enables discrimination even between very similar adsorption sites. ${ }^{55,56,141}$ These 
subtitle differentiation can be hardly obtained using more strongly interacting probe molecules such as $\mathrm{CO}^{58}$ and $\mathrm{NO},{ }^{58,142}$ as well as using conventional XAS. In agreement with previous studies on a vacuum activated $\mathrm{Cu}-\mathrm{SSZ}-13$ sample with $\mathrm{Cu} / \mathrm{Al} \sim 0.44$ and $\mathrm{Si} / \mathrm{Al} \sim 13,{ }^{58}$ the spectra exhibit two components: a (generally) predominant low-frequency (LF) band at $2292 \mathrm{~cm}^{-1}$ (light grey vertical lines in Fig. 13b) with a high-frequency (HF) shoulder at $2300 \mathrm{~cm}^{-1}$ (grey lines in Fig. 13b). In line with the recent quasi-simultaneous XANES/PXRD study by Andersen et al. ${ }^{35}$ (see Section 2.1), the two components were assigned by Martini et al. to $\mathrm{ZCu}(\mathrm{I})$ species in the $6 r$ (HF component) and $8 r$ (LF component), depicted in Fig. 13d.

In the context of this Section about composition-dependent $\mathrm{Cu}$ speciation, it is important to note that the relative intensities of the two $\mathrm{Cu}(\mathrm{I}) / \mathrm{N}_{2}$ IR bands vary in the set of samples, indicating an influence of the compositional parameters on $\mathrm{Cu}(\mathrm{I})$ siting. In particular, at $\mathrm{Si} / \mathrm{Al}=5$, the $\mathrm{HF}$ component appears dominant with respect to the $\mathrm{LF}$ one. Conversely, at $\mathrm{Si} / \mathrm{Al}=29$, the $\mathrm{LF}$ band is largely more developed than the HF one. For the samples with $\mathrm{Si} / \mathrm{Al}=14,15$ both components are clearly visible but the $\mathrm{LF}$ band is significantly enhanced at high $\mathrm{Cu} / \mathrm{Al}$.

These evidences of a non-monotonous redox behaviour as a function of the $\mathrm{Si} / \mathrm{Al}$ ratio were confirmed by Pappas et al., ${ }^{27}$ while investigating structure-activity relationship for the MTM conversion over Cu-SSZ-13 (see also Section 3.2). However, they seem in contrast with the previously discussed $\mathrm{H}_{2}$-TPR results by Gao et al. ${ }^{131}$ reporting efficient low-temperature reduction in $\mathrm{Si} / \mathrm{Al}=35$ catalysts $($ Fig. $10 \mathrm{c}$ ). Nonetheless one has to consider the different conditions - selfreduction in inert atmosphere and reduction by $\mathrm{H}_{2}$ during TPR (which indeed resulted in different XANES spectra as reported by Paolucci et al., ${ }^{68}$ see Fig. 11c). Overall, the data shown in Fig. 13, might hint towards the participation of an adjacent Brønsted acid sites in the self-reduction process of neighbouring $\mathrm{Cu}$-sites. In any case the data demonstrates that the redox-behaviour in high Si/Alratio $\mathrm{Cu}$-zeolites deserves further investigation, which hopefully results in a conclusive understanding of self-reduction mechanism in Cu-zeolites.

2.2.3.2. Saturation of $2 \mathrm{Al}$ sites and nature of $\mathrm{Z}_{2} \mathrm{Cu}(\mathrm{II})$ species. A second consideration arises in connection with the hypothesis of $2 A l$ sites saturation. The high reducibility observed by Martini $e t$ $a l .{ }^{52}$ for the low-loading sample $(\mathrm{Cu} / \mathrm{Al}=0.1)$ with $\mathrm{Si} / \mathrm{Al}=14$ contrasts with the $2 \mathrm{Al}$ saturation scenario. Indeed, according to the compositional phase diagram in Fig. $11 \mathrm{a}^{68}$ and the saturation threshold predicted by Bates et al. ${ }^{135}$ this composition should result into $>90 \%$ of redox-resistant $\mathrm{Z}_{2} \mathrm{Cu}$ (II). Conversely, $\mathrm{MCR}$ analysis revealed that the $\mathrm{Z}_{2} \mathrm{Cu}$ (II) contribution only reaches a maximum fraction of $\sim 18 \%$ total $\mathrm{Cu}$ in the final state at $400{ }^{\circ} \mathrm{C}$ in $\mathrm{He}$. From the concentration profiles reported in Fig. 12c, it is clear that there exists a preference in the stabilization of $\mathrm{Z}_{2} \mathrm{Cu}$ (II) species at low $\mathrm{Cu}$ loading: for the same $\mathrm{Si} / \mathrm{Al}$ ratio, a lower $\mathrm{Cu} / \mathrm{Al}$ results in a higher contribution from $\mathrm{Cu}$ at $2 \mathrm{Al}$ sites. Nonetheless, these results do not support an ideal sequential exchange, first into $2 A l$ sites up to saturation and only after into $1 A l$ ones. The populations of $\mathrm{Z}_{2} \mathrm{Cu}(\mathrm{II})$ and $\mathrm{Z}[\mathrm{Cu}(\mathrm{II}) \mathrm{OH}]$ are rather observed to grow simultaneously as temperature increases.

Other recent reports also highlighted the possibility that $\mathrm{Z}[\mathrm{Cu}(\mathrm{OH})]$ can be populated before saturation of the available $2 A l$ sites in $6 r .{ }^{82,143}$ As pointed out in the recent review by Gao and Peden, ${ }^{86}$ $\mathrm{Z}[\mathrm{Cu}(\mathrm{OH})]$, although disfavored by thermodynamics, can plausibly be kinetically stabilized along 
dehydration. In this respect, both composition and specific conditions (heating rate, activation temperature and dwell time, etc...) are envisaged to play a crucial role. Indeed, according to Luo et al., ${ }^{143}$ a kinetically stabilized, metastable state of the catalyst is expected to convert to a thermodynamically stable state, if the system is left to relax for a sufficient time at appropriate conditions. Indeed, recent works proved that during mild hydrothermal aging of state-of-the-art $\mathrm{Cu}$ SSZ-13 catalysts for $\mathrm{NH}_{3}-\mathrm{SCR}$, a gradual migration $\mathrm{Z}[\mathrm{Cu}(\mathrm{OH})]$ species occurs, accompanied by their conversion into $\mathrm{Z}_{2} \mathrm{Cu}(\mathrm{II})$, while consuming a Brønsted acid site according to the reaction: $\mathrm{Z}[\mathrm{Cu}(\mathrm{II}) \mathrm{OH}]+\mathrm{ZH} \rightarrow \mathrm{Z}_{2} \mathrm{Cu}(\mathrm{II})+\mathrm{H}_{2} \mathrm{O} .{ }^{82},{ }^{143}$ Further experimental support to these considerations came from the in situ EPR results reported by Gao et al. ${ }^{86,144}$ for a $\mathrm{Cu}-\mathrm{SSZ}-13$ sample with $\mathrm{Si} / \mathrm{Al}=6$ and $\mathrm{Cu} / \mathrm{Al}=0.032$ during dehydration in dry $\mathrm{N}_{2}$ (Fig. 14a). Based on the compositional characteristics and the previously mentioned thermodynamic arguments, in this sample $\mathrm{Cu}$ should exclusively be exchanged at $2 \mathrm{Al}$ sites as $\mathrm{Z}_{2} \mathrm{Cu}(\mathrm{II})$. Nevertheless, a pronounced loss of signal intensity is observed along the dehydration process, particularly evident at $150{ }^{\circ} \mathrm{C}$ (red curve in Fig. 14a). The transient loss of EPR signal at intermediate temperature during dehydration points to the transient stabilization of $\mathrm{Z}[\mathrm{Cu}(\mathrm{II}) \mathrm{OH}]$ species, proposed to be EPR silent due to pseudo Jahn-Teller effect ${ }^{78}$ (see also Section 2.1). At higher temperatures, the EPR intensity is observed to recover, resulting in the characteristic spectrum of EPR-active $\mathrm{Z}_{2} \mathrm{Cu}(\mathrm{II})$ species at $250{ }^{\circ} \mathrm{C}$.
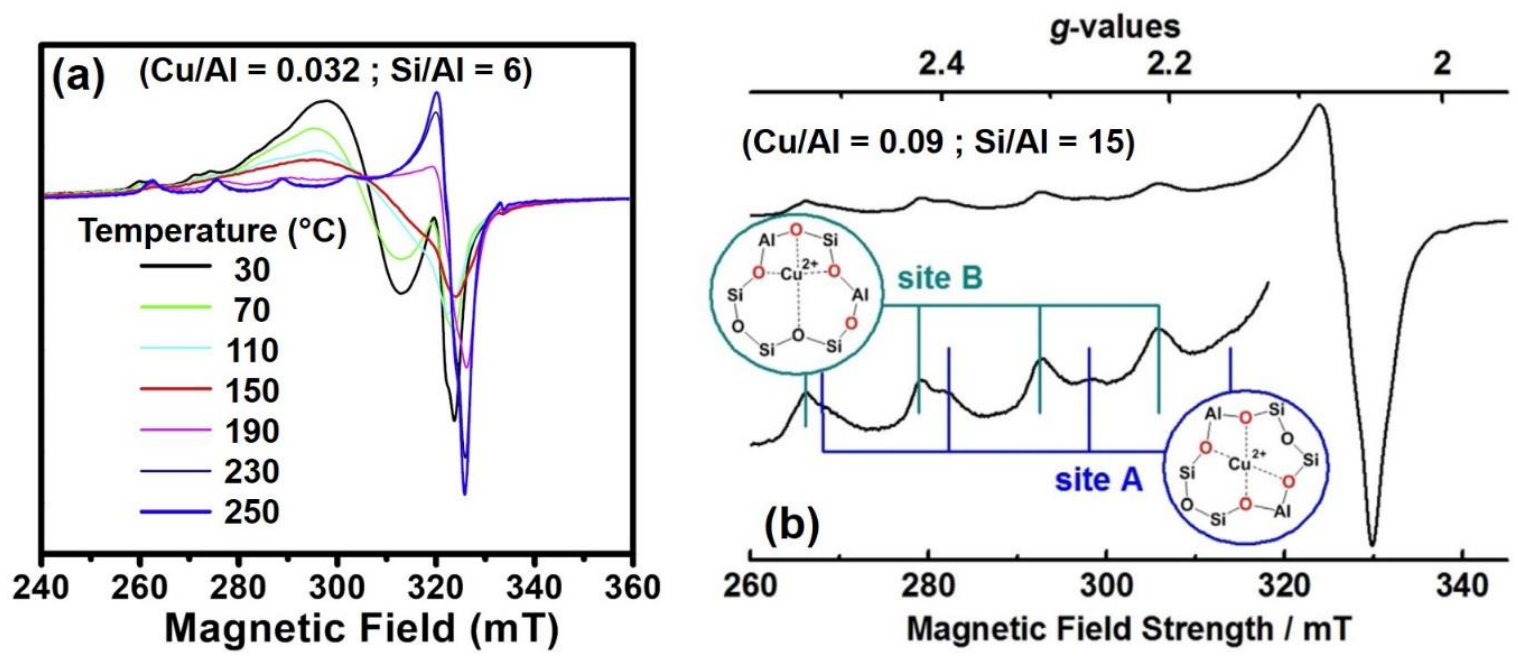

Fig. 14. (a) EPR spectra of a Cu-SSZ-13 sample $(\mathrm{Cu} / \mathrm{Al}=0.032 ; \mathrm{Si} / \mathrm{Al}=6)$ during dehydration in $\mathrm{N}_{2}$ from $30{ }^{\circ} \mathrm{C}$ to 250 ${ }^{\circ} \mathrm{C}$. Adapted by permission of Elsevier (copyright 2014) from ref. ${ }^{144}$ (b) EPR spectrum (measured at $200{ }^{\circ} \mathrm{C}$ ) of a $\mathrm{Cu}-$ SSZ-13 sample $(\mathrm{Cu} / \mathrm{Al}=0.09 ; \mathrm{Si} / \mathrm{Al}=15)$ after dehydration at $250{ }^{\circ} \mathrm{C}$ in $10 \% \mathrm{O}_{2} / \mathrm{He}$. The inset reports a magnification of the parallel region of the spectrum and the assignment of the feature to two different sites for $\mathrm{Z}_{2} \mathrm{Cu}(\mathrm{II}) \mathrm{species}$ in $6 r$, characterized by $\mathrm{Al}-\mathrm{Si}-\mathrm{Al}$ (site $\mathrm{A}$ ) and $\mathrm{Al}-\mathrm{Si}-\mathrm{Si}-\mathrm{Al}$ (site $\mathrm{B}$ ) linkages. Reproduced by permission of $\mathrm{Wiley}-\mathrm{VCH}$ (copyright 2018) from ref. ${ }^{80}$

Notably, EPR also directly proved that additional complexity exists in connection with $\mathrm{Z}_{2} \mathrm{Cu}$ (II) species in the $6 r$ of the CHA framework. Subject to the Löwenstein's rule, ${ }^{134} 6 r$ s with both $-\mathrm{Al}-\mathrm{Si}-$ $\mathrm{Al}-$ and $-\mathrm{Al}-\mathrm{Si}-\mathrm{Si}-\mathrm{Al}$ - linkages are possible. According to DFT models, these two configurations yield inequivalent $\mathrm{Cu}$ local environments (site B and site $\mathrm{A}$ in Fig. 14b, respectively). However, the structural and electronic similarity of the two $\mathrm{Z}_{2} \mathrm{Cu}$ (II) sites, together with the averaged character of the technique, complicates their conclusive discrimination with $\mathrm{XAS}^{46,52}$. In this respect, EPR provides the highest sensitivity. An example, from the recent study by Godiksen et al. ${ }^{80}$ is reported in Fig. 14b. The EPR spectrum collected on a Cu-SSZ-13 sample with $\mathrm{Cu} / \mathrm{Al}=0.09, \mathrm{Si} / \mathrm{Al}=15$ after 
dehydration at $250{ }^{\circ} \mathrm{C}$ in $10 \% \mathrm{O}_{2} / \mathrm{He}$ clearly shows two sets of signals in the parallel region, consistent with the $\mathrm{Z}_{2} \mathrm{Cu}(\mathrm{II})$ structural models in $6 r$ with $-\mathrm{Al}-\mathrm{Si}-\mathrm{Al}-$ and $-\mathrm{Al}-\mathrm{Si}-\mathrm{Si}-\mathrm{Al}-$ motifs.

Composition also appears to influence the relative population of sites $\mathrm{A}$ and $\mathrm{B}$. In the EPR spectrum collected by Gao et al. ${ }^{144}$ at $250{ }^{\circ} \mathrm{C}$ for a Cu-SSZ-13 sample with $\mathrm{Si} / \mathrm{Al}=6$ and $\mathrm{Cu} / \mathrm{Al}=$ 0.032 (in Fig. 14a, blue line), only the parallel hyperfine quadruplet assigned to site $\mathrm{B}$ is visible. The spectrum reported in Fig. $14 \mathrm{~b}(\mathrm{Cu} / \mathrm{Al}=0.09 ; \mathrm{Si} / \mathrm{Al}=15)$ has been instead modelled with $72 \%$ and $20 \%$ total $\mathrm{Cu}$ in sites $\mathrm{B}$ and $\mathrm{A}$, respectively. Moreover, for a Cu-SSZ-13 catalyst with $\mathrm{Cu} / \mathrm{Al}=0.44$, $\mathrm{Si} / \mathrm{Al}=13$ the same authors reported a balanced contribution from sites $\mathrm{A}$ and $\mathrm{B}(9 \%$ total $\mathrm{Cu}$ for each site), after dehydration at $250{ }^{\circ} \mathrm{C}$ in $50 \% \mathrm{O}_{2} / \mathrm{He}$. DFT calculations predicted a slightly more efficient stabilization of bare $\mathrm{Cu}$ (II) sites in $6 r$ with $-\mathrm{Al}-\mathrm{Si}-\mathrm{Si}-\mathrm{Al}-$ linkages ${ }^{68,142}$ (site A in Fig. 14b). Indeed, in the detailed DFT/FTIR study by Zhang et al., ${ }^{142}$ the author distinguished two bands assigned to $\mathrm{Z}_{2} \mathrm{Cu}$ (II)-NO adducts: a sharp band at $1948 \mathrm{~cm}^{-1}$ (very intense at $\mathrm{Si} / \mathrm{Al}=6$ and 12, almost undetectable at $\mathrm{Si} / \mathrm{Al}=35$ ) with an additional component at $1932 \mathrm{~cm}^{-1}$. In view of the computational results, the latter was connected with $\mathrm{Z}_{2} \mathrm{Cu}$ (II) species hosted in less energetically-favored $6 r$ s with $\mathrm{Al}-\mathrm{Si}-\mathrm{Al}$ - linkages (site B). However, EPR results reviewed above seem to indicate that site B is instead the one to be preferentially populated at low $\mathrm{Cu}$-loading. It is finally worth to mention that Godiksen et al. also evidenced a possible site-sensitive reactivity, connecting site A with a higher reactivity than site B towards oxidation in SCR-relevant mixtures. ${ }^{80}$

2.2.4. Composition impact on $\mathbf{C u}(\mathrm{II})$ species other than $\mathrm{Z}[\mathrm{Cu}(\mathrm{II}) \mathrm{OH}]$. As discussed in Section 2.1.2, there are evidences for the formation of mono- and multi-nuclear $\mathrm{Cu}$ (II) species other than $\mathrm{Z}[\mathrm{Cu}(\mathrm{II}) \mathrm{OH}]$ under high-temperature oxidative treatment of high-loading $\mathrm{Cu}-\mathrm{SSZ}-13$ materials with $\mathrm{Si} / \mathrm{Al}$ ratio in the 13-20 range. ${ }^{25,27,29,58,145,146}$ In this respect, the most sensitive techniques are UVVis-NIR and Raman spectroscopy, whereas FTIR in the $v(\mathrm{OH})$ region can be employed indirectly to track the temperature-dependent dynamics of $\mathrm{Z}[\mathrm{Cu}(\mathrm{II}) \mathrm{OH}]^{27}$ through its fingerprint band at ca. 3650 $\mathrm{cm}^{-1}$. 32, 46, 58, 68, 113

Here we provide a brief overview on a few reports where these techniques have been applied to $\mathrm{Cu}-\mathrm{SSZ}-13$ samples with different composition. Therein, we derive some considerations on the impact of composition on the possible stabilization of $\mathrm{Cu}$-oxo species, as well as on the interpretation of the relevant spectroscopic results.

Bates et al. ${ }^{135}$ used diffuse-reflectance (DR) UV-Vis-NIR spectroscopy to characterize, in their hydrated state, a series of $\mathrm{Cu}-\mathrm{SSZ}-13$ samples with $\mathrm{Si} / \mathrm{Al}=5$ and $\mathrm{Cu} / \mathrm{Al}$ ratios increasing from 0.02 to 0.35 . Until $\mathrm{Cu} / \mathrm{Al}=0.2$, the materials exhibited the characteristic $\mathrm{UV}-\mathrm{V}$ is spectrum of hydrated $\mathrm{Cu}$ (II) species, with broad and weak $\mathrm{Cu}$ (II) $\mathrm{d}-\mathrm{d}$ transitions from 6000 to $17000 \mathrm{~cm}^{-1}$, linearly growing in intensity with $\mathrm{Cu}$-loading, a shoulder at 35000 and main feature at $45000 \mathrm{~cm}^{-1}$ assigned to ligandto-metal charge transfer transitions from $\mathrm{O}$ ligands to $\mathrm{Cu}(\mathrm{II})$ d-orbitals. ${ }^{58,}{ }^{135}$ However, for $\mathrm{Cu} / \mathrm{Al}=$ 0.35 , the $\mathrm{d}-\mathrm{d}$ transition intensity decreased with respect to the $\mathrm{Cu} / \mathrm{Al}=0.2$ sample and shoulders at 20000 and $32000 \mathrm{~cm}^{-1}$ appeared in the spectrum, which were related to the presence of (SCRinactive) $\mathrm{Cu}$-oxide clusters formed in the as-prepared samples. 
Moving from the hydrated to the activated state of the catalyst, a conclusive interpretation of the DR UV-Vis spectra in Cu-SSZ-13 is still missing, especially concerning the characteristic 'quadruplet' dominating the $\mathrm{d}-\mathrm{d}$ transitions region (see Section 2.1.2).

Based on the abundant literature available on other $\mathrm{Cu}$-zeolites, such as $\mathrm{Cu}-\mathrm{MFI}$ and $\mathrm{Cu}-\mathrm{MOR},{ }^{66}$, $77,147-150$ the absorption bands occurring in the $25000-35000 \mathrm{~cm}^{-1}$ range for $\mathrm{O}_{2}$-activated $\mathrm{Cu}-\mathrm{CHA}$ should be related to the formation of redox-active $\mathrm{Cu}$-oxo species other than $\mathrm{Z}[\mathrm{Cu}(\mathrm{II})(\mathrm{OH})]$.

Some novel insights concerning this point can be obtained by the analysis of the DR UV-Vis spectra recently reported by Ipek et $\mathrm{al}^{25}$ for $\mathrm{Cu}-\mathrm{SSZ}-13$ treated at $450{ }^{\circ} \mathrm{C}$ in $\mathrm{O}_{2}$ at three representative compositions, namely $(\mathrm{Cu} / \mathrm{Al}=0.39 ; \mathrm{Si} / \mathrm{Al}=5) ;(\mathrm{Cu} / \mathrm{Al}=0.4 ; \mathrm{Si} / \mathrm{Al}=12) ;(\mathrm{Cu} / \mathrm{Al}=0.18 ; \mathrm{Si} / \mathrm{Al}=$ 12). The spectra are shown in Fig. 15, together with pictures of the corresponding $\mathrm{O}_{2}$-activated materials.

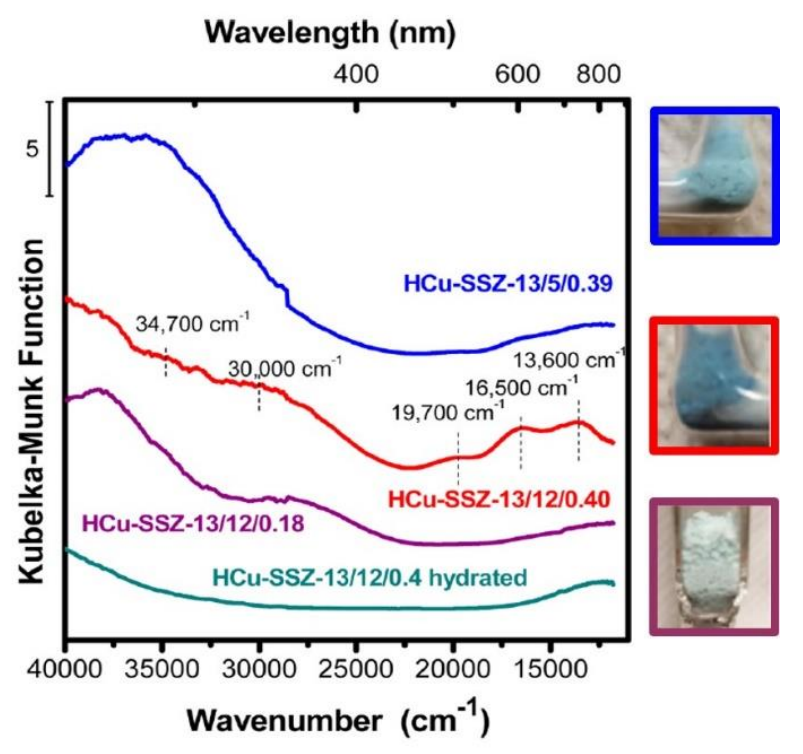

Fig. 15. (a) DR UV-Vis spectra of Cu-SSZ-13 samples with different composition after $\mathrm{O}_{2}$ treatment at $450{ }^{\circ} \mathrm{C}$. Blue line: $(\mathrm{Cu} / \mathrm{Al}=0.39 ; \mathrm{Si} / \mathrm{Al}=5)$; red line: $(\mathrm{Cu} / \mathrm{Al}=0.4 ; \mathrm{Si} / \mathrm{Al}=12) ;$ purple line $(\mathrm{Cu} / \mathrm{Al}=0.18 ; \mathrm{Si} / \mathrm{Al}=12)$. The spectrum of the $(\mathrm{Cu} / \mathrm{Al}=0.4 ; \mathrm{Si} / \mathrm{Al}=12)$ sample in its hydrated form is also reported for comparison (green line). The feature at 28500 $\mathrm{cm}^{-1}$ is an artifact caused by a lamp switch in the spectrometer. The pictures of the samples at $25{ }^{\circ} \mathrm{C}$ after $450{ }^{\circ} \mathrm{C} \mathrm{O}$ treatment are reported, within frames using the same colour code as for the corresponding spectra. Adapted by permission of the American Chemical Society (copyright 2017) from ref. ${ }^{25}$

A first observation relates to the dependence of the shoulders observed at 30000 and $34700 \mathrm{~cm}^{-1}$ on composition, especially $\mathrm{Si} / \mathrm{Al}$ ratio. As shown in Fig. 15, these bands in the CT region are much more pronounced in the two $\mathrm{Si} / \mathrm{Al}=12$ samples compared to the $\mathrm{Si} / \mathrm{Al}=5$ sample. Notably, the latter has more than twice the $\mathrm{Cu}$ concentration of the high $\mathrm{Cu}$-loading $\mathrm{Si} / \mathrm{Al}=12$ material. Hence, it is clear that the formation of $\mathrm{Cu}$-species giving rise to these spectral fingerprints is largely disfavoured in a $\mathrm{Al}$ rich framework, which should contain a larger fraction of redox-resistant $\mathrm{Z}_{2} \mathrm{Cu}(\mathrm{II})$ at $2 \mathrm{Al}$ sites. Well-defined bands around $30000 \mathrm{~cm}^{-1}$ are also absent in UV-Vis spectra of $\mathrm{O}_{2}$-activated Cu-SSZ13 samples reported by Wulfers et al. ${ }^{22}(\mathrm{Cu} / \mathrm{Al}=0.35, \mathrm{Si} / \mathrm{Al}=6)$ and by Korhonen et al. $(\mathrm{Cu} / \mathrm{Al}=0.18$, $\mathrm{Si} / \mathrm{Al}=9$ ); however, in the latter case the poor signal-to-noise ratio of the data in the CT region hampers a detailed analysis. 
These results are consistent with the general picture outlined by Pappas et al. ${ }^{27}$ where $\mathrm{Z}[\mathrm{Cu}(\mathrm{II}) \mathrm{OH}]$ complexes efficiently undergoing self-reduction are proposed as possible precursors to different $\mathrm{Cu}$ oxo moieties (see also Section 2.1.2). These include trans-( $\mu$-1,2-peroxo) dicopper(II) and mono( $\mu$ oxo) dicopper(II) species, characterized by high stability in the CHA framework (chemical potential of the $\mathrm{Cu}$ atoms $\mu_{\mathrm{Cu}}$ within $5 \mathrm{~kJ} / \mathrm{mol}$ from the $\mu_{\mathrm{Cu}}$ value computed for the most stable $\mathrm{Z}$ [Cu(II)OH] species, according to DFT calculation by Ipek et al. ${ }^{25}$ ). The characteristic Raman vibrations of these dimeric species were also identified in the $(\mathrm{Cu} / \mathrm{Al}=0.4 ; \mathrm{Si} / \mathrm{Al}=12)$ sample described above $\mathrm{e}^{25}$ and in a different $\mathrm{Cu}-\mathrm{SSZ}-13$ material with comparable composition $(\mathrm{Cu} / \mathrm{Al}=0.5 ; \mathrm{Si} / \mathrm{Al}=15){ }^{27}$

The comparison among the samples reported in Fig. 15 can also provide insightful indications about the origin of the spectral features occurring in the lower-energy portion of the UV-Vis spectrum. In particular, the bands at 13600,16500 , and $19700 \mathrm{~cm}^{-1}$ (belonging to the characteristic 'quadruplet' already described in Section 2.1.2) are well visible in the $\mathrm{Cu} / \mathrm{Al}=0.4 ; \mathrm{Si} / \mathrm{Al}=12$ sample, giving to this material a deep blue colour. Conversely, these bands can hardly be recognized in the other two Al-rich samples, which indeed show a paler blue color. The fact that, despite the higher $\mathrm{Cu}$ concentration, the quadruplet is significantly less developed in the $\mathrm{Si} / \mathrm{Al}=5$ sample seems to contrast with its previous assignment to the EPR-active $\mathrm{Z}_{2} \mathrm{Cu}(\mathrm{II})$ species in $6 r .{ }^{78}$ Indeed, as noted before, this composition should be most favourable for $\mathrm{Z}_{2} \mathrm{Cu}$ (II) species among the investigated ones. In light of these and other evidences, the assignment of the $\mathrm{Cu}$-SSZ-13 quadruplet still represents an open research question.

\section{Structure reactivity correlation}

\subsection{Selective Catalytic Reduction of $\mathrm{NO}_{x}$ by Ammonia}

The selective catalytic reduction of $\mathrm{NO}_{x}$ to $\mathrm{N}_{2}$ by ammonia $\left(\mathrm{NH}_{3}-\mathrm{SCR}\right)$ has played an important role in the abatement of $\mathrm{NO}_{\mathrm{x}}$ emissions in the exhausts of diesel engines and power plants since the 1970's. To date, the preferred catalysts for stationary $\mathrm{NH}_{3}$-SCR are based on supported vanadium oxides. ${ }^{151-}$ 159 However, for mobile applications, the reaction conditions are highly dynamic and the strongly varying temperatures and gas flow rates of the lean-burned exhaust gases required a new type of catalyst that would combine a high activity at low temperatures $\left(<300^{\circ} \mathrm{C}\right)$ with hydrothermal stability at elevated temperatures $\left(>500^{\circ} \mathrm{C}\right) .{ }^{160,161}$ Over several decades many metal loaded zeolites where tested for diesel automotive applications, ${ }^{162-167}$ but the commercialization of the $\mathrm{NH}_{3}$-SCR technology based on zeolites had to wait until the discovery of the $\mathrm{Cu}$-CHA system. ${ }^{10-21}$ In the following we will summarize the current state of understanding of how the $\mathrm{Cu}$-speciation in $\mathrm{Cu}-\mathrm{CHA}$ relates to the catalytic performance in $\mathrm{NH}_{3}-\mathrm{SCR}$.

In the so-called standard $\mathrm{NH}_{3}-\mathrm{SCR}$, NO reacts with ammonia and oxygen to form nitrogen and water, according to the equation ${ }^{18,69,70,167,168}$

$$
4 \mathrm{NO}+4 \mathrm{NH}_{3}+\mathrm{O}_{2} \rightarrow 4 \mathrm{~N}_{2}+6 \mathrm{H}_{2} \mathrm{O} .
$$

As described in Section 2, the $\mathrm{Cu}$-speciation in $\mathrm{Cu}-\mathrm{CHA}$ is strongly dependent on the catalyst activation, composition, temperature and gas composition. Hence, it is likely that also the structures of the active $\mathrm{Cu}$ sites in SCR catalysts differ for different catalyst compositions and undergo dynamic changes during SCR operation.

When considering $\mathrm{NH}_{3}$-SCR over $\mathrm{Cu}-\mathrm{CHA}$, it is important to highlight that the $\mathrm{NO}$ conversion typically shows a bimodal pattern, with a first maximum around $300{ }^{\circ} \mathrm{C}$ and a second maximum around $400{ }^{\circ} \mathrm{C} .^{21,144}$ The observed dip in conversion at around $350{ }^{\circ} \mathrm{C}$ has been proposed to be related 
to a change in the SCR mechanism. It is therefore interesting to consider the $\mathrm{Cu}$ speciation before and after the dip.

In order to experimentally establish structure reactivity correlations, in-situ and operando spectroscopic methods in the presence of reactant molecules at relevant reaction conditions, have proven to be a powerful tool. In particular, the reaction has been followed, as a function of the temperature, by operando X-ray absorption (in both XANES, Fig. 16a, and EXAFS, see Fig. 16b regions) and X-ray emission (Fig. 16a) spectroscopies. ${ }^{33}$ The unique element and ligand sensitivity of the combined XAS/XES approach techniques allowed Lomachenko et al. to shed light on the evolution of the different $\mathrm{Cu}$ species inside the $\mathrm{Cu}-\mathrm{CHA}$ catalyst 'in action' during operando $\mathrm{NH}_{3}-$ SCR experiments in the $150-400{ }^{\circ} \mathrm{C}$ range (Fig. 16d,e).
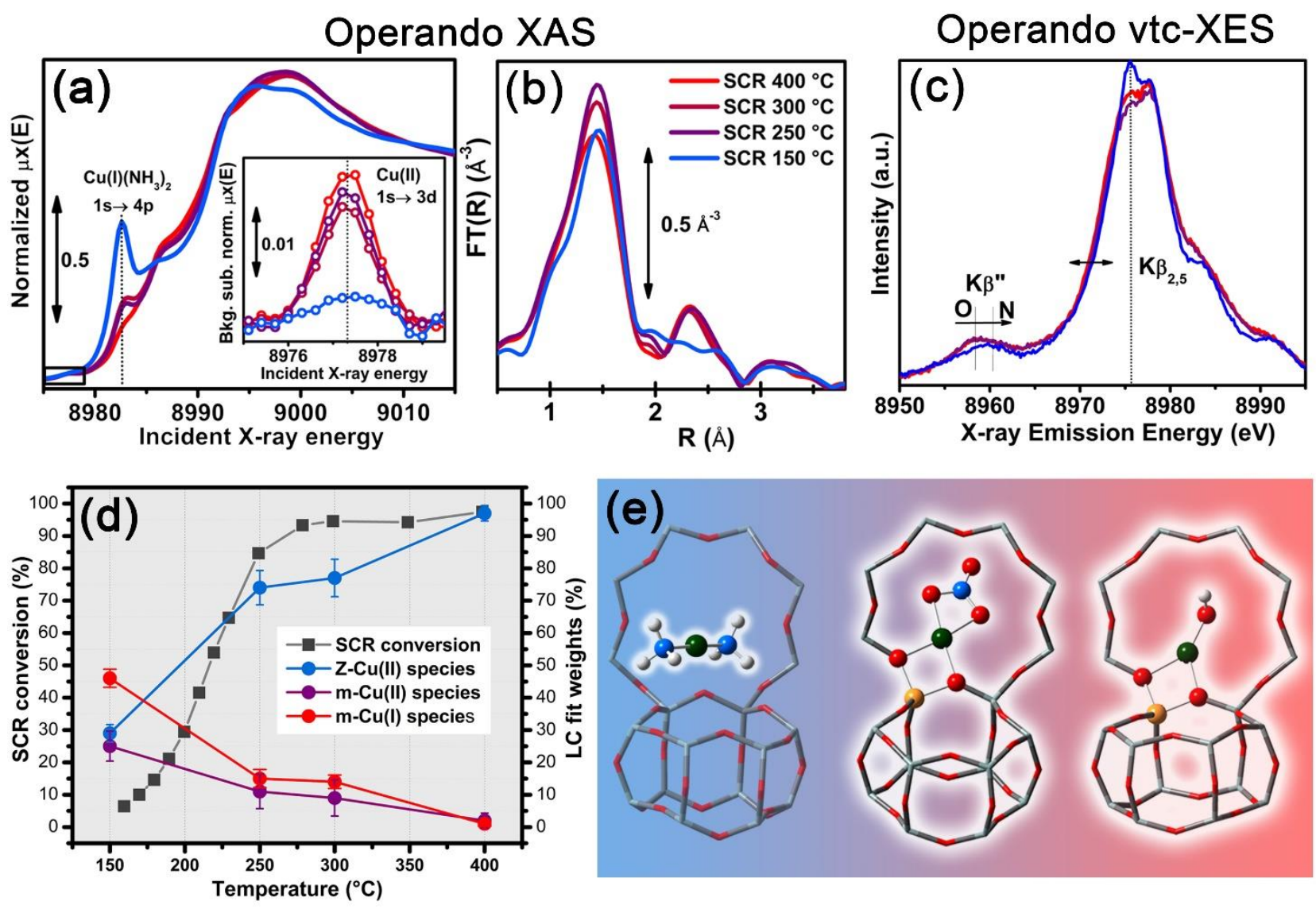

Fig. 16. Part (a): Cu K-edge XANES spectra collected during operando $\mathrm{NH}_{3}-\mathrm{SCR}$ at different temperatures: 150 , 250 , 300 and $400{ }^{\circ} \mathrm{C}$. The inset reports a magnification of the background-subtracted $\mathrm{Cu}(\mathrm{II}) 1 \mathrm{~s} \rightarrow 3 \mathrm{~d}$ pre-edge peaks (black boxes in the main panel). Part (b): as part (a) for the moduli of the, $\mathrm{k}^{2}$-weighted, FT of the corresponding EXAFS spectra. Part (c): as part (a) for the (K $\beta$-main)-subtracted $\mathrm{K} \beta$ ”, and $\mathrm{K} \beta_{2,5}$ XES satellite peaks. Part (d): Cu-speciation during temperature-dependent SCR on Cu-CHA from LCF analysis of operando XANES spectra (colored circles, right axis) and $\mathrm{NH}_{3}$-SCR conversion rate (black squares, left axis). Part (e): Structural snapshots of the dominant $\mathrm{Cu}$-species for each probed temperature: mobile $\left[\mathrm{Cu}(\mathrm{I})\left(\mathrm{NH}_{3}\right)_{2}\right]^{+}$complexes in the low-temperature range and framework-coordinated $\mathrm{Cu}(\mathrm{II})$ moieties in the high-temperature range (color code: $\mathrm{Cu}$ : green, O: red, Al: yellow, Si: gray, N: blue, H: white). Previously unpublished figure reporting spectra published in Ref. ${ }^{34}$

More in detail, by applying a linear combination fit (LCF) analysis of operando XANES, Fig. 16a, employing a series of well-characterized $\mathrm{Cu}$-references it was possible to quantitatively estimate temperature-dependent $\mathrm{Cu}$-speciation during SCR (Fig. 16e). The results were validated by complementary operando EXAFS (Fig. 16b) and valence-to-core-XES (Fig. 16c), which allows distinction between $\mathrm{O}$ - and $\mathrm{N}$-ligation at the $\mathrm{Cu}$-atom. Operando XAS/XES during SCR revealed a strong influence of reaction temperature on $\mathrm{Cu}$-speciation. In the low-temperature range up to $\mathrm{ca} .200$ ${ }^{\circ} \mathrm{C}$ the catalyst framework hosts balanced populations of $\mathrm{Cu}(\mathrm{I}) / \mathrm{Cu}$ (II) sites, with a dominant presence of mobile, $\mathrm{NH}_{3}$-solvated $\mathrm{Cu}$-species. The formation of these mobile species had already been 
observed by Giordanino et al. ${ }^{51}$ during low temperature interaction of $\mathrm{Cu}-\mathrm{CHA}$ with gaseous $\mathrm{NH}_{3}$ alone. In the $250-400{ }^{\circ} \mathrm{C}$ range, the local coordination of the metal ion changes: $\mathrm{Cu}$ loses part of the $\mathrm{NH}_{3}$ ligands and is dominantly present as framework-coordinated $\mathrm{Cu}$ (II) species, with preferential Oligation, accounting for ca. $70 \%$ to more than $90 \%$ of total $\mathrm{Cu}$ sites (XES in Fig. 16d). Importantly, the transition between low- and high-temperature $\mathrm{Cu}$-speciation coincides with the slight dip in NO conversion at around $350{ }^{\circ} \mathrm{C}$ (Fig. 16d, black squares) and indicates that the $\mathrm{NH}_{3}$ ligand loss and subsequent formation of a zeolite bound $\mathrm{Cu}$-species induces the observed change in SCR kinetics and related mechanistic steps.

The experimental results obtained by Lomachenko et al. ${ }^{34}$ are in good agreement with the theoretically calculated phase diagrams for $\mathrm{Cu}-\mathrm{CHA}$ at different compositions and reaction conditions, obtained by Paolucci et al., ${ }^{68}$ see Fig. 17.
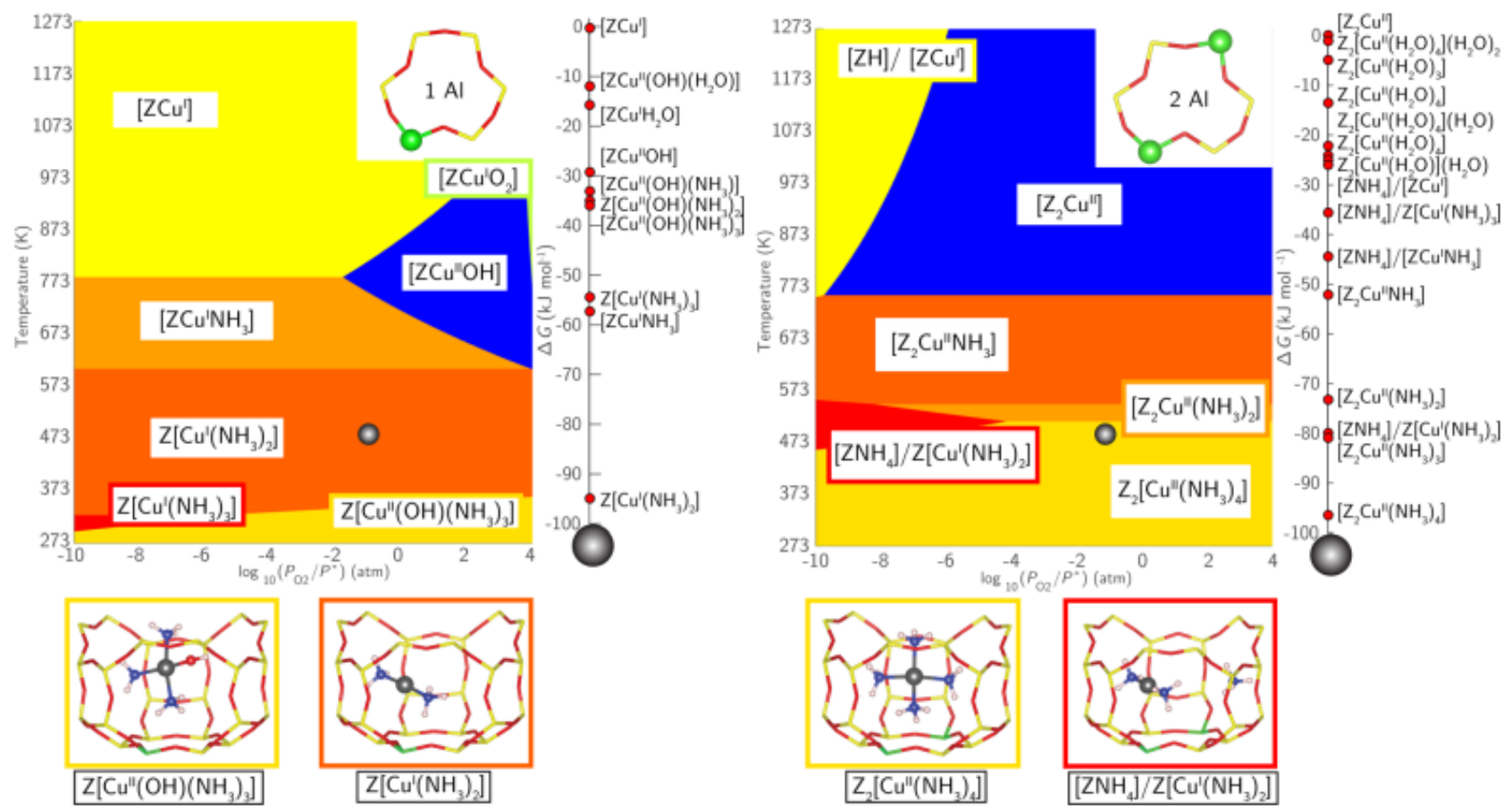

Fig. 17. Phase diagrams for $1 A l$ (left) and $2 A l$ (right) sites with varying temperature and oxygen equilibrium pressure $\left(\mathrm{P}_{\mathrm{O} 2}\right)$ at $300 \mathrm{ppm}$ of $\mathrm{NH}_{3}$ and $2 \% \mathrm{H}_{2} \mathrm{O}$. Relative rankings for all species $\Delta \mathrm{G}_{\text {form }}<0$ at $473 \mathrm{~K}$ and $10 \% \mathrm{O}_{2}$ (chrome spheres on the phase diagrams) are given to the right of each phase diagram. The structures shown on the bottom are the most stable $\mathrm{Cu}(\mathrm{I})$ (red) and $\mathrm{Cu}(\mathrm{II})$ (golden) under these conditions. Adapted by permission of the American Chemical Society (copyright 2016) from ref. ${ }^{68}$

The theoretical phase diagrams in Fig. 17 illustrate in an impressive way the complex dynamics in $\mathrm{Cu}$-speciation during the $\mathrm{NH}_{3}-\mathrm{SCR}$ reaction.

Despite the tremendous research efforts of many academic and industrial groups around the world, and the growing number of proposed reaction mechanisms for the $\mathrm{NH}_{3}-\mathrm{SCR}$ reaction (both at high and at low temperatures, see e.g. those reported in Fig. 18), a complete picture, comprising all the elementary steps is still missing.

One of the most puzzling questions for low temperature SCR remained to be the change in kinetics from quadratic to linear dependency and the decrease in the apparent $\mathrm{O}_{2}$ reaction order from 0.8 to 0.3 , both with increasing $\mathrm{Cu}$ density. ${ }^{70,144}$ Very recently, these experimental observations could be reconciled by a combination of steady-state and transient kinetic measurements, XAS, and firstprinciples calculations. Paolucci et al. ${ }^{70}$ propose that at low temperature reaction conditions $(\sim 200$ ${ }^{\circ} \mathrm{C}$ ), the $\mathrm{NH}_{3}$-solvated $\mathrm{Cu}(\mathrm{I})$ ions can travel through zeolite windows and form transient ion pairs that are able to activate oxygen via a $\mathrm{Cu}(\mathrm{I}) \rightarrow \mathrm{Cu}$ (II) redox step (Fig. 18a). 


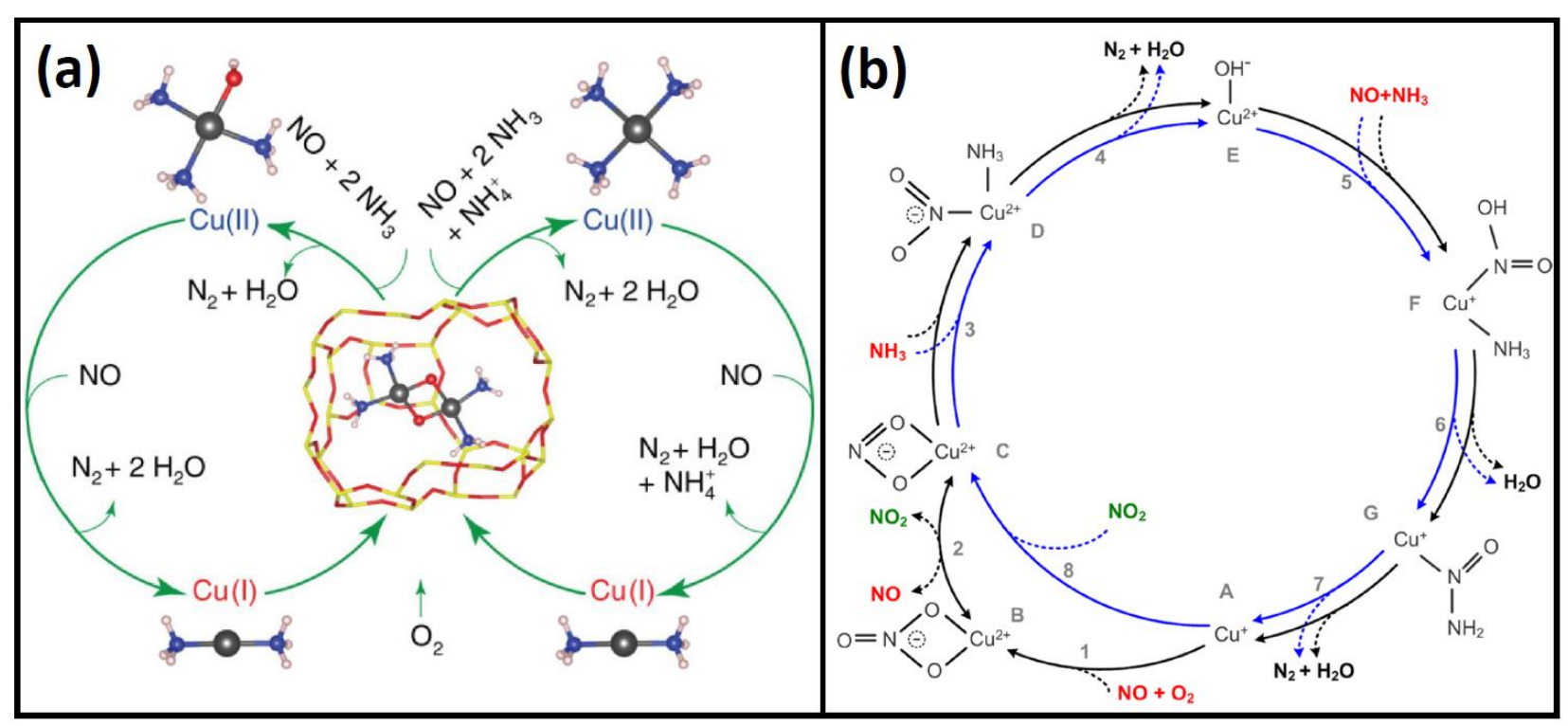

Fig. 18. Part (a): low-temperature SCR catalytic cycle proposed by Paolucci et al. ${ }^{70}$ reproduced by permission of the American Association for the Advancement of Science (copyright 2017) from ref. ${ }^{70}$ Reduction steps proceed on siteisolated $\mathrm{Cu}$ (II) ions residing near one (left-hand cycle) or two (right-hand cycle) framework Al centres with constrained diffusion of $\mathrm{Cu}(\mathrm{I})$ ions into single cages and oxidation by $\mathrm{O}_{2}$ (inner step). $\mathrm{NH}_{4}{ }^{+}$is formed and consumed in the right-hand cycle to maintain stoichiometry and charge balance. Gray, Cu; yellow, Si; red, O; blue, N; and white, H. Part (b): SCR cycle proposed by Janssens et al. ${ }^{18}$ reproduced by permission of the American Chemical Society (copyright 2015) from ref. ${ }^{18}$ The fast SCR cycle, Eq. (3), is represented in blue, and the NO activation cycle is represented in black. Reactants are indicated in red, reaction products are indicated in black, and the $\mathrm{NO}_{2}$ intermediate is indicated in green. In the standard SCR reaction, the NO activation cycle, and fast SCR cycle, vide infra Eq. (4), run at equal rates; the stoichiometry of the standard SCR reaction is then found by adding these two cycles. The oxidation states of the $\mathrm{Cu}$ ions have been assigned according to the magnetic moment found in DFT: $\mathrm{M}(\mathrm{Cu}(\mathrm{II}))>0.45$ and $\mathrm{M}(\mathrm{Cu}(\mathrm{I}))<0.1$.

In a recent contribution, Marberger et al. use transient methods followed by quick-scanning EXAFS and come to the conclusion that the rate-limiting step in low temperature $\mathrm{NH}_{3}$-SCR is related to the re-oxidation of $\left[\mathrm{Cu}\left(\mathrm{NH}_{3}\right)_{2}\right]^{+}$to $\left[\mathrm{Cu}\left(\mathrm{NH}_{3}\right)_{4}\right]^{2+}$, which at the same time is inhibited by the strong interaction of $\mathrm{NH}_{3}$ with the $\mathrm{Cu}(\mathrm{I})$ complex. ${ }^{21}$

While the formation and catalytic relevance of the mobile $\left[\mathrm{Cu}\left(\mathrm{NH}_{3}\right)_{2}\right]^{+}$and $\left[\mathrm{Cu}\left(\mathrm{NH}_{3}\right)_{4}\right]^{2+}$ complexes in low temperature SCR seems to be now fairly well documented, the observation and significance of other reaction intermediates is still debated. One prominent example is the question concerning the role of the often-observed Cu-nitrates in the SCR reaction. Janssens et al. proposed a consistent catalytic cycle for the $\mathrm{NH}_{3}-\mathrm{SCR}$ reaction over $\mathrm{Cu}-\mathrm{CHA}$, where $\mathrm{Cu}$-nitrate formation plays an important role (Fig. 18b). ${ }^{18}$ Their catalytic redox cycle is based on the observation that it is possible to separate the oxidation step from the reduction step and study the individual half-cycles by switching between $\mathrm{NH}_{3}+\mathrm{NO}$ and $\mathrm{NO}+\mathrm{O}_{2}$ atmospheres. Staring from $\mathrm{NO}+\mathrm{O}_{2}$ (oxidative) conditions $\mathrm{Cu}$ (II)-nitrate species are formed, which then react in $\mathrm{NH}_{3}+\mathrm{NO}$ (reductive) conditions to the solvated $\mathrm{Cu}(\mathrm{I})-\mathrm{NH}_{3}$ species (as described above). Switching back to $\mathrm{NO}+\mathrm{O}_{2}$ (oxidative) conditions, $\mathrm{Cu}(\mathrm{II})-$ nitrate species were re-formed (as identified by IR, EPR and XAS) proving a closed catalytic cycle. ${ }^{18 \text {, }}$ ${ }^{31}$ Janssens et al. proposed their mechanism originally as the simplest case for a SCR cycle, having only isolated $\mathrm{Cu}$-ions. In their mechanism the nitrate intermediate combines with $\mathrm{NO}$ to generate $\mathrm{Cu}$ nitrite and gaseous $\mathrm{NO}_{2}$, which agrees well with the experimentally often observed transient formation of gaseous $\mathrm{NO}_{2}$ when switching to oxidative conditions. The presence of $\mathrm{NO}_{2}$ as an intermediate in the standard SCR cycle allows to "short-cut" the oxidation half-cycle and thereby establishes a link to the so-called fast SCR given as: ${ }^{18}$

$$
\mathrm{NO}+2 \mathrm{NH}_{3}+\mathrm{NO}_{2} \rightarrow 4 \mathrm{~N}_{2}+3 \mathrm{H}_{2} \mathrm{O}
$$


In contrast, Marberger et al. argue that at low temperatures nitrates appeared only after the reaction environment is far away from SCR conditions, and suggest that they are not involved in the SCR reaction cycle. ${ }^{21}$ As we have just explained above, at high temperatures, $\mathrm{Cu}$ ions lose their $\mathrm{NH}_{3}$ ligands and thereby also their mobility. They are then attached to the walls of the zeolite (at ionexchange positions) and hence their possibility to dynamically form dimers (to activate oxygen) is greatly diminished. It is therefore conceivable that the nitrate route described by Janssens et al., i.e. the NO activation via oxygen, ${ }^{18}$ becomes a relevant step in the SCR reaction at higher temperatures (above $300{ }^{\circ} \mathrm{C}$ ). More experiments, in particular at high temperatures, are required to fill out the remaining gaps in our understanding of the $\mathrm{NH}_{3}$-SCR mechanism over $\mathrm{Cu}-\mathrm{CHA}$.

\subsection{Direct conversion of Methane into Methanol}

In a 2005 key publication, Schoonheydt and co-workers demonstrated the use of $\mathrm{Cu}$ loaded zeolites (ZSM-5 and mordenite) for low temperature conversion of methane to methanol. ${ }^{147}$ Later, several zeolite topologies, containing $\mathrm{Cu}, \mathrm{Fe}$, and $\mathrm{Co}$ have been investigated for this reaction, as recently summarized by van Bokhoven and co-workers. ${ }^{169-171}$ Usually, the process is carried out in a three step manner comprising i) oxidation (most frequently with oxygen) at high temperature $\left(450^{\circ} \mathrm{C}\right.$ is typical); ii) methane loading at substantially lower temperatures $\left(\sim 60-200{ }^{\circ} \mathrm{C}\right)$; iii) followed by methanol extraction, usually with steam, occasionally with liquid solvents. Thus, the reaction at hand is most often carried out using a chemical looping protocol. As methane and the oxidant are not mixed, the selectivity to methanol tends to be high ( $\sim 90 \%$, prominent byproducts are $\mathrm{CO}$ and $\mathrm{CO}_{2}$ ), whereas the yield expressed as moles of methanol per mole of metal is moderate. The production rate in real time is very low, due to the chemical looping principle comprising three lengthy steps.

A few examples of continuous, true catalytic processes have been reported for several $\mathrm{Cu}$ loaded zeolites, including SSZ-13, co-feeding methane with oxygen and steam at $210{ }^{\circ} \mathrm{C} .{ }^{172}$ Ipek and Lobo ${ }^{24}$ reported the catalytic conversion of methane to methanol on $\mathrm{Cu}$ loaded SSZ-13 (and other zeolites) using $\mathrm{N}_{2} \mathrm{O}$ as oxidant. Invariably, the turn over frequencies or site time yields are very low, and adverse conversion/selectivity relationships have been reported, as one normally would expect when abandoning the chemical looping concept. ${ }^{24}$

The objective of this section can be expressed as follows. First, we wish the review the performance of CHA based materials in the stepwise selective oxidation of methane to methanol, focusing on the productivity per $\mathrm{Cu}$ atom. This will include the aluminosilicate (SSZ-13) and the very relevant isostructural silicoaluminophosphate analogue (SAPO-34). Second, it will be demonstrated how these productivities depend quite profoundly on the exact conditions employed. Third, a remark will be made on the extent to which the methanol productivity depends on the initial properties of the zeolite and the exact procedure by which $\mathrm{Cu}$ is introduced. Finally, as the overall objective of the present contribution is to describe structure-reactivity relationships for $\mathrm{Cu}-\mathrm{CHA}$, we will highlight the importance of carrying out characterization at exactly the same conditions as when measuring reactivity.

\subsubsection{The performance of CHA based materials in the stepwise methane to methanol reaction.} Essentially, only a few papers have reported performance data for $\mathrm{Cu}$ loaded $\mathrm{CHA}$ materials in the selective oxidation of methane to methanol. ${ }^{22,24,27-29}$ The published data are summarized in Table 1, together with compositional data, details on the testing protocol, as well as specifics on the preparation procedure. It appears customary to present productivities in either micromoles of methanol per gram of material or as the ratio between methanol and $\mathrm{Cu}$, or both. The latter is a good descriptor for active $\mathrm{Cu}$ speciation, whereas from a process perspective, it is the production per mass 
of sample that is of primary interest. For convenience, both units are employed in Table 1 and Fig. 19.

It may be noted that the reaction is not perfectly selective. Dimethyl ether tends to be formed, as seen also for other zeolites. ${ }^{150,173,174}$ Dimethyl ether, which is readily formed on acid sites from methanol dehydration, can be considered a desired product in this context. Unwanted by-products are $\mathrm{CO}$ and $\mathrm{CO}_{2}$. In the limited context of CHA based materials, only Pappas et al. ${ }^{27}$ specify products other than methanol. The selectivities to methanol and dimethyl ether range from $\sim 50 \%$ to above 90 $\%$, but are usually above $85 \%$. The methane activation temperature seems to have a detrimental effect on selectivity; it should not be above $200{ }^{\circ} \mathrm{C} .{ }^{27}$
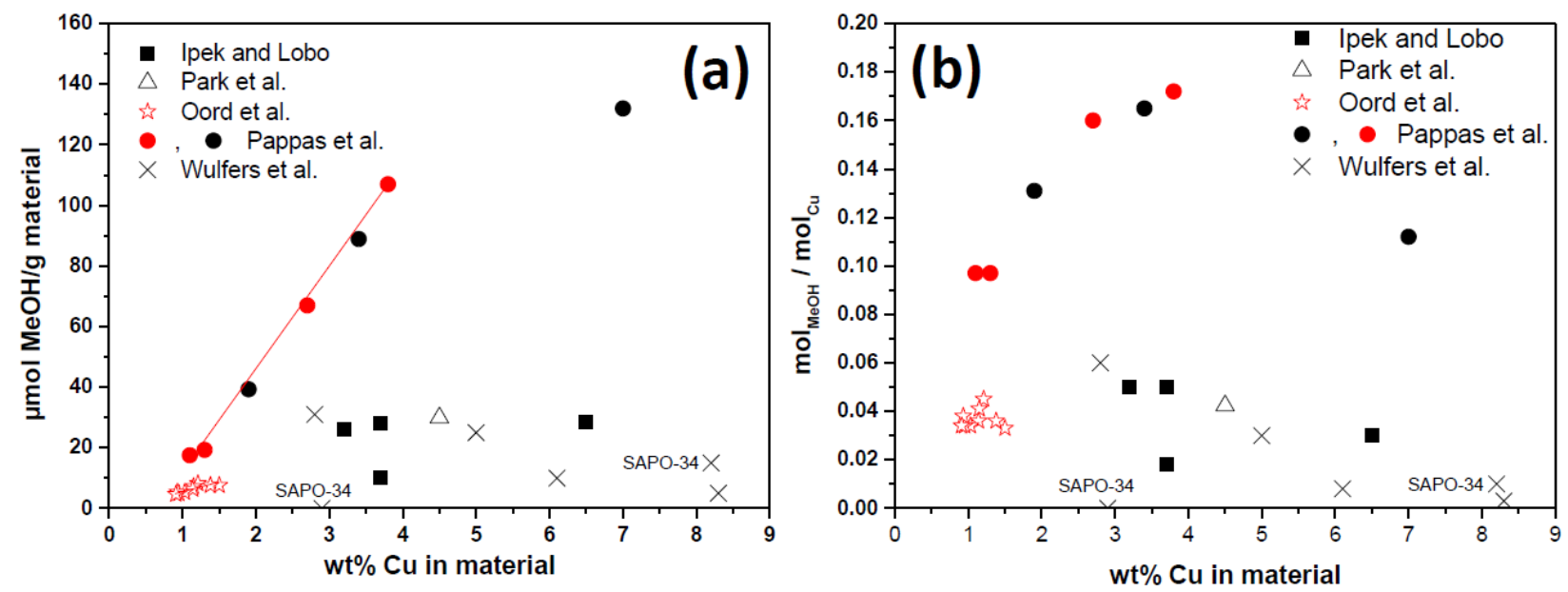

Fig. 19. Methanol productivities over Cu loaded CHA. Part (a): Productivities expressed per mass of material. Part (b): Productivities normalized to $\mathrm{Cu}$ loading. Red symbols represent subsets of data from refs. ${ }^{27,29}$ on catalysts prepared using the same zeolite support: for these two subsets, the results can be directly compared to the copper loading without any interferences related to the zeolite properties. The red line in part (a) connects data from one such consistent subsets. Exact reaction conditions can be found in Table 1. It should be noted that only Pappas et al. ${ }^{27}$ specifies that dimethyl ether is considered among the products. Further, Pappas et al. have employed an optimized (and lengthy) reaction protocol. Previously unpublished figure summarizing data taken form Refs. ${ }^{22,24,27-29}$

The maximum productivity reported for CHA is $132 \mu \mathrm{mol} / \mathrm{g}$ or $0.112 \mathrm{~mol}_{\mathrm{MeOH}} / \mathrm{mol}_{\mathrm{Cu}}$, for the first reaction cycle for a sample with $\mathrm{Si} / \mathrm{Al}=5.2 ; \mathrm{Cu} / \mathrm{Al}=0.49 ; \mathrm{Cu}$ content $7.0 \mathrm{wt} \%{ }^{27}$ This can be compared to values of $89 \mu \mathrm{mol} / \mathrm{g}$ or $0.23 \mathrm{~mol}_{\mathrm{MeOH}} / \mathrm{mol}_{\mathrm{Cu}}$ for $\mathrm{Cu}-\mathrm{ZSM}-5(\mathrm{Si} / \mathrm{Al}=14 ; \mathrm{Cu} / \mathrm{Al}=0.67$; $\mathrm{Cu}$ content $4.2 \mathrm{wt} \%)^{175}$ and $170 \mu \mathrm{mol} / \mathrm{g}$ or $0.33 \mathrm{~mol}_{\mathrm{MeOH}} / \mathrm{mol}_{\mathrm{Cu}}$ (including both $\mathrm{MeOH}$ and DME) for $\mathrm{Cu}$-mordenite $(\mathrm{Si} / \mathrm{Al}=7.2 ; \mathrm{Cu} / \mathrm{Al}=0.27 ; \mathrm{Cu}$ content $3.3 \mathrm{wt} \%) .{ }^{150}$ Perusal of Fig. 19 reveals that the most productive sample $(132 \mu \mathrm{mol} / \mathrm{g})^{27}$ is not the one that performs best when normalizing to $\mathrm{Cu}$ loading. This is rather the sample giving $107 \mu \mathrm{mol} / \mathrm{g}$ or $0.172 \mathrm{~mol}_{\mathrm{MeOH}} / \mathrm{mol}_{\mathrm{Cu}}(\mathrm{Si} / \mathrm{Al}=12 ; \mathrm{Cu} / \mathrm{Al}=$ 0.49 ; $\mathrm{Cu}$ content $3.8 \mathrm{wt} \%$ ). Thus, having taken the trouble of converting the data for straightforward comparison, it becomes clear that the highest productivities reported for $\mathrm{Cu}$ loaded CHA, MFI, and MOR are strikingly similar, even when comparing per gram of material, per mass of $\mathrm{Cu}$ or per mole of $\mathrm{Cu}$. Based on the data reported, SAPO-34 appears to perform poorly. 


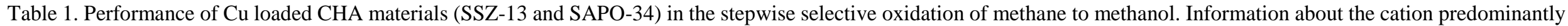

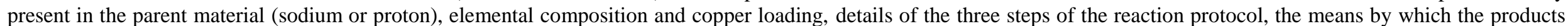

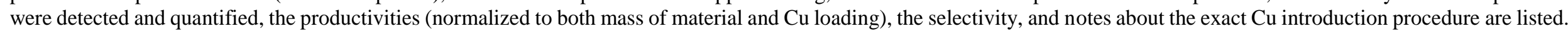
Values in italics have been recalculated by us from the published data for completeness. Some of the here reported data are summarized in Fig. 19. Previously unpublished Table.

\begin{tabular}{|c|c|c|c|c|c|c|c|c|c|c|c|c|}
\hline Zeolite & \begin{tabular}{|l|}
$\mathrm{Si} / \mathrm{Al}$ \\
or \\
$(\mathrm{Al}+\mathrm{P})$ \\
$\mathrm{Si}$ \\
\end{tabular} & $\begin{array}{l}\mathrm{Cu} / \mathrm{Al} \text { or } \\
\mathrm{Cu} / \mathrm{Si}\end{array}$ & $\begin{array}{l}\mathrm{Cu} \\
\text { (wt\%) }\end{array}$ & Protocol & $\begin{array}{l}\text { Detection } \\
\text { principle }\end{array}$ & \multicolumn{2}{|c|}{$\begin{array}{l}\text { Productivity } \\
(\mu \mathrm{mol} / \mathrm{g})\end{array}$} & \multicolumn{2}{|c|}{$\begin{array}{l}\text { Productivity } \\
\left(\mathrm{mol}_{\mathrm{MeOH}} / \mathrm{mol}_{\mathrm{Cu}}\right)\end{array}$} & Selectivity & Preparation & Ref. \\
\hline Na-SSZ-13 & 6 & $\begin{array}{l}0.35 \pm \\
0.07\end{array}$ & $5.0^{a}$ & $\begin{array}{l}\text { i) } 10 \mathrm{~h} \mathrm{in} \mathrm{O}_{2} \text { at } 450{ }^{\circ} \mathrm{C} \\
\text { ii) } 20+20 \mathrm{~min} \text { in } 7.5 \mathrm{kPa} \mathrm{CH} 4 \text { at } 60 \text { and } 200{ }^{\circ} \mathrm{C} \\
\text { iii) } 5 \mathrm{~h} \text { with } \mathrm{N}_{2} \text { saturated with water vapor at } 200{ }^{\circ} \mathrm{C}\end{array}$ & $\begin{array}{l}\text { On-line GC and } \\
\text { MS }\end{array}$ & \multicolumn{2}{|l|}{28} & \multicolumn{2}{|l|}{0.03} & Not reported & $\begin{array}{l}\text { Liquid exchange of Na- } \\
\text { form with } \\
\text { copper(II)acetate }\end{array}$ & 22 \\
\hline Na-SSZ-13 & 12 & $\begin{array}{l}0.35 \pm \\
0.06 \\
\end{array}$ & 2.8 & As above & As above & \multicolumn{2}{|l|}{31} & \multicolumn{2}{|l|}{0.06} & As above & As above & 22 \\
\hline Na-SAPO-34 & 5 & $\begin{array}{l}0.17 \pm \\
0.06\end{array}$ & 2.9 & As above & As above & \multicolumn{2}{|l|}{$<1$} & \multicolumn{2}{|l|}{$<0.001$} & As above & As above & 22 \\
\hline H-SAPO-34 & 6 & $0.6 \pm 0.2$ & 8.2 & $\begin{array}{l}\text { i) } 10 \mathrm{~h} \mathrm{in} \mathrm{N}_{2} \text { at } 650^{\circ} \mathrm{C} ; 15 \mathrm{~h} \mathrm{in} \mathrm{O}_{2} \text { at } 450^{\circ} \mathrm{C} \\
\text { ii) } 20+20 \mathrm{~min} \text { in } 7.5 \mathrm{kPa} \mathrm{CH}_{4} \text { at } 60 \text { and } 200^{\circ} \mathrm{C} \\
\text { iii) } 8 \mathrm{~h} \text { with } \mathrm{N}_{2} \text { saturated with water vapor at } 200{ }^{\circ} \mathrm{C}\end{array}$ & As above & \multicolumn{2}{|l|}{15} & \multicolumn{2}{|l|}{0.01} & As above & $\begin{array}{l}\text { High temperature gas- } \\
\text { solid exchange of } \mathrm{H}- \\
\text { form with } \\
\text { copper(I)chloride }\end{array}$ & 22 \\
\hline H-SSZ-13 & 6 & $0.6 \pm 0.3$ & 8.3 & As above & As above & \multirow{2}{*}{\multicolumn{2}{|c|}{$\begin{array}{l}5 \\
10\end{array}$}} & \multirow{2}{*}{\multicolumn{2}{|c|}{\begin{tabular}{|l|}
0.003 \\
0.008 \\
\end{tabular}}} & As above & As above & 22 \\
\hline H-SSZ-13 & 12 & $0.8 \pm 0.3$ & 6.1 & As above & As above & & & & & As above & As above & 22 \\
\hline H-SSZ-13 & 5 & 0.39 & 6.5 & $\begin{array}{l}\text { i) } 7 \mathrm{~h} \text { in } \mathrm{O}_{2} \text { at } 4500^{\circ} \mathrm{C} \\
\text { ii) } 20 \text { min in neat } \mathrm{CH}_{4} \text { at } 50{ }^{\circ} \mathrm{C} \\
\text { iii) } \mathrm{N}_{2} \text { saturated with water vapor at } 200{ }^{\circ} \mathrm{C}\end{array}$ & $\begin{array}{l}\text { On-line GC and } \\
\text { MS }\end{array}$ & \multicolumn{2}{|l|}{28.5} & \multicolumn{2}{|l|}{0.03} & Not reported & $\begin{array}{l}\text { Liquid exchange of } \mathrm{H}- \\
\text { form with } \\
\text { copper(II)acetate }\end{array}$ & 24 \\
\hline H-SSZ-13 & 12 & 0.40 & 3.2 & As above & As above & \multirow{2}{*}{\multicolumn{2}{|c|}{$\begin{array}{ll}26 \\
28.1\end{array}$}} & \multirow{2}{*}{\multicolumn{2}{|c|}{$\begin{array}{l}0.05 \\
0.05\end{array}$}} & As above & As above & 24 \\
\hline Na-SSZ-13 & 12 & 0.47 & 3.7 & As above & As above & & & & & As above & $\begin{array}{l}\text { Liquid exchange of Na- } \\
\text { form with } \\
\text { copper(II)acetate }\end{array}$ & 24 \\
\hline Na-SSZ-13 & 12 & 0.47 & 3.7 & $\begin{array}{l}\text { i) } 4 \mathrm{~h} \mathrm{in} \mathrm{He} \text { at } 450{ }^{\circ} \mathrm{C} \\
\text { ii) } 20 \text { min in neat } \mathrm{CH}_{4} \text { at } 50{ }^{\circ} \mathrm{C} \\
\text { iii) } \mathrm{N}_{2} \text { saturated with water vapor at } 200{ }^{\circ} \mathrm{C}\end{array}$ & As above & \multicolumn{2}{|l|}{10} & \multicolumn{2}{|l|}{0.018} & As above & As above & 24 \\
\hline Na-SSZ-13 & 15.8 & 0.84 & 4.5 & $\begin{array}{l}\text { i) } 4 \mathrm{~h} \text { in } \mathrm{O}_{2} \text { at } 450{ }^{\circ} \mathrm{C} \\
\text { ii) } 30 \text { min in neat } \mathrm{CH}_{4} \text { at } 200{ }^{\circ} \mathrm{C} \\
\text { iii) repeated stirring with deionized water for } 24 \mathrm{~h}\end{array}$ & $\begin{array}{l}\text { GC-FID analysis } \\
\text { of extracts }\end{array}$ & \multicolumn{2}{|l|}{30.0} & \multicolumn{2}{|l|}{0.0424} & Not reported & $\begin{array}{l}\text { Liquid exchange of Na- } \\
\text { form with } \\
\text { copper(II)acetate }\end{array}$ & 28 \\
\hline Na-SSZ-13 & 20 & 0.30 & 1.5 & $\begin{array}{l}\text { i) } 2 \mathrm{~h} \mathrm{in} \mathrm{O}_{2} \text { at either } 4500^{\circ} \mathrm{C} \text { or } 550{ }^{\circ} \mathrm{C} \\
\text { ii) } 20 \mathrm{~min} \text { in } 38 \mathrm{kPa} \mathrm{CH}_{4} \text { at } 60{ }^{\circ} \mathrm{C} \text {, heating to } 200{ }^{\circ} \mathrm{C} \\
\text { in } 38 \mathrm{kPa} \mathrm{CH}_{4} \\
\text { iii) } \mathrm{N}_{2} \text { saturated with water vapor at } 200{ }^{\circ} \mathrm{C} \text { for } 110 \\
\text { min }\end{array}$ & On-line GC-FID & \multicolumn{2}{|l|}{7.6} & \multicolumn{2}{|l|}{0.033} & Not reported & $\begin{array}{l}\text { Liquid exchange of Na- } \\
\text { form with } \\
\text { copper(II)acetate }\end{array}$ & 29 \\
\hline Na-SSZ-13 & 20 & 0.28 & 1.38 & As above & As above & \multicolumn{2}{|l|}{7.6} & \multicolumn{2}{|l|}{0.036} & As above & $\begin{array}{l}\text { Liquid exchange of Na- } \\
\text { form with } \\
\text { copper(II)sulfate }\end{array}$ & 29 \\
\hline Na-SSZ-13 & 20 & 0.23 & 1.15 & As above & As above & \multicolumn{2}{|l|}{7.2} & \multicolumn{2}{|l|}{0.041} & As above & As above & 29 \\
\hline Na-SSZ-13 & 20 & 0.24 & 1.21 & As above & As above & $8.2^{b}$ & \begin{tabular}{|c|}
$9.0^{c}$ \\
\end{tabular} & $0.045^{b}$ & $0.049^{c}$ & As above & As above & 29 \\
\hline H-SSZ-13 & 20 & 0.23 & 1.14 & As above & As above & $6.3^{b}$ & $7.6^{c}$ & $0.036^{b}$ & $0.043^{c}$ & As above & $\begin{array}{l}\text { Liquid exchange of } \mathrm{H}- \\
\text { form with } \\
\text { copper(II)sulfate }\end{array}$ & 29 \\
\hline
\end{tabular}




\begin{tabular}{|c|c|c|c|c|c|c|c|c|c|c|c|c|}
\hline Na-SSZ-13 & 20 & 0.19 & 0.95 & As above & As above & $4.9^{b}$ & $7.5^{c}$ & $0.034^{b}$ & $0.052^{c}$ & As above & $\begin{array}{l}\text { Liquid exchange of Na- } \\
\text { form with } \\
\text { copper(II)sulfate }\end{array}$ & 29 \\
\hline Na-SSZ-13 & 20 & 0.20 & 1.03 & As above & As above & 5.3 & & 0.034 & & As above & As above & 29 \\
\hline Na-SSZ-13 & 20 & 0.19 & 0.93 & As above & As above & 5.4 & & 0.038 & & As above & $\begin{array}{l}\text { Liquid exchange of Na- } \\
\text { form with } \\
\text { copper(II)acetate }\end{array}$ & 29 \\
\hline Na-SSZ-13 & 20 & 0.18 & 0.91 & As above & As above & 4.7 & & 0.034 & & As above & $\begin{array}{l}\text { Liquid exchange of Na- } \\
\text { form with } \\
\text { copper(II)sulfate }\end{array}$ & 29 \\
\hline Na-SSZ-13 & 5.2 & 0.49 & 7.0 & $\begin{array}{l}\text { i) } 8 \mathrm{~h} \mathrm{in} \mathrm{O}_{2} \text { at } 500{ }^{\circ} \mathrm{C} \\
\text { ii) } 6 \mathrm{~h} \text { in neat } \mathrm{CH}_{4} \text { at } 200{ }^{\circ} \mathrm{C} \\
\text { iii) } \mathrm{He} / \mathrm{Ne} \text { saturated with water vapor (saturator at } 45 \\
{ }^{\circ} \mathrm{C} \text { ) at } 200{ }^{\circ} \mathrm{C} \text { for } 110 \mathrm{~min}\end{array}$ & $\begin{array}{l}\text { GC-MS Both } \\
\text { dimethyl ether } \\
\text { and methanol } \\
\text { considered } \\
\text { products; } \mathrm{CO} \text { and } \\
\mathrm{CO}_{2} \text { as by- } \\
\text { products. }\end{array}$ & 132 & & 0.112 & & $\begin{array}{l}87 \% \text { to } \\
\mathrm{MeOH} \text { and } \\
\mathrm{DME}\end{array}$ & $\begin{array}{l}\text { Liquid exchange of H- } \\
\text { form with } \\
\text { copper(II)acetate }\end{array}$ & 27 \\
\hline Na-SSZ-13 & 12.1 & 0.14 & 1.1 & As above & As above & 17.5 & & 0.097 & & $85 \%$ & As above & 27 \\
\hline Na-SSZ-13 & 12.1 & 0.16 & 1.3 & As above & As above & 19.3 & & 0.097 & & $85 \%$ & As above & 27 \\
\hline Na-SSZ-13 & 12.1 & 0.34 & 2.7 & As above & As above & 67 & & 0.16 & & $87 \%$ & As above & 27 \\
\hline Na-SSZ-13 & 12.1 & 0.49 & 3.8 & As above & As above & 107 & & 0.172 & & $87 \%$ & As above & 27 \\
\hline Na-SSZ-13 & 14.8 & 0.53 & 3.4 & As above & As above & 88.9 & & 0.165 & & $87 \%$ & As above & 27 \\
\hline Na-SSZ-13 & 28 & 0.52 & 1.9 & As above & As above & 39.3 & & 0.131 & & $86 \%$ & As above & 27 \\
\hline
\end{tabular}

${ }^{a}$ Values in italics are calculated by us from published data

${ }^{b}$ Pre-treated in oxygen at $450^{\circ} \mathrm{C}$

${ }^{\circ}$ Pre-treated in oxygen at $550^{\circ} \mathrm{C}$ 
It is of interest to consider the productivity as a function of $\mathrm{Cu}$ loading. Oord et al. ${ }^{29}$ and Pappas et $a l .{ }^{27}$ have investigated the effects of $\mathrm{Cu}$ loading for the same zeolite support for more than two data points (see Fig. 19a). It does appear that the productivity, when expressed per amount of material, can be positively correlated to $\mathrm{Cu}$ loading, in line with data reported for mordenite by Grundner $e t$ $a l .{ }^{150}$ However, the range that can be investigated is invariably limited. For Oord et al. ${ }^{29}$ a slope of 0.035 is found when plotting the productivity (in units of $\mu \mathrm{mol}_{\mathrm{MeOH}} / \mathrm{g}$ per $\mu \mathrm{mol}_{\mathrm{Cu}} / \mathrm{g}$ ), whereas a substantially steeper relationship with a slope of 0.21 is found by Pappas et al. ${ }^{27}$ Grundtner et al. ${ }^{150}$ reported a slope of $0.33 \mu \mathrm{mol}_{\mathrm{MeOH}} / \mathrm{g}$ per $\mu \mathrm{mol}_{\mathrm{Cu}} / \mathrm{g}$ for $\mathrm{Cu}$-mordenite. The data from Oord et al. ${ }^{29}$ do appear to pass through the origin, whereas the data from Pappas et al. ${ }^{27}$ have a negative intercept. A non-zero intercept or a non-linear evolution of productivity might be linked to dynamic changes of the $\mathrm{Cu}$ speciation with differing loading, in line with the recent discoveries of Paolucci et al. ${ }^{70}$ and Gao et al. ${ }^{176}$ for selective catalytic reduction. However, much more work would be needed in order to verify if similar effects can play a role also for the methane oxidation reaction. Finally, when considering the productivities normalized to $\mathrm{Cu}$ loading (Fig. 19b), it is not straightforward to draw definitive conclusions.

3.2.2. The effects of reaction protocol and material preparation procedure. As indicated, the oxidation of methane to methanol is usually carried out in three steps. Clearly, the amount of methanol produced will depend on the exact conditions employed for each of these three steps, i.e. the temperature, the duration, and the partial pressure of reactive gas or atmosphere employed. Oord $e t$ $a l .{ }^{29}$ compared the effects of carrying out the high temperature oxidation step at either 450 or $550{ }^{\circ} \mathrm{C}$ (for $2 \mathrm{~h}$ in neat $\mathrm{O}_{2}$ ). This increase resulted in improved productivities by as much as 10-50\%. Pappas et al. ${ }^{27}$ performed a very detailed investigation of the effects of reaction protocol on productivity, and the results are reproduced in Fig. 20.

The methanol productivity is positively influenced by oxygen activation temperature, partial pressure, and time. The productivity is quite profoundly positively influenced by the methane partial pressure and time, whereas there is a clear optimum for the methane activation temperature. Temperatures above $200{ }^{\circ} \mathrm{C}$ rapidly leads to loss of selectivity and productivity. The temperature employed during steam extraction has only moderate effect on the selectivity, indicating that the two last steps could be executed isothermally. Panel (h) in Fig. 13 also conveys the point that the productivity cannot be expected to be stable during multiple reaction cycles. ${ }^{27}$ These findings for $\mathrm{Cu}$ loaded CHA are to a large degree in line with data reported for other zeolites. In particular, the positive impact of elevated methane pressure is well documented. ${ }^{171}$ Bozbag et al. ${ }^{177}$ investigated the effects of multiple reaction cycles using $\mathrm{Cu}$ loaded mordenite, where the $\mathrm{Cu}$ was introduced either by liquid ion exchange or solid state ion exchange. When preparing the material using liquid ion exchange, it was found that the yield increased by at least $30 \%$ for the second cycle and remained constant afterwards. For the material prepared via solid state ion exchange, a successive improvement with cycles was seem due to a gradual removal of chlorine. A warning was issued, stating that analyzing only one reaction cycle is not representative of the long-term performance. ${ }^{177}$ Although not systematically explored for CHA, it is also well known that the material performance can change depending on the starting characteristics of the zeolite ( $\mathrm{Si} / \mathrm{Al}$ ratio) and the exact preparation procedure, e.g. liquid ion exchange vs. solid state ion exchange, choice of $\mathrm{Cu}$ salt, $\mathrm{pH}$ during preparation, if $\mathrm{Cu}$ is introduced to the $\mathrm{Na}$-form or $\mathrm{H}$-form of the zeolite, etc. ${ }^{150,174,177}$ 

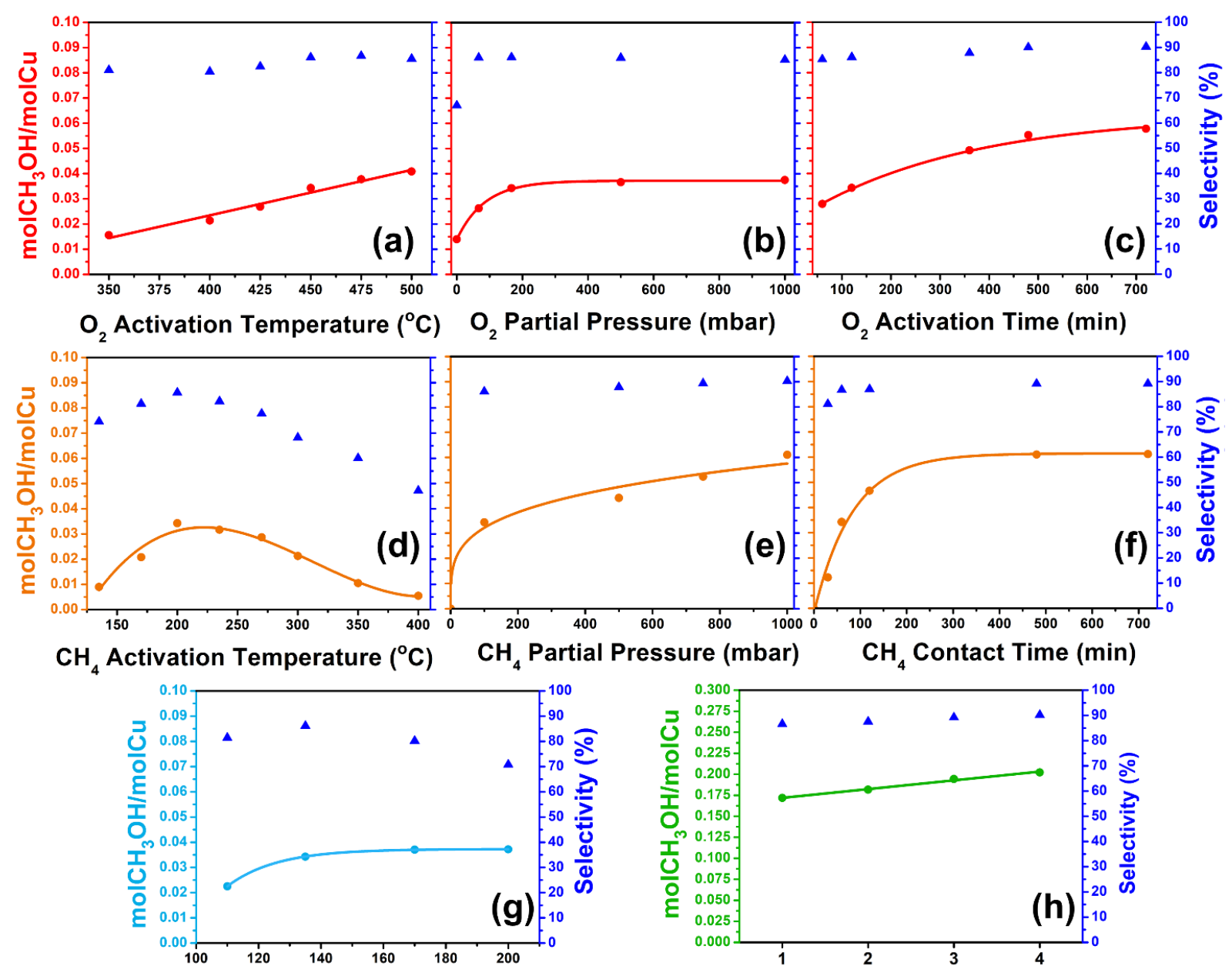

$\mathrm{H}_{2} \mathrm{O}$ Assisted ExtractionTemperature $\left({ }^{\circ} \mathrm{C}\right)$

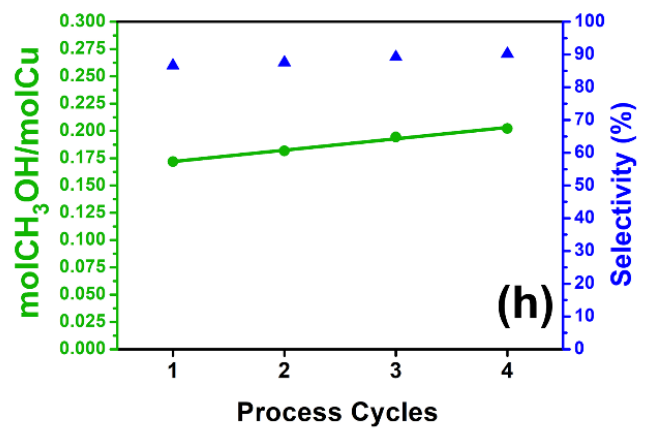

Fig. 20. The effects of various protocol parameters on the normalized methanol productivity (circles) and selectivities (triangles). General conditions applied: Panels (a-g): $\mathrm{O}_{2}$ activation at $450{ }^{\circ} \mathrm{C}$ for $120 \mathrm{~min}$ in $187 \mathrm{mbar} \mathrm{O}_{2}, \mathrm{CH}_{4}$ loading at

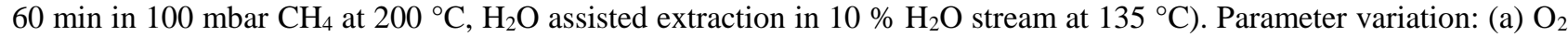
activation temperature; (b) $\mathrm{O}_{2}$ partial pressure; (c) $\mathrm{O}_{2}$ activation time, (d) $\mathrm{CH}_{4}$, loading temperature; (e) $\mathrm{CH}_{4}$ partial pressure; (g) $\mathrm{CH}_{4}$ contact time; (g) $\mathrm{H}_{2} \mathrm{O}$ assisted extraction temperature. Panel (h) shows the effect of multiple cycles of the process at optimized conditions, i.e. $\mathrm{O}_{2}$ activation at $500{ }^{\circ} \mathrm{C}$ for $480 \mathrm{~min}$ in $1000 \mathrm{mbar}_{2}, \mathrm{CH}_{4}$ loading for $360 \mathrm{~min}$ in 1000 mbar $\mathrm{CH}_{4}$ at $200{ }^{\circ} \mathrm{C}$, and online $\mathrm{H}_{2} \mathrm{O}$ assisted extraction with a $10 \% \mathrm{H}_{2} \mathrm{O}$ stream at $200{ }^{\circ} \mathrm{C}$ ). Reproduced by permission of the American Chemical Society (copyright 2017) from ref. ${ }^{27}$

The concentration of methanol produced is fairly low, and the extraction time is considerable. See for example Figure 1 of ref. ${ }^{22}$ and Figure 2 of ref. ${ }^{29}$ Thus, the study of this reaction constitutes a considerable analytical challenge, and Table 1 lists also the means of product quantification employed in the various studies. Wulfers et $_{\text {al. }}{ }^{22}$ report that all productivities were reproducible within $5 \mu \mathrm{mol} / \mathrm{g}$, whereas Oord et al. ${ }^{29}$ report productivities with four digits. In our experience, the productivities are reproducible within $3 \%$ for the same materials ( 5 replicate tests), and about $10 \mu \mathrm{mol} / \mathrm{g}$ when comparing two materials that were prepared to be identical. The reproducibility within a laboratory does therefore appear to be very good. However, no inter-laboratory comparisons have been reported, so there is no information available on the effects of errors or bias of a systematic nature. Fig. 19 does imply that quite different productivities are reported for seemingly similar materials when tested by different laboratories. However, it is clear that the methanol productivities are also highly dependent on material preparation procedure and the reaction protocol employed.

Altogether, this means that attempts to compare data reported by different laboratories could be associated with serious pitfalls. As some differences in the applied reaction conditions invariably are encountered, a compilation of data as presented in Fig. 19 becomes substantially less useful than one 
might desire. Using the data found by Wulfers et al. ${ }^{22}$ as an example, it can be found that different oxygen activation times and product extraction times were used for materials prepared using gassolid ion exchange and liquid ion exchange. The exact effects on the productivity are unknown. In this particular case, the objective was primarily to demonstrate activity, so the difference in protocol was immaterial. Nevertheless, the use of a plethora of reaction protocols does constitute a major obstacle for the establishment of fundamental insights. Moreover, this will have consequences when relating materials performance to characterization data in attempts to establish structure-function relationships. Even though operando characterization is desired, some adaptation of the experimental procedures are often needed, due to practical limitations or time constraints (e.g. when using synchrotron radiation). Taking our own work as an example, it was established (Fig. 19) that $\mathrm{O}_{2}$ activation at $500{ }^{\circ} \mathrm{C}$ for $8 \mathrm{~h}$ in neat $\mathrm{O}_{2}$ gave the highest methanol productivity. However, when doing operando XAS, activation was carried out by maintaining the sample at $500{ }^{\circ} \mathrm{C}$ in $\mathrm{O}_{2}$ for $2 \mathrm{~h}$ (see Figure 3 of ref. ${ }^{27}$ and Section 3.2.4 here after). The obvious consequence is that the concentration of active species or intermediates might not be the same during characterization as it is during reactivity measurements, again making it harder to establish structure-function relationships.

3.2.3. Other oxidants. It is known that the temperature alone can influence the redox chemistry of $\mathrm{Cu}$ in zeolites. Thus, the effects of activation in inert at high temperature (without oxidant) on methanol productivity has been widely investigated, and here reviewed in Section 2.1. Ipek et al. ${ }^{25}$ found non-negligible methanol production when activating $\mathrm{Cu}$ loaded SSZ-13 (3.7 wt\% $\mathrm{Cu}$ ) in $\mathrm{He}$ at $450{ }^{\circ} \mathrm{C}$. A productivity of $10 \mu \mathrm{mol} / \mathrm{g}$ or $0.018 \mathrm{~mol}_{\mathrm{MeOH}} / \mathrm{mol}_{\mathrm{Cu}}$ was reported. Pappas et al. ${ }^{27}$ found 4.7 $\mu \mathrm{mol} / \mathrm{g}$ or $0.008 \mathrm{~mol}_{\mathrm{MeOH}} / \mathrm{mol}_{\mathrm{Cu}}$ when activating in $\mathrm{He}$ at $500{ }^{\circ} \mathrm{C}(\mathrm{SSZ}-13 ; \mathrm{Si} / \mathrm{Al}=12 ; \mathrm{Cu} / \mathrm{Al}=0.5$; $3.9 \mathrm{wt} \% \mathrm{Cu}$ ); whereas Oord et $_{\text {al. }}{ }^{29}$ detected no methanol when activating in $\mathrm{He}(\mathrm{SSZ}-13$; $\mathrm{Si} / \mathrm{Al}=20$; $\mathrm{Cu} / \mathrm{Al}=0.12 ; 0.95 \mathrm{wt} \% \mathrm{Cu})$. However, it is hard to envisage that the very minor productivities observed upon activation in inert represents anything beyond a curiosity.

However, other oxidants than oxygen/air have been investigated. Sheppard et al. ${ }^{178}$ employed NO (and $\mathrm{N}_{2} \mathrm{O}$ ) as the oxidant for $\mathrm{Cu}$ loaded ZSM-5. When using $\mathrm{NO}$, it was possible to operate isothermally, i.e. all three steps of the chemical looping were carried out at $150{ }^{\circ} \mathrm{C}$, which has obvious advantages from a process perspective. However, the productivities were lower than those observed using $\mathrm{O}_{2}$ activation at $500{ }^{\circ} \mathrm{C}$. Sushkevich et al. ${ }^{170}$ were able to demonstrate that the oxidation can be facilitated by a combination of steam treatment (extraction) at $200^{\circ} \mathrm{C}$ followed by a thermal treatment in inert at $400{ }^{\circ} \mathrm{C}$ over $\mathrm{Cu}$ loaded mordenite. A key feature of this protocol is the loading of methane at high pressures $\left(7\right.$ bar). A productivity of $0.204 \mathrm{~mol}_{\mathrm{MeOH}} / \mathrm{mol}_{\mathrm{Cu}}$ was reported after several reaction cycles. $^{170}$

Ipek and $\mathrm{Lobo}^{24}$ also investigated the use of $\mathrm{N}_{2} \mathrm{O}$, and were able to run the oxidation reaction catalytically, i.e. not using chemical looping (for a number of zeolites, including SSZ-13; Si/Al = 12; $\mathrm{Cu} / \mathrm{Al}=0.4 ; 3.1 \mathrm{wt} \% \mathrm{Cu}$ ). The maximum rate of methanol production was $55 \mu \mathrm{mol} / \mathrm{gh}$ The catalytic reaction was carried out at $300{ }^{\circ} \mathrm{C}$ with $30.4 \mathrm{kPa}$ of $\mathrm{CH}_{4}, 30.4 \mathrm{kPa}$ of $\mathrm{N}_{2} \mathrm{O}, 3.2 \mathrm{kPa}$ of $\mathrm{H}_{2} \mathrm{O}$, and 37.3 $\mathrm{kPa} \mathrm{He}$. The methane conversion was $0.75 \%$, and the selectivity to methanol was $2.3 \%$; the main products were $\mathrm{CO}$ and $\mathrm{CO}_{2} .{ }^{24}$ Finally, Narsimham et al. ${ }^{172}$ also reported a catalytic production of methanol, now using oxygen as the oxidant. A wide range of $\mathrm{Cu}$ loaded zeolite frameworks were investigated. The highest activity was reported for $\mathrm{Cu}$ loaded SSZ-13 $(\mathrm{Si} / \mathrm{Al}=13.8 ; \mathrm{Cu} / \mathrm{Al}=0.50$; $3.5 \mathrm{wt} \% \mathrm{Cu}$ ) at a value of $3.12 \mu \mathrm{mol} / \mathrm{gh}$. The reaction temperature was $210{ }^{\circ} \mathrm{C}$ with $98.1 \mathrm{kPa}^{\circ} \mathrm{CH}_{4}$, $0.0025 \mathrm{kPa}$ of $\mathrm{O}_{2}$, and $3.2 \mathrm{kPa}$ of $\mathrm{H}_{2} \mathrm{O} .{ }^{172}$

\subsubsection{Spectroscopic insights into the MTM conversion over $\mathrm{Cu}-\mathrm{SSZ}-13$}

Due to the relatively recent demonstration of MTM activity over $\mathrm{Cu}-\mathrm{CHA}$-based materials, the number of advanced characterization results reported in this context is still limited, especially if 
compared with the much more studied $\mathrm{Cu}-\mathrm{MOR}$ and $\mathrm{Cu}-\mathrm{MFI}$ zeolites. ${ }^{28,}$, 53, 65, 66, 127, 147, 148, 150, 170, 177 , 179-182 Nonetheless, in the last two years, a few studies appeared ${ }^{22,25,27,29}$ employing XAS and UVVis-NIR spectroscopy under in situ and operando conditions to monitor the MTM reaction over Cu$\mathrm{CHA}$, aiming to identify the spectroscopic fingerprints of the methane-converting $\mathrm{Cu}$-active sites in the CHA framework.

In the above-mentioned work by Pappas et al. ${ }^{27}$ beside the detailed investigation of the reaction parameters discussed in Section 3.2.2, the authors have combined laboratory activity measurements with in situ/operando XAS to explore the MTM conversion over $\mathrm{Cu}$-SSZ-13 for a wide range of material compositions and reaction conditions, aiming at establishing structure-activity relationships (Fig. 21a-c).

In particular, the authors employed operando XAS to track the oxidation state and average coordination environment of the $\mathrm{Cu}$ ions in a $\mathrm{Cu}-\mathrm{SSZ}-13$ sample with $\mathrm{Si} / \mathrm{Al}=12, \mathrm{Cu} / \mathrm{Al}=0.5$ during each step of the process, including $\mathrm{O}_{2}$-activation at $500{ }^{\circ} \mathrm{C}$, cooling in $\mathrm{O}_{2}$ to $200{ }^{\circ} \mathrm{C}, \mathrm{CH}_{4}$ loading at $200{ }^{\circ} \mathrm{C}$ and steam-assisted methanol extraction at $200^{\circ} \mathrm{C}$. XAS revealed tri-coordinated frameworkinteracting $\mathrm{Cu}$ (II) centers as the dominant species in the $\mathrm{O}_{2}$-activated state at $500{ }^{\circ} \mathrm{C}$, while cooling to $200{ }^{\circ} \mathrm{C}$ in $\mathrm{O}_{2}$ promote an increase in the average first-shell $\mathrm{Cu}$ coordination number, tentatively associated with a temperature-induced modification in the oxygen binding mode in $\mathrm{Z}\left[\mathrm{Cu}(\mathrm{II}) \mathrm{O}_{2}{ }^{\circ}\right]$ superoxo moieites. ${ }^{27}$ During methane loading, XANES linear combination fit indicated the $\mathrm{Cu}(\mathrm{II})$ to $\mathrm{Cu}(\mathrm{I})$ reduction for $27 \%$ of the $\mathrm{Cu}$ sites, in line with previous reports on $\mathrm{Cu}-\mathrm{MOR} .{ }^{150,}{ }^{181}$ During steam-assisted methanol extraction, the fraction of $\mathrm{Cu}(\mathrm{I})$ present in the system is observed to diminish to $14 \%$ together with the formation of $24 \%$ of mobile $\mathrm{Cu}(\mathrm{II})$ aquo complexes. It is thus clear that, also over $\mathrm{Cu}-\mathrm{CHA}$, the MTM process involves reversible redox chemistry at $\mathrm{Cu}$ sites. ${ }^{27}$

To obtain deeper insights in the nature of the active sites, Pappas et al. ${ }^{27}$ also explored the impact of different pre-treatments by combining in situ XAS with activity measurements (Fig. 21a). Hightemperature reaction with $\mathrm{O}_{2}$, yielding the XAS signature of a tridentate, framework-interacting $\mathrm{Cu}$ (II) species, is again evidenced as a key requirement to form the methane-converting active sites. The impact of the composition $(\mathrm{Cu} / \mathrm{Al}$ and $\mathrm{Si} / \mathrm{Al}$ ratios) on the normalized productivity and its correlation with $\mathrm{Cu}$-speciation was also investigated. Notably, a positive linear correlation was discovered between the normalized methanol productivity and the reducibility of the Cu centres under high-temperature treatment in He, as evaluated from XANES (Fig. 21a). ${ }^{27}$ Here, for a quantitative determination of the fraction of $\mathrm{ZCu}(\mathrm{I})$ formed, the authors employed previous results from MCR analysis of the large composition-dependent XANES dataset ${ }^{52}$ described in Section 2.2.3 (see in particular Fig. 12 and Fig. 13).

The authors rationalized the effect of composition on the normalized methanol productivity according to the scheme reported in Fig. 21c. High populations of bare $2 \mathrm{Al} \mathrm{Z}_{2} \mathrm{Cu}$ (II) sites, favored at low Si/Al ratios, inhibit the performance of the material: these redox-resistant species are completely inactive for the conversion. $\mathrm{Z}[\mathrm{Cu}(\mathrm{II}) \mathrm{OH}]$ complexes are instead identified as possible precursors to the active sites, though their ability to undergo self-reduction. This is optimal at intermediate $\mathrm{Si} / \mathrm{Al}$ ratios, while, as pointed out in section 2.2.3.1, it becomes hampered at high $\mathrm{Si} / \mathrm{Al}$. As also supported by FTIR and Raman analysis of $\mathrm{O}_{2}$-activated $\mathrm{Cu}$-SSZ-13 (see section 2.1.2, see Fig. 4d,e), $\mathrm{Z}[\mathrm{Cu}(\mathrm{II}) \mathrm{OH}]$ species are progressively depleted during high-temperature oxidative treatment, evolving towards different mono- and multimeric $\mathrm{Cu}(\mathrm{II})$ /active-oxygen species, among which the MTM active sites should be searched. 

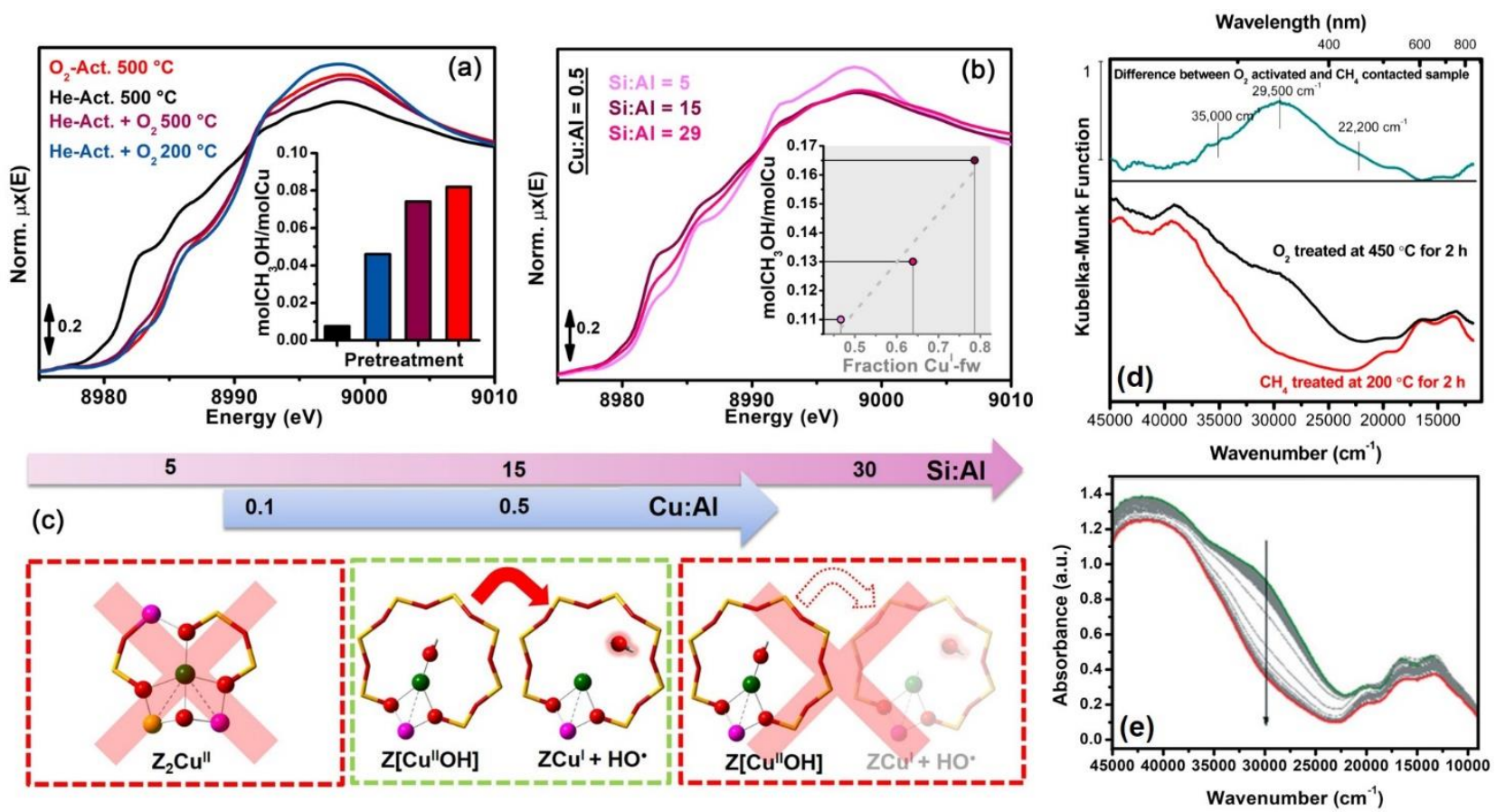

Fig. 21. Parts (a)-(b): in situ XANES spectra collected for: (a) $\mathrm{Cu}-\mathrm{SSZ}-13$ with $\mathrm{Cu} / \mathrm{Al}=0.5, \mathrm{Si} / \mathrm{Al}=12$ after different pre-treatments (inset: corresponding normalized $\mathrm{CH}_{3} \mathrm{OH}$ productivities); (b) He-activated Cu-SSZ-13 with $\mathrm{Cu} / \mathrm{Al}=0.5$ and $\mathrm{Si} / \mathrm{Al}$ ratio of 5, 15 and 29 (inset: linear correlation between the normalized productivity and the fraction of $\mathrm{ZCu}(\mathrm{I})$ species in the He-activated state. Part (c): rationalization of the effect of composition on the productivity for the MTM conversion over $\mathrm{Cu}-\mathrm{SSZ}-13$. Part (d): in situ UV-Vis spectra collected on a Cu-SSZ-13 sample $(\mathrm{Si} / \mathrm{Al}=12, \mathrm{Cu} / \mathrm{Al}=0.4)$ after $\mathrm{O}_{2}$ treatment at $450{ }^{\circ} \mathrm{C}$ (black) followed by $2 \mathrm{~h} \mathrm{CH}_{4}$ treatment at $200{ }^{\circ} \mathrm{C}$ (red). The difference spectrum is shown in green in the top panel. Before the spectra were collected, the sample was cooled to room temperature. Note that small changes in sample position after each treatment render comparison of spectral intensities only qualitative. (e) Operando $\mathrm{UV}-\mathrm{Vis}$ spectra of $\mathrm{Cu}-\mathrm{SSZ}-13\left(\mathrm{Si} / \mathrm{Al}=20\right.$ and $1.21 \mathrm{Cu}$ wt \%, same sample investigated during $\mathrm{O}_{2}$ and He-activation, see Fig. 4b,c) during methane addition from at 60 to $200{ }^{\circ} \mathrm{C}$ (68 min or 68 scans are shown), arrows indicate the time evolution, the green spectrum is the starting point of the experiment, while the red spectrum is the endpoint. Parts (a)-(c): unpublished figures reporting data published in ref. ${ }^{27}$ Part (d): adapted by permission of the American Chemical Society (copyright 2017) from ref. ${ }^{25}$ Part (e): adapted with permission of the Royal Chemical Society (copyright 2018) from ref. ${ }^{29}$.

Additional insights into the nature of the active site for MTM conversion over in $\mathrm{Cu}-\mathrm{SSZ}-13$ have been provided in the recent reports by Ipek et al. ${ }^{25}$ and Oord et al., ${ }^{29}$ where the reactivity of $\mathrm{O}_{2-}$ activated $\mathrm{Cu}-\mathrm{SSZ}-13$ towards $\mathrm{CH}_{4}$ has been monitored by UV-Vis spectroscopy. Ipek et al. worked under in situ conditions, reporting UV-Vis data for a $\mathrm{Cu}$-SSZ-sample with $\mathrm{Cu} / \mathrm{Al}=0.4$ and $\mathrm{Si} / \mathrm{Al}=$ $12, \mathrm{O}_{2}$-treated at $450{ }^{\circ} \mathrm{C}$ for $2 \mathrm{~h}$, and subsequently exposed to $\mathrm{CH}_{4}$ at $200{ }^{\circ} \mathrm{C}$ for $2 \mathrm{~h}$ (Fig. $21 \mathrm{~d}$ ). ${ }^{25}$ Oord et al. performed operando measurements monitoring the evolution of the UV-Vis spectrum of a Si/Al $=20,1.21 \mathrm{Cu}$ wt \% Cu-SSZ-13 sample (pre-activated in $\mathrm{O}_{2}$ at $450{ }^{\circ} \mathrm{C}$, see Fig. $4 \mathrm{~b}$ in section 2.1.2) during $\mathrm{CH}_{4}$ addition from at $60{ }^{\circ} \mathrm{C}$ to $200{ }^{\circ} \mathrm{C}$ (Fig. 21e). ${ }^{29}$

In both cases, the CT band at $\sim 29000 \mathrm{~cm}^{-1}$, already discussed in sections 2.1 .2 and 2.2.2, is well visible after high-temperature activation in $\mathrm{O}_{2}$. Crucially, this band is observed to clearly decrease upon/after interaction with $\mathrm{CH}_{4}$ (see the arrow in Fig. 21e), indicating that the $\mathrm{Cu}$-species responsible of the $29000 \mathrm{~cm}^{-1}$ band are reacting with $\mathrm{CH}_{4}$. Similar observations were previously reported for $\mathrm{Cu}-$ MOR and Cu-ZSM-5, ${ }^{147,}{ }^{148,}{ }^{150}$ although in these cases the relevant CT bands, decreasing in the presence of $\mathrm{CH}_{4}$, occur at different wavenumbers $\left(31000 \mathrm{~cm}^{-1}\right.$ for $\mathrm{Cu}-\mathrm{MOR}^{150}$ and $22700 \mathrm{~cm}^{-1}$ for $\left.\mathrm{Cu}-Z \mathrm{ZSM}-5^{147}\right)$. These lines of evidences corroborate that a $\mathrm{Cu}(\mathrm{II})$ species associated with an activated-oxygen, giving rise to the characteristic CT band observed around $\sim 29000 \mathrm{~cm}^{-1}$ in $\mathrm{O}_{2}-$ activated $\mathrm{Cu}-\mathrm{SSZ}-13$, could also represent the active site for the MTM conversion over this material.

Globally, the recent spectroscopic results reviewed in this section mark a first step towards an improved understanding of methane activation over $\mathrm{Cu}$-CHA-based systems, crucial to advance in the design of materials with an optimal density of active sites for the MTM reaction. 


\section{Industrial application}

\section{1. $\mathrm{NH}_{3}-\mathrm{SCR}$ for diesel vehicle $\mathrm{NO}_{\mathrm{x}}$ emission control}

The first $\mathrm{NH}_{3}$-SCR systems for heavy-duty vehicles came on the market in 2005, and were based on $\mathrm{V}_{2} \mathrm{O}_{5} / \mathrm{WO}_{3} / \mathrm{TiO}_{2}$, similar to the already existing de- $\mathrm{NO}_{\mathrm{x}}$ catalyst used in stationary power stations. However, the highly dynamic conditions encountered in diesel vehicle emissions, early lead to the search for improved catalysts that could combine low temperature activity with high temperature stability. The potential of metal exchanged zeolites for such application was quickly identified, but despite significant research efforts for more than two decades, it was not until the discovery of the small pore $\mathrm{Cu}-\mathrm{CHA}$, that zeolite catalysts would have a breakthrough on the diesel vehicle market. $\mathrm{Cu}$-CHA catalysts are very efficient and robust catalysts and able to meet the EuroVI requirements for removal of $\mathrm{NO}_{\mathrm{x}}$ from mobile diesel engine exhaust gases, also under real driving emissions (RDE). ${ }^{183}$ They are therefore the preferred choice for modern $\mathrm{NH}_{3}$-SCR technology in diesel vehicle applications in particular for engines with displacement $>2$ liters.

A modern commercial SCR emission control system for diesel engines comprises several key components (see top part of Fig. 22), such as a diesel oxidation catalyst (DOC), a diesel particulate filter (DPF), the SCR catalyst, and an ammonia slip catalyst (ASC). The effect of the individual components on the composition of the exhaust gas is shown schematically in the bottom part of Fig. 22.

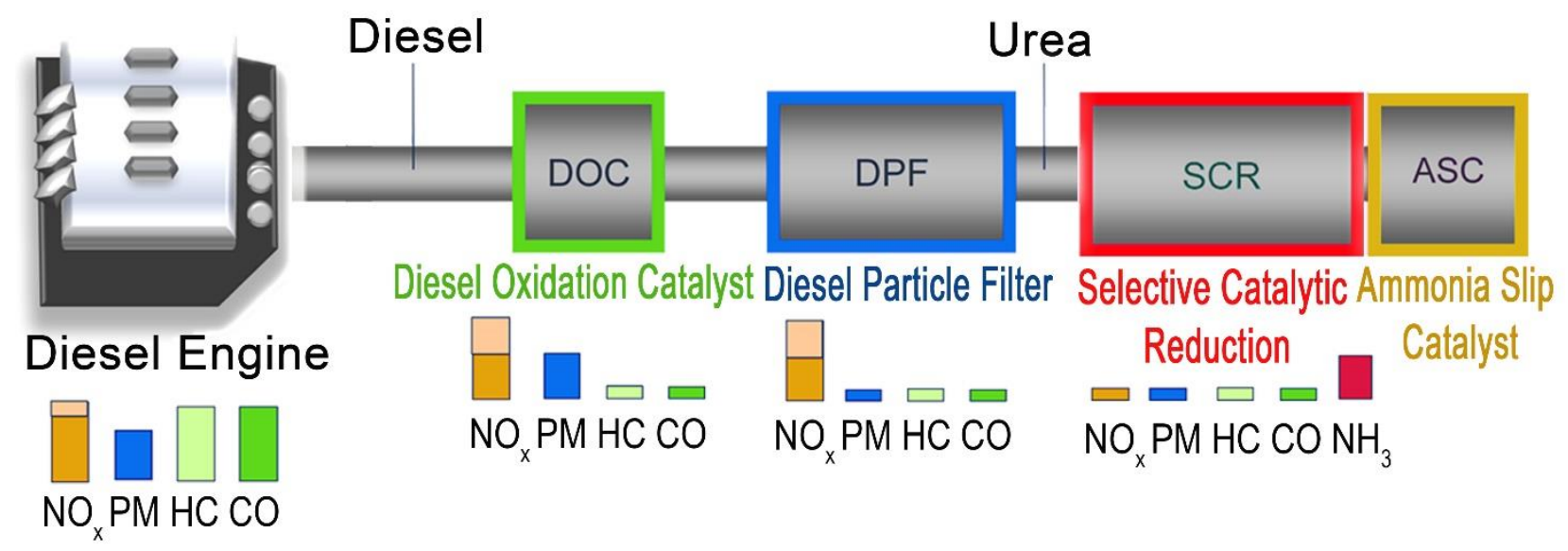

Fig. 22. Top: scheme of the different key components in a modern commercial SCR emission control system for diesel engines. Bottom: qualitative indication of the content of the different pollutants at the successive stages of the SCR emission control system.

In the DOC, hydrocarbons ( $\mathrm{HC}$ ) and $\mathrm{CO}$ are oxidized to $\mathrm{CO}_{2}$. Some particulate matter (PM) and NO are oxidized as well. The heat produced in the DOC and the increased ratio of $\mathrm{NO}_{2}$ to $\mathrm{NO}$ is beneficial for the effectiveness of the Cu-zeolite based SCR. The DPF effectively reduces the PM, but the trapped carbon particles need to be removed periodically by combustion, inducing very high temperature spikes which the downstream SCR catalyst needs to withstand. Just before the SCR component, urea is spray-dosed into the exhaust gas, where it decomposes to form $\mathrm{NH}_{3}$ and $\mathrm{CO}_{2}$. The urea dosing system is one of the most critical parts in the exhaust after-treatment system, since enough $\mathrm{NH}_{3}$ needs to be added to convert all the $\mathrm{NO}_{\mathrm{x}}$, but a large excess should be avoided in order to reduce the $\mathrm{NH}_{3}$ slip. In practice, a small excess of $\mathrm{NH}_{3}$ is usually added which is handled by the ASC. The slip catalyst combines balanced amounts of an oxidation and a SCR component to oxidize part of the excess $\mathrm{NH}_{3}$ to $\mathrm{NO}_{x}$ and the final mixture into $\mathrm{H}_{2} \mathrm{O}$ and $\mathrm{N}_{2}$.

More recent developments focus on intensification of the after-treatment system by combining DOC/DPF and SCR in a multifunctional catalytic body in order to improve the heat management and reduce the size/weight of the overall system. ${ }^{184}$ 
4.1.1. Market considerations. Despite the higher energy conversion efficiency of diesel versus gasoline engines, and the related potentially lower emissions of $\mathrm{CO}_{2}$, diesel vehicles are still in the focus of the public debate.

This is mainly related to the inherent higher emissions of nitrogen oxides $\left(\mathrm{NO}_{\mathrm{x}}\right)$ and $\mathrm{PM}$ for diesel engines compared to spark-ignition engines. The public debate was enlivened on the one hand by the fact that many of the diesel vehicles on our roads today are not equipped with the latest exhaust gas treatment technology and on the other hand by the deceptive practice of several car producers to reduce or circumvent the exhaust gas treatment under real driving conditions (as opposed to laboratory tests). Since the protection of air quality is however a priority to the European Commission (EC), stricter regulations and testing procedures are likely to be further implemented in the very near future. For example, and as a direct consequence of the so-called Dieselgate, ${ }^{185}$ the EC introduced in September 2017 a modification of the Euro 6 regulations, by a new test protocol for diesel passenger cars which mimics the RDE and uses portable emission measurement systems (PEMS). In November 2017, the EC proposed a revision of the "Clean Vehicles Directive" from 2009, which is expected to enter into force by September 2018. ${ }^{186}$ The revised directive should deliver incentives to invest in fuel-efficient and low-emitting vehicles. Some regulations might even be adapted beforehand by individual states. This has recently happened in the case of the federal administrative court of Germany, which approved a ban on driving for diesel vehicles that are not conform with Euro VI standards, in case that the legal threshold values for $\mathrm{NO}_{\mathrm{x}}$ and $\mathrm{PM}$ in the air are exceeded. ${ }^{187}$ It is obviously very difficult to predict reliably the market for diesel vehicles in the short- and mid-term future. Clearly, the European vehicle market is moving towards zero emission and plug-in hybrid vehicles (based fully or partly on battery technology), but the share of these vehicles will probably not exceed $20 \%$ within the next two decades. ${ }^{188}$ It is therefore expected that the short- and mid-term market (5-15 years ahead) for $\mathrm{Cu}-\mathrm{CHA}$ catalysts is rapidly increasing due to the high demand.

\subsection{Direct conversion of methane to methanol}

Catalytic oxidations belong to the most important reactions in the current chemical industry, accounting for $\sim 30 \%$ of the total world production in chemicals. One of the most challenging selective oxidation reactions is the one where methane is partially oxidized to methanol while at the same time avoiding complete oxidation to $\mathrm{CO}_{2}$ and water. As all current routes for exploitation of methane rely on syngas as an intermediate, a low temperature activation and transformation of methane into methanol is commonly considered a dream reaction due to its enormous industrial potential. The direct conversion of MTM has attracted the attention of researchers in academia and industry for over half a century and a multitude of homogeneous and heterogeneous catalytic systems have been explored. Despite significant advancement in selected cases, ${ }^{189,} 190$ the inherent dilemma of not being able to achieve high conversion of methane and concurrent high methanol selectivity seems to persist in all cases.

As already mentioned in Section 3.2, the reaction over metal loaded zeolites, is currently carried out in a cyclic, i.e. non-catalytic way. It basically comprises three steps; i) oxidation; ii) methane loading; iii) steam assisted product release. Thus, these three steps involve different atmospheres, and also different temperatures. It is clear that such complex process operations cannot easily be realized on an industrial scale. This would, at the very minimum, involve non-standard (and expensive) engineering concepts such as employing a set of swing reactors cyclically exposed to different environments or circulating fluidized bed (CFB) technology.

On the other hand, the separation of the oxidation reaction (contact with gaseous oxygen) and the reaction of the substrate with an activated surface oxygen (in the absence of gaseous oxygen) might be the only feasible way of circumventing the above stated conversion-selectivity dilemma. In principle, one could envisage a CFB process similar to the rather recently developed technology known as chemical looping combustion (CLC), where a metal oxide is usually employed as oxygen carrier to combust a hydrocarbon fuel. ${ }^{191}$ 
At the lack of any process layout, not to mention process engineering data, but the one reported in the open literature where the reaction is performed stepwise in bench scale reactors, it is impossible to assess reliably the suitability of metal loaded zeolites for any kind of industrial process. In the following we therefore can only outline some general considerations for a chemical looping type of process.

The most important requirements for any oxygen carrier in a chemical looping process are a high oxygen capacity, fast up-take and release kinetics and both chemical and mechanical durability. The active oxygen capacity of metal loaded zeolites can be estimated from the best methanol yields reported in the literature. As mentioned in section 3.2, so far the highest productivity values for $\mathrm{Cu}-$ MOR and $\mathrm{Cu}-\mathrm{CHA}$ samples are reported to be 170 and $132 \mu \mathrm{mol}_{\mathrm{MeOH}} / \mathrm{g}_{\text {cat }}$ (per cycle) respectively. The oxygen and methane up-take and methanol release kinetics have not been determined precisely, but the data from Pappas et al. (Fig. 20) indicates that oxygen activation is slow and the required methane contact time is high. Both parameters are therefore not in favor of a fast looping process and hence would negatively affect the overall productivity.

Moulijn et al. ${ }^{192}$ have pointed out that for most processes encountered in oil refineries and chemical industry, the reaction rates are rarely less than 1 and seldom more than $10 \mathrm{~mol}$ product $/ \mathrm{m}^{3}$ reactor $\mathrm{s}$. The catalytic productivity reported by Ipek and $\mathrm{Lobo}^{24}$ of $55 \mu \mathrm{mol} / \mathrm{gh}$ corresponds to 0.015 $\mathrm{mol}_{\text {product }} / \mathrm{m}^{3}$ reactor $\mathrm{s}$, assuming a reactor filling density of $1 \mathrm{~g} / \mathrm{cm}^{3}$. One can analyze the data reported for chemical looping in an analogous manner. For SSZ-13, the highest productivity reported so far is $132 \mu \mathrm{mol} / \mathrm{g} .{ }^{27}$ Aiming for a rate of $1 \mathrm{~mol}_{\text {product }} / \mathrm{m}^{3}$ reactor $\mathrm{s}$, one arrives at a target cycle time of ca. 2 min. One could imagine improvements in catalyst performance. Assuming a maximum $\mathrm{Cu}$ loading of $10 \mathrm{wt} \%$ and a maximum productivity of $0.5 \mathrm{~mol} \mathrm{MeOH}_{\mathrm{Hol}} / \mathrm{mol}_{\mathrm{Cu}}$, corresponding to a dimeric active site, a productivity close to $800 \mu \mathrm{mol} / \mathrm{g}$ would be the maximum achievable. This would lead to a target cycle time of ca. $13 \mathrm{~min}$, which one could compare to the total cycle time of ca. $20 \mathrm{~h}$ for the optimized protocol reported by Pappas et al. ${ }^{27}$ Of course, many parameters such as very basic things like heat input and selectivities have not been considered here. However, these very simplified "back of the envelope" estimations do indicate that there is still some way to go.

It is clear that technology and catalyst development for a commercial MTM process are still in the fledgling stages. In addition, any new development will have to compete with one of the most mature processes in chemical industries, i.e. the syngas based large scale methanol synthesis. From a purely economic point of view it will therefore be difficult to justify the investment into a new technology. However, a driver for the development could be a changing legislation with respect to flaring of associated gas. So far, only legally non-binding agreements have been pursued, such as the "Zero Routine Flaring by 2030" initiative, led by the world bank. ${ }^{193}$ Compared to $\mathrm{CO}_{2}$, methane is a much more powerful greenhouse gas and has a much shorter lifetime in the atmosphere. The possibility to selectively convert methane directly to higher value products, in particular for small scale applications, might therefore be a viable way to meet the short and long-term targets for climate change mitigation.

\section{Conclusions and perspectives}

The aim of this review was manifold: we wanted to provide the reader with a comprehensive overview on the structural complexity of $\mathrm{Cu}-\mathrm{CHA}$ materials and show that despite this complexity it is possible to obtain a rather detailed picture of the $\mathrm{Cu}$-speciation within the $\mathrm{CHA}$ topology by applying advanced characterization tools. The observed complexity can be rationalized by considering the interplay between chemical composition of the material and the chemical potential of the environment. Once one is equipped with this insight, it is possible to use the available functionalities of the material and obtain catalysts with unique properties. One of the most surprising observations is that the active state of the currently best low temperature $\mathrm{NH}_{3}$-SCR catalyst is in fact so dynamic that it does not anymore 
fit into the classical definition of a heterogeneous catalyst, but should be considered a hybrid system, consisting of an active molecular entity that "lives in symbiosis" with an inorganic solid framework.

There are other prominent catalytic systems which show similar characteristics, like for example the industrial catalyst for sulfuric acid synthesis, which consists of a molecular molten active phase entrapped in a solid silica matrix. That system exists as such for more than 60 years and is used to produce one of the largest bulk chemicals in the world and still we are far away from understanding the nature of its active sites.

When the reaction temperature is increased, the $\mathrm{Cu}-\mathrm{CHA}$ system changes, as the mobile $\mathrm{Cu}-$ species lose their ligands and find docking sites at the internal walls of the zeolite framework. Now, the internal surface of the catalyst is covered with a range of less dynamic, but still highly active sites. Those sites are probably similar to the ones that are encountered in classical selective oxidation catalysts such as (mixed) oxides.

So, if we come back to the title of this review, we believe that $\mathrm{Cu}-\mathrm{CHA}$ can indeed be considered a model system for applied redox catalysis. The activation of molecular oxygen is key to any selective oxidation reaction and the insight that we are able to obtain from the $\mathrm{Cu}-\mathrm{CHA}$ system can be very useful to rationalize much more complex existing industrial systems. The ability to study in detail the fundamental steps of the redox-chemistry involved, might even allow to develop new concepts which are certainly needed to tackle some of the most urgent challenges related to energy conversion and climate change mitigation. The field is still new, further discoveries and improvements appear in the literature literally every month, and the underlying chemistry is fascinating.

\section{Abbreviations}

$1 \mathrm{Al} \mathrm{Z} \quad$ fraction of the zeolite framework characterized by only one $\mathrm{Al}$ in the proximity

$2 \mathrm{Al} \mathrm{Z} \mathrm{Z}_{2} \quad$ fraction of the zeolite framework characterized by two $\mathrm{Al}$ in the proximity

$4 r$

$6 r$ four-membered rings

six-membered rings

8r eight-membered rings

ALS alternating least square

ASC ammonia slip catalyst

CFB circulating fluidized bed

CLC chemical looping combustion

CHA chabazite framework

CT charge transfer

$d 6 r \quad$ double six-membered ring

DFT density functional theory

DOC diesel oxidation catalyst

DPF diesel particulate filter

DR diffuse-reflectance

EC European commission

EPR election paramagnetic resonance

ESRF European synchrotron radiation facility

EXAFS X-ray absorption fine structure

FID flame ionization detector

FTIR Fourier-transform IR

FWHM full width at half maximum

GC gas chromatography

HC hydrocarbons

HERFD high energy resolution fluorescence detected (XANES) 


$\begin{array}{ll}\text { HF } & \text { high-frequency } \\ \text { ICP } & \text { inductively coupled plasma (mass spectrometry) } \\ \text { IR } & \text { infra-red } \\ \text { LCF } & \text { linear combination fit } \\ \text { LF } & \text { low-frequency } \\ \text { MAS NMR } & \text { magic angle spinning NMR } \\ \text { MCR } & \text { multivariate curve resolution } \\ \text { MFI } & \text { ZSM-5 framework } \\ \text { MOR } & \text { mordenite framework } \\ \text { MS } & \text { mass spectrometry } \\ \text { MTM } & \text { methane to methanol } \\ \text { MTO } & \text { methanol into light olefins } \\ \text { NIR } & \text { near infra-red } \\ \text { NMR } & \text { nuclear magnetic resonance } \\ \text { PC } & \text { principal component } \\ \text { PCA } & \text { principal component analysis } \\ \text { PCO } & \text { CO equilibrium pressure } \\ \text { PEMS } & \text { portable emission measurement systems } \\ \text { PN2 } & \text { N2 equilibrium pressure } \\ \text { PNO } & \text { NO equilibrium pressure } \\ \text { PM } & \text { particulate matter } \\ \text { PXRD } & \text { powder X-ray diffraction } \\ \text { RDE } & \text { real driving emissions } \\ \text { RT } & \text { room temperature } \\ \text { SAPO } & \text { silicon-aluminophosphate } \\ \text { SCR } & \text { selective catalytic reduction } \\ \text { TPR } & \text { temperature programmed desorption } \\ \text { UV-Vis } & \text { ultraviolet-visible } \\ \text { XANES } & \text { X-ray absorption near edge structure } \\ \text { XAS } & \text { X-ray absorption spectroscopy (both XANES and EXAFS) } \\ \text { XES } & \text { X-ray emission spectroscopy } \\ & \end{array}$

\section{Acknowledgements}

This publication forms a part of the iCSI (industrial Catalysis Science and Innovation) Centre for Research-based Innovation, which receives financial support from the Research Council of Norway under contract no. 237922. CL acknowledges the Mega-grant of the Russian Federation Government to support scientific research at Southern Federal University, No. 14.Y26.31.0001. EB acknowledges Innovation Fund Denmark (Industrial postdoc n. 5190-00018B). We are deeply indebted with many colleagues from different institutions working in the context of a fruitful and stimulating collaboration on $\mathrm{Cu}$-zeolite catalysts, for insightful discussions and support on chemistry and catalysis of the studied materials as well as on data collection and analysis. In particular we thank: G. Berlier, F. Giordanino, A. Lazzarini, K. A. Lomachenko, C. Negri, A. Martini, M. Signorile from University of Turin (Italy); H. Falsig, L. F. Lundegaard, C. Tyrsted, S. Teketel, S. B. Rasmussen, P. Vennestrøm and T.V.W. Janssens from Haldor Topsøe A/S (Denmark); M. M. Dyballa, D. K. Pappas and K. P. Lillerud from University of Oslo (Norway); A. Godiksen and S. Mossin, from Technical University of Denmark; C. Andersen, M. Bremholm and B. Iversen from University of Åarhus (Denmark); A. A. Guda, K. A. Lomachenko, I. A. Pankin and A. V. Soldatov, from Southern Federal University (Russia); G. Agostini, R. Baran, H. Emerich, E. Gallo, P. Glatzel, A. Longo, K. A. Lomachenko, O. Mathon, M. Monte Caballero and W. Van Beek, from the European Synchrotron Radiation Facility (ESRF, France). For all collaborators, the reported affiliations refer to the time where the collaboration occurred and not the present ones. 


\section{References}

1. L. S. Dent and J. V. Smith, Nature, 1958, 181, 1794.

2. J. V. Smith, F. Rinaldi and L. S. D. Glasser, Acta Cryst., 1963, 16, 45.

3. J. J. Pluth, J. V. Smith and W. J. Mortier, Mater. Res. Bull., 1977, 12, 1001.

4. U.S. Patent US4544538 A, 1985.

5. B. M. Lok, C. A. Messina, R. L. Patton, R. T. Gajek, T. R. Cannan and E. M. Flanigen, J. Am. Chem. Soc., 1984, 106, 6092.

6. C. Andersen, M. Bremholm, P. Vennestrøm, A. Blichfeld, L. Lundegaard and I. B., IUCrJ, $2014,1,382$.

7. S. Bordiga, L. Regli, D. Cocina, C. Lamberti, M. Bjorgen and K. P. Lillerud, J. Phys. Chem. B, $2005,109,2779$.

8. R. Martinez-Franco, M. Moliner, C. Franch, A. Kustov and A. Corma, Appl. Catal. B-Environ., 2012, $127,273$.

9. U. Olsbye, S. Svelle, M. Bjorgen, P. Beato, T. V. W. Janssens, F. Joensen, S. Bordiga and K. P. Lillerud, Angew. Chem.-Int. Edit., 2012, 51, 5810.

10. J. H. Kwak, R. G. Tonkyn, D. H. Kim, J. Szanyi and C. H. F. Peden, J. Catal., 2010, 275, 187.

11. J. H. Kwak, D. Tran, S. D. Burton, J. Szanyi, J. H. Lee and C. H. F. Peden, J. Catal., 2012, $287,203$.

12. U. Deka, A. Juhin, E. A. Eilertsen, H. Emerich, M. A. Green, S. T. Korhonen, B. M. Weckhuysen and A. M. Beale, J. Phys. Chem. C, 2012, 116, 4809.

13. J. Xue, X. Wang, G. Qi, J. Wang, M. Shen and W. Li, J. Catal., 2013, 297, 56.

14. F. Gao, E. D. Walter, E. M. Karp, J. Luo, R. G. Tonkyn, J. H. Kwak, J. Szanyi and C. H. F. Peden, J. Catal., 2013, 300, 20.

15. U. Deka, I. Lezcano-Gonzalez, B. M. Weckhuysen and A. M. Beale, ACS Catal., 2013, 3, 413.

16. D. E. Doronkin, M. Casapu, T. Gunter, O. Muller, R. Frahm and J. D. Grunwaldt, J. Phys. Chem. C, 2014, 118, 10204.

17. A. M. Beale, F. Gao, I. Lezcano-Gonzalez, C. H. F. Peden and J. Szanyi, Chem. Soc. Rev., 2015, 44, 7371.

18. T. V. W. Janssens, H. Falsig, L. F. Lundegaard, P. N. R. Vennestrøm, S. B. Rasmussen, P. G. Moses, F. Giordanino, E. Borfecchia, K. A. Lomachenko, C. Lamberti, S. Bordiga, A. Godiksen, S. Mossin and P. Beato, ACS Catal., 2015, 5, 2832.

19. J. C. Wang, Z. L. Peng, Y. Chen, W. R. Bao, L. P. Chang and G. Feng, Chem. Eng. J., 2015, $263,9$.

20. M. Moreno-Gonzalez, A. E. Palomares, M. Chiesa, M. Boronat, E. Giamello and T. Blasco, ACS Catal., 2017, 7, 3501 .

21. A. Marberger, A. W. Petrov, P. Steiger, M. Elsener, O. Krocher, M. Nachtegaal and D. Ferri, Nat. Catal., 2018, 1, 221.

22. M. J. Wulfers, S. Teketel, B. Ipek and R. F. Lobo, Chem. Commun., 2015, 51, 4447.

23. A. R. Kulkarni, Z. J. Zhao, S. Siahrostami, J. K. Norskov and F. Studt, ACS Catal., 2016, 6, 6531.

24. B. Ipek and R. F. Lobo, Chem. Commun., 2016, 52, 13401.

25. B. Ipek, M. J. Wulfers, H. Kim, F. Goltl, I. Hermans, J. P. Smith, K. S. Booksh, C. M. Brown and R. F. Lobo, ACS Catal., 2017, 7, 4291.

26. M. H. Mahyuddin, A. Staykov, Y. Shiota, M. Miyanishi and K. Yoshizawa, ACS Catal., 2017, 7, 3741.

27. D. K. Pappas, E. Borfecchia, M. Dyballa, I. A. Pankin, K. A. Lomachenko, A. Martini, M. Signorile, S. Teketel, B. Arstad, G. Berlier, C. Lamberti, S. Bordiga, U. Olsbye, K. P. Lillerud, S. Svelle and P. Beato, J. Am. Chem. Soc., 2017, 139, 14961.

28. M. B. Park, S. H. Ahn, A. Mansouri, M. Ranocchiari and J. A. van Bokhoven, ChemCatChem, $2017,9,3705$.

29. R. Oord, J. E. Schmidt and B. M. Weckhuysen, Catal. Sci. Technol., 2018, 8, 1028.

30. C. Paolucci, A. A. Verma, S. A. Bates, V. F. Kispersky, J. T. Miller, R. Gounder, W. N. Delgass, F. H. Ribeiro and W. F. Schneider, Angew. Chem.-Int. Edit., 2014, 53, 11828.

31. C. Tyrsted, E. Borfecchia, G. Berlier, K. A. Lomachenko, C. Lamberti, S. Bordiga, P. N. R. Vennestrom, T. V. W. Janssens, H. Falsig, P. Beato and A. Puig-Molina, Catal. Sci. Technol., 2016, 6, 8314.

32. J. H. Kwak, T. Varga, C. H. F. Peden, F. Gao, J. C. Hanson and J. Szanyi, J. Catal., 2014, $314,83$.

33. K. A. Lomachenko, E. Borfecchia, C. Negri, G. Berlier, C. Lamberti, P. Beato, H. Falsig and S. Bordiga, J. Am. Chem. Soc., 2016, 138, 12025.

34. K. A. Lomachenko, E. Borfecchia, S. Bordiga, A. V. Soldatov, P. Beato and C. Lamberti, J. Phys.: Conf. Ser., 2016, 712, 012041.

35. C. W. Andersen, E. Borfecchia, M. Bremholm, M. R. V. Jorgensen, P. N. R. Vennestrom, C. Lamberti, L. F. Lundegaard and B. B. Iversen, Angew. Chem.-Int. Edit., 2017, 56, 10367.

36. S. Bordiga, E. Groppo, G. Agostini, J. A. van Bokhoven and C. Lamberti, Chem. Rev., 2013, 113, 1736.

37. J. A. van Bokhoven and C. Lamberti, eds., X-Ray Absorption and X-ray Emission Spectroscopy: Theory and Application, John Wiley \& Sons, Chichester (UK), 2016.

38. C. Lamberti, S. Bordiga, M. Salvalaggio, G. Spoto, A. Zecchina, F. Geobaldo, G. Vlaic and M. Bellatreccia, J. Phys. Chem. B, 1997, 101, 344.

39. A. Zecchina, S. Bordiga, G. T. Palomino, D. Scarano, C. Lamberti and M. Salvalaggio, J. Phys. Chem. B, 1999, 103, 3833.

40. Y. Kuroda, A. Itadani, R. Kumashiro, T. Fujimoto and M. Nagao, Phys. Chem. Chem.Phys., 2004, 6, 2534. 
41. C. Lamberti, G. Spoto, D. Scarano, C. Pazé, M. Salvalaggio, S. Bordiga, A. Zecchina, G. T. Palomino and F. Dacapito, Chem. Phys. Lett., 1997, 269, 500.

42. C. Lamberti, S. Bordiga, A. Zecchina, M. Salvalaggio, F. Geobaldo and C. O. Arean, J. Chem. Soc.-Faraday Trans., 1998, 94, 1519.

43. C. Lamberti, G. T. Palomino, S. Bordiga, G. Berlier, F. D'Acapito and A. Zecchina, Angew. Chem.-Int. Edit., 2000, 39, 2138.

44. C. Prestipino, L. Capello, F. D'Acapito and C. Lamberti, Phys. Chem. Chem. Phys., 2005, 7, 1743.

45. S. T. Korhonen, D. W. Fickel, R. F. Lobo, B. M. Weckhuysen and A. M. Beale, Chem. Commun., $2011,47,800$.

46. E. Borfecchia, K. A. Lomachenko, F. Giordanino, H. Falsig, P. Beato, A. V. Soldatov, S. Bordiga and C. Lamberti, Chem. Sci., 2015, 6, 548.

47. M. Anpo, M. Matsuoka, Y. Shioya, H. Yamashita, E. Giamello, C. Morterra, M. Che, H. H. Patterson, S. Webber, S. Ouellette and M. A. Fox, J. Phys. Chem., 1994, 98, 5744.

48. C. Garino, E. Borfecchia, R. Gobetto, L. Salassa, J. A. van Bokhoven and C. Lamberti, Coord. Chem. Rev., 2014, 277-278 130 .

49. J. Singh, C. Lamberti and J. A. van Bokhoven, Chem. Soc. Rev., 2010, 39, 4754.

50. E. I. Solomon, D. E. Heppner, E. M. Johnston, J. W. Ginsbach, J. Cirera, M. Qayyum, M. T. Kieber-Emmons, C. H. Kjaergaard, R. G. Hadt and L. Tian, Chem. Rev., 2014, 114, 3659.

51. F. Giordanino, E. Borfecchia, K. A. Lomachenko, A. Lazzarini, G. Agostini, E. Gallo, A. V. Soldatov, P. Beato, S. Bordiga and C. Lamberti, J. Phys. Chem. Lett., 2014, 5, 1552.

52. A. Martini, E. Borfecchia, K. A. Lomachenko, I. A. Pankin, C. Negri, G. Berlier, P. Beato, H. Falsig, S. Bordiga and C. Lamberti, Chem. Sci., 2017, 8, 6836.

53. J. A. van Bokhoven and C. Lamberti, in XAFS Techniques for Catalysts, Nanomaterials, and Surfaces, eds. Y. Yasuhiro Iwasawa, K. Asakura and M. Tada, Springer, Switzerland, 2017, ch. 20, pp. 299.

54. C. Lamberti, E. Groppo, G. Spoto, S. Bordiga and A. Zecchina, Adv. Catal., 2007, 51, 1.

55. A. Vimont, F. Thibault-Starzyk and M. Daturi, Chem. Soc. Rev., 2010, 39, 4928.

56. S. Bordiga, C. Lamberti, F. Bonino, A. Travert and F. Thibault-Starzyk, Chem. Soc. Rev., 2015, 44, 7262.

57. C. Lamberti, A. Zecchina, E. Groppo and S. Bordiga, Chem. Soc. Rev., 2010, 39, 4951.

58. F. Giordanino, P. N. R. Vennestrom, L. F. Lundegaard, F. N. Stappen, S. L. Mossin, P. Beato, S. Bordiga and C. Lamberti, Dalton Trans., 2013, 42, 12741.

59. G. Spoto, E. Gribov, S. Bordiga, C. Lamberti, G. Ricchiardi, D. Scarano and A. Zecchina, Chem. Comm., 2004, 23, 2768.

60. S. Bordiga, C. Pazé, G. Berlier, D. Scarano, G. Spoto, A. Zecchina and C. Lamberti, Catal. Today, $2001,70,91$.

61. G. Ricchiardi, A. Damin, S. Bordiga, C. Lamberti, G. Spano, F. Rivetti and A. Zecchina, J. Am. Chem. Soc., 2001, 123, 11409.

62. S. Bordiga, A. Damin, F. Bonino, G. Ricchiardi, C. Lamberti and A. Zecchina, Angew. Chem.-Int. Edit., 2002, 41, 4734.

63. S. Bordiga, A. Damin, F. Bonino, G. Ricchiardi, A. Zecchina, R. Tagliapietra and C. Lamberti, Phys. Chem. Chem. Phys., 2003, 5, 4390.

64. A. Damin, F. Bonino, S. Bordiga, E. Groppo, C. Lamberti and A. Zecchina, ChemPhysChem, $2006,7,342$.

65. J. S. Woertink, P. J. Smeets, M. H. Groothaert, M. A. Vance, B. F. Sels, R. A. Schoonheydt and E. I. Solomon, $P$. Natl. Acad. Sci. USA., 2009, 106, 18908.

66. P. J. Smeets, R. G. Hadt, J. S. Woertink, P. Vanelderen, R. A. Schoonheydt, B. F. Sels and E. I. Solomon, J. Am. Chem. Soc., 2010, 132, 14736.

67. E. Borfecchia, A. Amedjkouh, M. Dyballa, D. K. Pappas, G. Berlier, V. G. H. Eijsink, Å. R. Kjendseth, C. Lamberti, K. L. Lillerud, S. Svelle, S. Bordiga, M. Sørlie and U. Olsbye, ACS Catal., submitted.

68. C. Paolucci, A. A. Parekh, I. Khurana, J. R. Di Iorio, H. Li, J. D. Albarracin Caballero, A. J. Shih, T. Anggara, W. N. Delgass, J. T. Miller, F. H. Ribeiro, R. Gounder and W. F. Schneider, J. Am. Chem. Soc., 2016, 138, 6028.

69. C. Paolucci, J. R. Di Iorio, F. H. Ribeiro, R. Gounder and W. F. Schneider, in Advances in Catalysis, ed. C. Song, Academic Press, 2016, vol. 59, pp. 1.

70. C. Paolucci, I. Khurana, A. A. Parekh, S. C. Li, A. J. Shih, H. Li, J. R. Di Iorio, J. D. Albarracin-Caballero, A. Yezerets, J. T. Miller, W. N. Delgass, F. H. Ribeiro, W. F. Schneider and R. Gounder, Science, 2017, $357,898$.

71. H. Falsig, P. N. R. Vennestrøm, P. G. Moses and T. V. W. Janssens, Top. Catal., 2016, 59, 861.

72. L. Chen, H. Falsig, T. V. W. Janssens and H. Gronbeck, J. Catal., 2018, 358, 179.

73. E. Giamello, D. Murphy, G. Magnacca, C. Morterra, Y. Shioya, T. Nomura and M. Anpo, J. Catal., $1992,136,510$.

74. M. Lo Jacono, G. Fierro, R. Dragone, X. B. Feng, J. dItri and W. K. Hall, J. Phys. Chem. B, 1997, $101,1979$.

75. G. T. Palomino, P. Fisicaro, S. Bordiga, A. Zecchina, E. Giamello and C. Lamberti, J. Phys. Chem. B, 2000, 104, 4064.

76. F. Xamena, P. Fisicaro, G. Berlier, A. Zecchina, G. T. Palomino, C. Prestipino, S. Bordiga, E. Giamello and C. Lamberti, J. Phys. Chem. B, 2003, 107, 7036.

77. P. J. Smeets, J. S. Woertink, B. F. Sels, E. I. Solomon and R. A. Schoonheydt, Inorg. Chem., $2010,49,3573$.

78. A. Godiksen, F. N. Stappen, P. N. R. Vennestrom, F. Giordanino, S. B. Rasmussen, L. F. Lundegaard and S. Mossin, J. Phys. Chem. C, 2014, 118, 23126. 
79. A. Godiksen, P. Vennestrom, S. Rasmussen and S. Mossin, Top. Catal., 2017, 60, 13.

80. A. Godiksen, O. L. Isaksen, S. B. Rasmussen, P. N. R. Vennestrom and S. Mossin, ChemCatChem, $2018,10,366$.

81. Z. Sojka, M. Che and E. Giamello, J. Phys. Chem. B, 1997, 101, 4831.

82. J. Song, Y. L. Wang, E. D. Walter, N. M. Washton, D. H. Mei, L. Kovarik, M. H. Engelhard, S. Prodinger, Y. Wang, C. H. F. Peden and F. Gao, ACS Catal., 2017, 7, 8214.

83. Z. C. Zhao, R. Yu, R. R. Zhao, C. Shi, H. Gies, F. S. Xiao, D. De Vos, T. Yokoi, X. H. Bao, U. Kolb, M. Feyen, R. McGuire, S. Maurer, A. Moini, U. Muller and W. P. Zhang, Appl. Catal. B-Environ., 2017, $217,421$.

84. M. Moreno-Gonzalez, B. Hueso, M. Boronat, T. Blasco and A. Corma, J. Phys. Chem. Lett., $2015,6,1011$.

85. D. W. Fickel, J. M. Fedeyko and R. F. Lobo, J. Phys. Chem. C, 2010, 114, 1633.

86. F. Gao and C. H. F. Peden, Catalysts 2018, 8, 140.

87. J. R. Di Iorio and R. Gounder, Chem. Mat., 2016, 28, 2236.

88. J. M. Thomas, Chem.-Eur. J., 1997, 3, 1557.

89. M. Iwamoto, H. Yahiro, Y. Torikai, T. Yoshioka and N. Mizuno, Chem. Lett., 1990, 1967.

90. Y. J. Li and W. K. Hall, J. Phys. Chem., 1990, 94, 6145.

91. M. Iwamoto, H. Yahiro, K. Tanda, N. Mizuno, Y. Mine and S. Kagawa, J. Phys. Chem., 1991, $95,3727$.

92. Y. J. Li and W. K. Hall, J. Catal., 1991, 129, 202.

93. S. Sato, Y. Yoshihiro, H. Yahiro, N. Mizuno and M. Iwamoto, Appl. Catal., 1991, 70, L1.

94. M. Iwamoto, H. Yahiro, N. Mizuno, W. X. Zhang, Y. Mine, H. Furukawa and S. Kagawa, J. Phys. Chem., 1992, 96, 9360.

95. M. Shelef, Chem. Rev., 1995, 95, 209.

96. G. Spoto, A. Zecchina, S. Bordiga, G. Ricchiardi, G. Martra, G. Leofanti and G. Petrini, Appl. Catal. B-Environ., 1994, 3, 151.

97. G. T. Palomino, S. Bordiga, A. Zecchina, G. L. Marra and C. Lamberti, J. Phys. Chem. B, 2000, $104,8641$.

98. V. Bolis, S. Maggiorini, L. Meda, F. D'Acapito, G. T. Palomino, S. Bordiga and C. Lamberti, J. Chem. Phys., 2000, 113, 9248.

99. C. Prestipino, G. Berlier, F. Xamena, G. Spoto, S. Bordiga, A. Zecchina, G. T. Palomino, T. Yamamoto and C. Lamberti, Chem. Phys. Lett., 2002, 363, 389.

100. Y. Kuroda, K. Yagi, N. Horiguchi, Y. Yoshikawa, R. Kumashiro and M. Nagao, Phys. Chem. Chem. Phys., 2003, 5, 3318.

101. Z. Li, K. C. Xie and R. C. T. Slade, Appl. Catal. A-Gen., 2001, 209, 107.

102. Y. H. Zhang, I. J. Drake, D. N. Briggs and A. T. Bell, J. Catal., 2006, 244, 219.

103. Y. H. Zhang, I. J. Drake and A. T. Bell, Chem. Mater., 2006, 18, 2347.

104. J. Sárkány, J. d'Itri and W. H. Sachtler, Catal. Lett., 1992, 16, 241.

105. J. Valyon and W. K. Hall, J. Phys. Chem., 1993, 97, 7054.

106. S. C. Larsen, A. Aylor, A. T. Bell and J. A. Reimer, J. Phys. Chem., 1994, 98, 11533.

107. Y. Kuroda, Y. Yoshikawa, S. Konno, H. Hamano, H. Maeda, R. Kumashiro and M. Nagao, J. Phys. Chem., 1995, 99, 10621.

108. H. J. Jong, W. K. Hall and J. L. d'Itri, J. Phys. Chem., 1996, 100, 9416.

109. D. Nachtigallova, P. Nachtigall and J. Sauer, Phys. Chem. Chem. Phys., 2001, 3, 1552.

110. T. Cheung, S. K. Bhargava, M. Hobday and K. Foger, J. Catal., 1996, 158, 301.

111. H. J. Jang, W. K. Hall and J. dItri, J. Phys. Chem., 1996, 100, 9416.

112. J. Szanyi, J. H. Kwak, H. Zhu and C. H. F. Peden, Phys. Chem. Chem. Phys. , 2013, 15, 2368.

113. I. Lezcano-Gonzalez, U. Deka, B. Arstad, A. Van Yperen-De Deyne, K. Hemelsoet, M. Waroquier, V. Van Speybroeck, B. M. Weckhuysen and A. M. Beale, Phys. Chem. Chem. Phys., 2014, 16, 1639.

114. K. I. Hadjiivanov and G. N. Vayssilov, Adv. Catal., 2002, 47, 307.

115. V. Bolis, A. Barbaglia, S. Bordiga, C. Lamberti and A. Zecchina, J. Phys. Chem. B, 2004, 108, 9970.

116. A. Zecchina, S. Bordiga, M. Salvalaggio, G. Spoto, D. Scarano and C. Lamberti, J. Catal., 1998, $173,540$.

117. G. T. Palomino, E. Giamello, P. Fisicaro, S. Bordiga, C. Lamberti and A. Zecchina, Stud. Surf. Sci. Catal., 2000, 130, 2915.

118. A. Zecchina, S. Bordiga, G. Spoto, L. Marchese, G. Petrini, G. Leofanti and M. Padovan, J. Phys. Chem., 1992, 96, 4991.

119. S. Bordiga, D. Scarano, G. Spoto, A. Zecchina, C. Lamberti and C. O. Arean, Vib. Spectrosc., $1993,5,69$.

120. S. Bordiga, E. Escalona Platero, C. Otero Areán, C. Lamberti and A. Zecchina, J. Catal., 1992, 137, 179.

121. C. Lamberti, C. Morterra, S. Bordiga, G. Cerrato and D. Scarano, Vib. Spectrosc., 1993, 4, 273.

122. C. Prestipino, L. Regli, J. G. Vitillo, F. Bonino, A. Damin, C. Lamberti, A. Zecchina, P. L. Solari, K. O. Kongshaug and S. Bordiga, Chem. Mater., 2006, 18, 1337.

123. F. X. Llabrés i Xamena, P. Fisicaro, G. Berlier, A. Zecchina, G. T. Palomino, C. Prestipino, S. Bordiga, E. Giamello and C. Lamberti, J. Phys. Chem. B, 2003, 107, 7036.

124. G. Leofanti, A. Marsella, B. Cremaschi, M. Garilli, A. Zecchina, G. Spoto, S. Bordiga, P. Fisicaro, G. Berlier, C. Prestipino, G. Casali and C. Lamberti, J. Catal., 2001, 202, 279.

125. J. H. Kwak, H. Y. Zhu, J. H. Lee, C. H. F. Peden and J. Szanyi, Chem. Comm., 2012, 48, 4758. 
126. E. I. Solomon, J. W. Ginsbach, D. E. Heppner, M. T. Kieber-Emmons, C. H. Kjaergaard, P. J. Smeets, L. Tian and J. S. Woertink, Faraday Discuss., 2011, 148, 11.

127. P. Vanelderen, R. G. Hadt, P. J. Smeets, E. I. Solomon, R. A. Schoonheydt and B. F. Sels, J. Catal., $2011,284,157$.

128. W. van Beek, O. V. Safonova, G. Wiker and H. Emerich, Phase Transit., 2011, 84, 726.

129. P. M. Abdala, O. V. Safonova, G. Wiker, W. van Beek, H. Emerich, J. A. van Bokhoven, J. Sa, J. Szlachetko and M. Nachtegaal, Chimia, 2012, 66, 699.

130. A. L. Bugaev, A. A. Guda, K. A. Lomachenko, V. V. Shapovalov, A. Lazzarini, J. G. Vitillo, L. A. Bugaev, E. Groppo, R. Pellegrini, A. V. Soldatov, J. A. van Bokhoven and C. Lamberti, J. Phys. Chem. C, 2017, $121,18202$.

131. F. Gao, N. M. Washton, Y. L. Wang, M. Kollar, J. Szanyi and C. H. F. Peden, J. Catal., 2015, 331, 25.

132. M. Sierka and J. Sauer, J. Phys. Chem. B, 2001, 105, 1603.

133. B. R. Goodman, K. C. Hass, W. F. Schneider and J. B. Adams, Catal. Lett., 2000, $68,85$.

134. W. Loewenstein, Am. Mineral., 1954, 39, 92.

135. S. A. Bates, A. A. Verma, C. Paolucci, A. A. Parekh, T. Anggara, A. Yezerets, W. F. Schneider, J. T. Miller, W. N. Delgass and F. H. Ribeiro, J. Catal., 2014, 312, 87.

136. J. Jaumot, R. Gargallo, A. de Juan and R. Tauler, Chemometrics Intell. Lab. Syst., 2005, 76, 101.

137. A. de Juan, J. Jaumot and R. A. Tauler, Anal. Methods, 2014, 6, 4964.

138. J. Jaumot, A. de Juan and R. Tauler, Chemometr. Intell. Lab., 2015, 140, 1.

139. J. S. McEwen, T. Anggara, W. F. Schneider, V. F. Kispersky, J. T. Miller, W. N. Delgass and F. H. Ribeiro, Catal. Today, 2012, 184, 129.

140. J. Dědeček, B. Wichterlova and P. Kubat, Micr. Mesop. Mater., 1999, 32, 63.

141. G. Busca, Phys. Chem. Chem. Phys., 1999, 1, 723.

142. R. Q. Zhang, J. S. McEwen, M. Kollar, F. Gao, Y. L. Wang, J. Szanyi and C. H. F. Peden, ACS Catal., 2014, 4, 4093.

143. J. Y. Luo, F. Gao, K. Kamasamudram, N. Currier, C. H. F. Peden and A. Yezerets, J. Catal., $2017,348,291$.

144. F. Gao, E. D. Walter, M. Kollar, Y. Wang, J. Szanyi and C. H. F. Peden, J. Catal., 2014, 319, 1.

145. Q. Guo, F. Fan, D. A. J. M. Ligthart, G. Li, Z. Feng, E. J. M. Hensen and C. Li, ChemCatChem, $2014,6,634$.

146. A. Martini, E. Alladio and E. Borfecchia, Top. Catal., accepted.

147. M. H. Groothaert, P. J. Smeets, B. F. Sels, P. A. Jacobs and R. A. Schoonheydt, J. Am. Chem. Soc., $2005,127,1394$.

148. P. J. Smeets, M. H. Groothaert and R. A. Schoonheydt, Catal. Today, 2005, 110, 303.

149. P. Vanelderen, J. Vancauwenbergh, B. F. Sels and R. A. Schoonheydt, Coord. Chem. Rev., 2013, $257,483$.

150. S. Grundner, M. A. C. Markovits, G. Li, M. Tromp, E. A. Pidko, E. J. M. Hensen, A. Jentys, M. Sanchez-Sanchez and J. A. Lercher, Nat. Commun., 2015, 6.

151. M. Inomata, A. Miyamoto and Y. Murakami, J. Catal., 1980, 62, 140.

152. G. T. Went, L. J. Leu, R. R. Rosin and A. T. Bell, J. Catal., 1992, 134, 492.

153. N. Y. Topsoe, Science, 1994, 265, 1217.

154. N. Y. Topsoe, J. A. Dumesic and H. Topsoe, J. Catal., 1995, 151, 241.

155. N. Y. Topsoe, H. Topsoe and J. A. Dumesic, J. Catal., 1995, 151, 226.

156. G. Busca, L. Lietti, G. Ramis and F. Berti, Appl. Catal. B-Environ., 1998, 18, 1.

157. B. M. Weckhuysen and D. E. Keller, Catal. Today, 2003, 78, 25.

158. M. Calatayud, B. Mguig and C. Minot, Surf. Sci. Rep., 2004, 55, 169.

159. P. Granger and V. I. Parvulescu, Chem. Rev., 2011, 111, 3155.

160. M. Koebel, M. Elsener and M. Kleemann, Catal. Today, 2000, 59, 335.

161. P. L. T. Gabrielsson, Top. Catal., 2004, 28, 177.

162. K. Rahkamaa-Tolonen, T. Maunula, M. Lomma, M. Huuhtanen and R. L. Keiski, Catal. Today, $2005,100,217$.

163. A. Zecchina, M. Rivallan, G. Berlier, C. Lamberti and G. Ricchiardi, Phys. Chem. Chem. Phys., $2007,9,3483$.

164. M. Moliner, C. Franch, E. Palomares, M. Grill and A. Corma, Chem. Commun., 2012, 48, 8264.

165. J. Li, H. Chang, L. Ma, J. Hao and R. T. Yang, Catal. Today, 2011, 175, 147.

166. M. Stanciulescu, G. Caravaggio, A. Dobri, J. Moir, R. Burich, J. P. Charland and P. Bulsink, Appl. Catal. B: Environ., 2012, 123-124, 229.

167. R. D. Zhang, N. Liu, Z. G. Lei and B. H. Chen, Chem. Rev., 2016, 116, 3658.

168. S. Brandenberger, O. Krocher, A. Tissler and R. Althoff, Catal. Rev., 2008, 50, 492.

169. M. Ravi, M. Ranocchiari and J. A. van Bokhoven, Angew. Chem.-Int. Edit., 2017, 56, 16464.

170. V. L. Sushkevich, D. Palagin, M. Ranocchiari and J. A. van Bokhoven, Science, 2017, $356,523$.

171. P. Tomkins, M. Ranocchiari and J. A. van Bokhoven, Accounts Chem. Res., 2017, 50, 418.

172. K. Narsimhan, K. Iyoki, K. Dinh and Y. Roman-Leshkov, ACS Central Sci., 2016, 2, 424.

173. S. Grundner, W. Luo, M. Sanchez-Sanchez and J. A. Lercher, Chem. Commun., 2016, 52, 2553.

174. H. V. Le, S. Parishan, A. Sagaltchik, C. Gobel, C. Schlesiger, W. Malzer, A. Trunschke, R. Schomacker and A. Thomas, ACS Catal., 2017, 7, 1403.

175. M. A. C. Markovits, A. Jentys, M. Tromp, M. Sanchez-Sanchez and J. A. Lercher, Top. Catal., $2016,59,1554$.

176. F. Gao, D. Mei, Y. Wang, J. Szanyi and C. H. F. Peden, J. Am. Chem. Soc., 2017, 139, 4935.

177. S. E. Bozbag, E. M. C. Alayon, J. Pechacek, M. Nachtegaal, M. Ranocchiari and J. A. van Bokhoven, Catal. Sci. Technol., 2016, 6, 5011 . 
178. T. Sheppard, C. D. Hamill, A. Goguet, D. W. Rooney and J. M. Thompson, Chem. Commun., $2014,50,11053$.

179. P. Vanelderen, P. J. Smeets, R. G. Hadt, J. S. Woertink, R. A. Schoonheydt, B. F. Sels and E. I. Solomon, Abstr. Pap. Am. Chem. Soc., 2011, 242.

180. E. M. Alayon, M. Nachtegaal, M. Ranocchiari and J. A. van Bokhoven, Chem. Comm., 2012, $48,404$.

181. E. M. C. Alayon, M. Nachtegaal, A. Bodi and J. A. van Bokhoven, ACS Catal., 2014, 4, 16.

182. E. M. C. Alayon, M. Nachtegaal, A. Bodi, M. Ranocchiari and J. A. van Bokhoven, Phys. Chem. Chem. Phys., 2015, 17, 7681 .

183. V. Franco, F. P. Sánchez, J. German and P. Mock, "Real-World Exhaust Emissions from Modern Diesel Cars. White paper from October ICCT, International Council on Clean Transportation (ICCT), Beijing, 2014 Downloadable at: https://www.theicct.org/publications/real-world-exhaust-emissions-modern-diesel-cars.

184. A. Kufferath, M. Krüger, D. Dirk Naber, E. Mailänder and R. Maier, The Path to a Negligible $\mathrm{NO}_{2}$ Immission Contribution from the Diesel Powertrain, presented at the $39^{\text {th }}$ international Motor Symposium, Vienna April 2627, 2018. Manuscript downloadable at http://www.autonews.com/article/20180426/BLOG06/180429820/forbosch-diesel-claim-technical-details-to-come.

185. M. Horn, C. Grundler and P. Brooks, (witnesses), Hearing on "Volkswagen's Emissions Cheating Allegations: Initial Questions". U.S House of Representatives Committee on Energy and Commerce, October 6, 2015, downloadable at : https://docs.house.gov/meetings/IF/IF02/20151008/104046/HHRG.

186. EU Clean Vehicles Directive, downloadable at https://ec.europa.eu/transport/themes/urban/vehicles/directive_en.

187. Press release of the Federal Administrative Court of Germany from February, 22, 2018, (in German), accessible at http://www.bverwg.de/pm/2018/9.

188. in High Level Group GEAR 2030 report on automotive competitiveness and sustainability (downloadable at: https://ec.europa.eu/growth/content/high-level-group-gear-2030-report-on-automotive-competitiveness-andsustainability_de), 18/10/2017.

189. R. A. Periana, D. J. Taube, S. Gamble, H. Taube, T. Satoh and H. Fujii, Science, 1998, 280, 560.

190. R. Palkovits, C. von Malotki, M. Baumgarten, K. Mullen, C. Baltes, M. Antonietti, P. Kuhn, J. Weber, A. Thomas and F. Schuth, ChemSusChem, 2010, 3, 277.

191. A. Lyngfelt and B. Leckner, Appl. Energy, 2015, 157, 475.

192. J. A. Moulijn, M. Makkee and A. E. Van Diepen, Chemical Process Technology, $2^{\text {nd }}$ Ed., John Wiley, Hoboken, 2013.

193. The world bank, Zero Routine Flaring by 2030, available at: http://www.worldbank.org/en/programs/zero. 